\title{
AIR FORCE RESEARCH LABORATORY RESIDENT ASSOCIATESHIP PROGRAM Continuation
}

\section{Robert Day}

NATIONAL ACADEMY OF SCIENCES

$12 / 04 / 2014$

Final Report 


\section{REPORT DOCUMENTATION PAGE}

Form Approved

OMB No. 0704-0188

The public reporting burden for this collection of information is estimated to average 1 hour per response, including the time for reviewing instructions, searching existing data sources, gathering and maintaining the data needed, and completing and reviewing the collection of information. Send comments regarding this burden estimate or any other aspect of this collection of information, including suggestions for reducing the burden, to Department of Defense, Executive Services, Directorate (0704-0188). Respondents should be aware that notwithstanding any other provision of law, no person shall be subject to any penalty for failing to comply with a collection of information if it does not display a currently valid OMB control number.

PLEASE DO NOT RETURN YOUR FORM TO THE ABOVE ORGANIZATION.
1. REPORT DATE (DD-MM-YYYY)
2. REPORT TYPE
25-11-2014
Final Performance

4. TITLE AND SUBTITLE

AIR FORCE RESEARCH LABORATORY RESIDENT ASSOCIATESHIP PROGRAM

Continuation

5b. GRANT NUMBER

3. DATES COVERED (From - TO)

01-12-2011 to 30-11-2012

5a. CONTRACT NUMBER

FA9550-12-C-0009

5c. PROGRAM ELEMENT NUMBER

5d. PROJECT NUMBER

6. AUTHOR(S)

Robert Day 5e. TASK NUMBER

5f. WORK UNIT NUMBER
7. PERFORMING ORGANIZATION NAME(S) AND ADDRESS(ES)

NATIONAL ACADEMY OF SCIENCES

2101 CONSTITUTION AVE NW

WASHINGTON, DC 204180006 US
8. PERFORMING ORGANIZATION REPORT NUMBER

9. SPONSORING/MONITORING AGENCY NAME(S) AND ADDRESS(ES)

AF Office of Scientific Research

875 N. Randolph St. Room 3112

Arlington, VA 22203

10. SPONSOR/MONITOR'S ACRONYM(S) AFOSR

11. SPONSOR/MONITOR'S REPORT NUMBER(S)

\section{DISTRIBUTION/AVAILABILITY STATEMENT}

A DISTRIBUTION UNLIMITED: PB Public Release

\section{SUPPLEMENTARY NOTES}

\section{ABSTRACT}

The promotional schedule to advertise the National Research Council (NRC) Research Associateship Programs included the following: 1) attendance at meetings of major scientific and engineering professional societies; 2) advertising in programs and career centers for these and other professional society meetings; 3 ) direct mailing and emailing of announcements and program materials to presidents, graduate deans, and heads of appropriate science and engineering departments and minority-affairs offices of all academic degree-granting institutions in the United States; 4) posting announcements on internet job sites, electronic newsletters and professional society websites; 5) print advertising in high profile publications (e.g., Science magazine, the Chronicle of Higher Education); and, 6) maintaining a presence on social media sites such as Facebook. The NRC attended a number of minority focused events in which we maintained exhibit booths, participated in workshops and advertised in meeting literature, newsletters and websites or submitted materials for distribution. In addition, ads were placed in a variety of minority publications (e.g., Affirmative Action, Black Collegian).

\section{SUBJECT TERMS}

Post-Doctoral research

16. SECURITY CLASSIFICATION OF:

\begin{tabular}{c|c|c|}
\hline a. REPORT & b. ABSTRACT & c. THIS PAGE \\
$U$ & $U$ & $U$ \\
& & \\
\hline
\end{tabular}

17. LIMITATION OF ABSTRACT

UU
18. NUMBER

OF PAGES

81 19a. NAME OF RESPONSIBLE PERSON Robert Day

19b. TELEPHONE NUMBER (Include area code) 202-334-3873 


\section{THE NATIONAL ACADEMIES}

Advisers to the Nation on Science, Engineering, and Medicine

\section{National Research Council RESEARCH ASSOCIATESHIP PROGRAM with}

Air Force Research Laboratory

Final Contract Technical Report

Contract No. FA9550-12-C-0009

Contract Period: 12/01/2011-11/30/2012

Report Period: 12/01/2011-11/30/2012 
During the reporting period, the NRC conducted the following activities in support of the subject contract:

\section{Outreach and Promotion}

The promotional schedule to advertise the National Research Council (NRC) Research Associateship Programs included the following: 1) attendance at meetings of major scientific and engineering professional societies; 2) advertising in programs and career centers for these and other professional society meetings; 3 ) direct mailing and emailing of announcements and program materials to presidents, graduate deans, and heads of appropriate science and engineering departments and minority-affairs offices of all academic degree-granting institutions in the United States; 4) posting announcements on internet job sites, electronic newsletters and professional society websites; 5) print advertising in high profile publications (e.g., Science magazine, the Chronicle of Higher Education); and, 6) maintaining a presence on social media sites such as Facebook.

The NRC attended a number of minority focused events in which we maintained exhibit booths, participated in workshops and advertised in meeting literature, newsletters and websites or submitted materials for distribution. In addition, ads were placed in a variety of minority publications (e.g., Affirmative Action, Black Collegian).

In advertising the Research Opportunities available to prospective applicants, the NRC maintained an up-to-date listing of all active Research Advisers, current Adviser contact information and details of each Research Opportunity.

\section{Processing and Review of Applications}

Applications to the Research Associateship Program were submitted via a web-based application system. Each of the four application cycles opened two months prior to the application deadline. NRC staff provided support to prospective applicants including providing application instructions, technical support and additional information as requested.

A summary of applications for the reporting period is shown in Table 1.

For each applicant, the NRC received and processed an application form, a research proposal, transcripts, a statement of previous and current research, and confidential reference reports. An application file check was made prior to the review and each applicant was notified if required documents were missing.

The NRC convened panels in five broad discipline areas for the competitive review of applications in the Research Associateship Programs. Results of the review were made available to Laboratory Program Representatives immediately following the conclusion of the each review.

A summary of the outcome of the review of applications for the reporting period is shown in Table 1.

\section{Administration of Awards}

The NRC made awards to applicants based on sponsor authorization. A summary of awards authorized and the acceptance or declination by the applicant during the current reporting period is shown in Table 1.

For Associates beginning or continuing tenure, the NRC provided the administrative functions described in the contract Statement of Work. These functions included stipend payments, management of a major medical benefits insurance program, and reimbursement for relocation and travel to professional meetings. 
A summary of NRC Research Associates on tenure during the reporting period is shown in Table 2.

\section{Outcomes Reporting}

All NRC Associates who completed tenure were required to submit a final report that described the outcome of their Associateship award. Final reports received by the NRC during the current reporting period are attached to this technical report.

The activities of Associates submitting final reports during this reporting period, including publications, presentations and patents, as well as an assessment of their experience in the program, are summarized in Table 3. Specific research accomplishments of Associates completing tenure during the reporting period are summarized in Table 4.

Table 1. Applications and Awards

Table 2. Associates on Tenure

Table 3. Associates Activity

Table 4. Summary of Associate Research

Attachments: Associate Final Reports 


\section{Air Force Research Laboratory}

\section{Table 1: Applications and Awards}

\section{TOTAL APPLICATIONS}

Applications not reviewed

Applications reviewed

Not recommended

Recommended

Withdrawn

Lab decision pending

Awards offered

Applicant decision pending

Awards accepted

Awards declined

Not funded

\begin{tabular}{rrrrr} 
Feb 2012 & May 2012 & Aug 2012 & Nov 2012 & Total \\
\hline 24 & 25 & 13 & 19 & 81 \\
4 & 1 & 3 & 19 & 27 \\
20 & 24 & 10 & 0 & 54 \\
0 & 0 & 0 & 0 & 0 \\
20 & 24 & 10 & 0 & 54 \\
0 & 0 & 0 & 0 & 0 \\
9 & 13 & 8 & 0 & 30 \\
7 & 7 & 1 & 0 & 15 \\
0 & 0 & 1 & 0 & 1 \\
6 & 5 & 0 & 0 & 11 \\
1 & 2 & 0 & 0 & 3 \\
4 & 4 & 1 & 0 & 9
\end{tabular}


Table 2: Associates on Tenure

\begin{tabular}{|c|c|c|c|c|}
\hline Associate & Adviser & Tenure Dates & $\begin{array}{l}\text { Country of } \\
\text { Citizenship }\end{array}$ & $\begin{array}{c}\text { Final } \\
\text { Report }\end{array}$ \\
\hline \multicolumn{5}{|l|}{711 Human Performance Wing } \\
\hline Beier, Hope Thomas & Rockwell, Benjamin A. & $1 / 4 / 2010-11 / 16 / 2012$ & United States & Received \\
\hline Billock, Vincent Alan & Tsou, Brian $\mathrm{H}$. & $4 / 9 / 2010-4 / 8 / 2013$ & United States & \\
\hline $\begin{array}{l}\text { Carhuatanta, Kimberly A } \\
\text { Krawczewski }\end{array}$ & Jankord, Ryan & $11 / 4 / 2011-11 / 3 / 2013$ & United States & \\
\hline Comfort, Kristen Krupa & Hussain, Saber M. & 8/2/2010-8/1/2012 & United States & Received \\
\hline Dillard, Michael & Nelson, W. Todd & $4 / 17 / 2012-4 / 16 / 2013$ & United States & \\
\hline Echchgadda, Ibtissam & Wilmink, Gerald J & 7/1/2011-6/30/2013 & Morocco & \\
\hline Greer, Kimberly Ann & Wilmink, Gerald J & 7/30/2012-7/29/2013 & United States & \\
\hline Martin, Jennifer Anne & Stone, Morley & $11 / 1 / 2010-10 / 31 / 2012$ & United States & Received \\
\hline Schroeder, Paul James & Warren, Richard & $8 / 15 / 2011-8 / 14 / 2013$ & United States & \\
\hline Smith, Joshua Elliott & Stone, Morley & $6 / 1 / 2011-5 / 31 / 2013$ & United States & \\
\hline Thompson, Gary L. & Ibey, Bennett Luke & $5 / 31 / 2011-5 / 30 / 2013$ & United States & \\
\hline Tolstykh, Gleb & Ibey, Bennett Luke & 10/3/2011-10/2/2013 & United States & \\
\hline Towle, Erica L. & Rockwell, Benjamin A. & $9 / 4 / 2012-9 / 3 / 2013$ & United States & \\
\hline Veksler, Bella & Gunzelmann, Glenn & $12 / 19 / 2011-12 / 18 / 2013$ & United States & \\
\hline Veksler, Vladislav Daniel & Gluck, Kevin & $9 / 1 / 2011-8 / 31 / 2013$ & United States & \\
\hline Walsh, Matthew Miles & Gluck, Kevin & 9/17/2012-9/16/2013 & United States & \\
\hline Xin, Hao & Wilmink, Gerald J & 4/2/2012-8/1/2013 & United States & \\
\hline \multicolumn{5}{|l|}{ Aerospace Systems Directorate } \\
\hline Alekseenko, Alexander & Josyula, Eswar & 8/5/2011-8/4/2013 & Russia & \\
\hline Alfano, Angelo Joseph & Boatz, Jerry A. & 5/17/2010-5/16/2012 & United States & Not Recv'd \\
\hline Alleyne, Andrew George & Yerkes, Kirk L. & 6/8/2011-6/7/2012 & United States & Received \\
\hline Anderson, Eric Karl & Zelina, Joseph & $11 / 2 / 2009-5 / 1 / 2012$ & United States & Received \\
\hline Buszek, Robert Joseph & Boatz, Jerry A. & 12/1/2011-11/30/2013 & United States & \\
\hline Cain, Jeremy Patrick & Edwards, J. Tim & $3 / 14 / 2011-3 / 13 / 2013$ & United States & \\
\hline Cao, Yongcan & Schumacher, Corey J & $3 / 5 / 2012-3 / 4 / 2013$ & China & \\
\hline Eigenbrodt, Bryan Christopher & Reitz, Thomas L. & $6 / 1 / 2011-5 / 31 / 2013$ & United States & \\
\hline Juliano, Thomas James & Kimmel, Roger & $9 / 10 / 2012-9 / 9 / 2013$ & United States & \\
\hline Karnesky, James Alan & Schauer, Fred & $3 / 1 / 2011-2 / 28 / 2013$ & United States & \\
\hline Langhoff, Peter Wolfgang & Boatz, Jerry A. & $9 / 4 / 2012-9 / 3 / 2013$ & United States & \\
\hline Lipke, David William & Hoffman, Wesley P. & $1 / 3 / 2011-1 / 2 / 2013$ & United States & \\
\hline Panasyuk, George Yurievich & Yerkes, Kirk L. & $6 / 6 / 2011-6 / 5 / 2013$ & Russia & \\
\hline Peterson, David Michael & Gruber, Mark R. & $10 / 9 / 2012-10 / 8 / 2013$ & United States & \\
\hline Reams, Josiah & Mabry, Joseph M. & $3 / 21 / 2011-6 / 21 / 2012$ & United States & Not Recv'd \\
\hline Richardson, Daniel Reed & Zelina, Joseph & $7 / 30 / 2012-7 / 29 / 2013$ & United States & \\
\hline Sahagun, Christopher Michael & Guenthner, Andrew J & 6/4/2012-6/3/2013 & United States & \\
\hline Sanders, Nathaniel Louis & $\begin{array}{l}\text { Bunker, Christopher } \\
\text { Eastwood }\end{array}$ & $8 / 1 / 2011-6 / 30 / 2012$ & United States & Received \\
\hline Sell, Brian Christopher & Schauer, Fred & 9/1/2011-8/31/2013 & United States & \\
\hline Wrzesinski, Paul J. & Gord, James R. & $8 / 15 / 2011-8 / 14 / 2013$ & United States & \\
\hline Wu, Thomas Xinzhang & Yerkes, Kirk L. & $9 / 1 / 2010-8 / 14 / 2012$ & United States & Received \\
\hline \multicolumn{5}{|l|}{ Air Force Inst of Technology } \\
\hline Brant, Adam Taylor & Giles, Nancy C & 9/4/2012-9/3/2013 & United States & \\
\hline Kanel, Sushil Raj & Goltz, Mark N. & $8 / 2 / 2010-8 / 1 / 2012$ & Nepal & Received \\
\hline Keenan, Cameron Bradley & Perram, Glen P. & $5 / 23 / 2011-5 / 22 / 2013$ & United States & \\
\hline Struckhoff, Garrett Cletus & Shelley, Michael L. & 9/1/2009-7/31/2012 & United States & Not Recv'd \\
\hline \multicolumn{5}{|l|}{ Directed Energy Directorate } \\
\hline Naderi, Nader Ali & Kaspi, Ron & $8 / 15 / 2011-8 / 14 / 2013$ & United States & \\
\hline Naderi, Shadi Askarian & Madden, Timothy J. & 9/1/2011-8/31/2013 & United States & \\
\hline Schmitt-Sody, Andreas & Roach, William P. & $8 / 1 / 2011-7 / 31 / 2013$ & United States & \\
\hline Yang, Chi & Kaspi, Ron & 6/22/2010-6/21/2012 & United States & Received \\
\hline Zunoubi, Mohammad R. & Roach, William P. & $8 / 1 / 2011-7 / 31 / 2012$ & United States & Received \\
\hline \multicolumn{5}{|l|}{ Information Directorate } \\
\hline Chen, Pinyuen & Antonik, Paul & 6/1/2010-9/2/2013 & United States & \\
\hline Kamhoua, Charles Alexandre & Kwiat, Kevin A. & 8/15/2011-12/14/2012 & Cameroon & \\
\hline McDonald, Jonathan R. & Alsing, Paul M. & 1/18/2011-6/29/2012 & United States & Received \\
\hline
\end{tabular}




\begin{tabular}{|c|c|c|c|c|}
\hline Odejide, Olusegun Olufemi & Matyjas, John D. & $1 / 3 / 2012-1 / 2 / 2014$ & Nigeria & \\
\hline Park, Joon S. & Kwiat, Kevin A. & $8 / 8 / 2011-8 / 7 / 2013$ & United States & \\
\hline Shen, Lixin & Suter, Bruce W. & $7 / 23 / 2012-7 / 22 / 2013$ & China & \\
\hline Smith, Amos Matthew M. & Alsing, Paul M. & $1 / 18 / 2011-1 / 17 / 2013$ & United States & \\
\hline Su, Weifeng & Matyjas, John D. & $9 / 1 / 2010-1 / 31 / 2013$ & China & \\
\hline Wang, Peng & Medley, Michael J. & $10 / 1 / 2009-8 / 3 / 2012$ & United States & Received \\
\hline \multicolumn{5}{|l|}{ Materials \& Manufacturing Directorate } \\
\hline Bedford, Nicholas M & Naik, Rajesh & 3/1/2012-2/28/2013 & United States & \\
\hline Biswas, Sushmita & Vaia, Richard A. & 7/1/2011-6/30/2013 & India & \\
\hline Clark, Michael David & Durstock, Michael F. & $4 / 18 / 2011-4 / 17 / 2013$ & United States & \\
\hline Fillery, Scott Pierson & Durstock, Michael F. & 1/5/2009-1/4/2012 & United States & Received \\
\hline Juhl, Abigail Therese & Bunning, Timothy J. & 4/18/2011-7/9/2012 & United States & Not Recv'd \\
\hline Kramb, Ryan C & Miracle, Daniel B. & $8 / 23 / 2010-8 / 22 / 2012$ & United States & Not Recv'd \\
\hline Leslie, Clifford James & Cinibulk, Michael K. & $12 / 1 / 2011-11 / 30 / 2013$ & United States & \\
\hline McClung, Amber Joy Woods & Baur, Jeffrey W. & 7/1/2009-2/13/2012 & United States & Received \\
\hline McConney, Michael Edward & Bunning, Timothy J. & 9/1/2009-8/17/2012 & United States & Received \\
\hline Mehmood, Faisal & Pachter, Ruth & $9 / 1 / 2011-8 / 31 / 2013$ & Pakistan & \\
\hline Pattanaik, Gyanaranjan & Durstock, Michael F. & $4 / 1 / 2010-12 / 14 / 2012$ & India & \\
\hline Smith, Matthew Lauren & Vaia, Richard A. & 6/1/2010-6/30/2012 & United States & Received \\
\hline Vasudev, Milana Coorg & Naik, Rajesh & 7/1/2011-6/30/2013 & India & \\
\hline Volk, Brent Louis & Baur, Jeffrey W. & $10 / 24 / 2012-10 / 23 / 2013$ & United States & \\
\hline Yen, Chun-Wan & Durstock, Michael F. & 8/15/2011-9/28/2012 & Taiwan & Received \\
\hline \multicolumn{5}{|l|}{ Munitions Directorate } \\
\hline Chakravarty, Uttam Kumar & Curtis, Jess Willard & $10 / 1 / 2010-8 / 13 / 2012$ & Bangladesh & Received \\
\hline Douglass, John K & Miller, Mikel Mark & $12 / 13 / 2011-12 / 12 / 2013$ & United States & \\
\hline Emery, Samuel Bartlett & Lindsay, C. Michael & 2/1/2011-1/31/2013 & United States & \\
\hline Little, Brian Kevin & Lindsay, C. Michael & $12 / 16 / 2010-12 / 15 / 2012$ & United States & \\
\hline Lowe, Ryan Daniel & Foley, Jason R & $9 / 12 / 2012-9 / 11 / 2013$ & United States & \\
\hline Rider, Keith B. & Lindsay, C. Michael & $7 / 18 / 2011-7 / 17 / 2012$ & United States & Received \\
\hline Veremyev, Alexander Fedorovich & Pasiliao, Eduardo Lewis & $8 / 1 / 2012-7 / 31 / 2013$ & Russia & \\
\hline \multicolumn{5}{|l|}{ Sensors Directorate } \\
\hline Aga, Roberto Sabas & Heckman, Emily M & 10/1/2012-9/30/2013 & Philippines & \\
\hline Ariyawansa, Gamini & Eismann, Michael T. & $3 / 4 / 2011-3 / 3 / 2013$ & Sri Lanka & \\
\hline Dirisu, Afusat Olayinka & Anisimov, Igor & $9 / 6 / 2011-9 / 5 / 2013$ & United States & \\
\hline Husaini, Saima & Bedford, Robert G. & $10 / 24 / 2011-10 / 23 / 2013$ & United States & \\
\hline Kim, Richard (Seongku) & Szep, Attila A. & $4 / 18 / 2011-4 / 17 / 2013$ & United States & \\
\hline O'Connor, Alan Christopher & $\begin{array}{l}\text { Perlovsky, Leonid } \\
\text { Isaacovich }\end{array}$ & $9 / 12 / 2011-7 / 31 / 2012$ & United States & Received \\
\hline Voccola, Kaitlyn Elizabeth & Rangaswamy, Muralidhar & $9 / 15 / 2011-9 / 14 / 2012$ & United States & Received \\
\hline \multicolumn{5}{|l|}{ Space Vehicles Directorate } \\
\hline Ard, Shaun Gerald & Viggiano, Albert A. & $10 / 3 / 2011-10 / 2 / 2013$ & United States & \\
\hline Cooper, Russell James & Stearns, Jaime A & $1 / 18 / 2012-1 / 17 / 2014$ & United States & \\
\hline DeMars, Kyle Jordan & Jah, Moriba K. & $5 / 2 / 2011-12 / 31 / 2012$ & United States & \\
\hline Dennison, John Robert & Ferguson, Dale C & $1 / 17 / 2012-1 / 16 / 2013$ & United States & \\
\hline Frueh, Carolin & Jah, Moriba K. & $11 / 1 / 2011-10 / 31 / 2013$ & Germany & \\
\hline Heinrich, Jonathon Robert & Cooke, David L. & $3 / 16 / 2012-3 / 15 / 2013$ & United States & \\
\hline Hock, Rachel Allison & $\begin{array}{l}\text { Balasubramaniam, } \\
\text { Karatholuvu S. }\end{array}$ & $5 / 1 / 2012-4 / 30 / 2013$ & United States & \\
\hline Hussein Ali, Islam Ibrahim & Erwin, Richard Scott & $7 / 11 / 2011-7 / 10 / 2013$ & Egypt & \\
\hline Lee, Christina On-Yee & Mozer, Joel B. & $10 / 4 / 2010-10 / 3 / 2012$ & United States & Not Recv'd \\
\hline Melko, Joshua Jennings & Viggiano, Albert A. & $10 / 24 / 2011-10 / 23 / 2013$ & United States & \\
\hline Seletskiy, Denis V. & LeVan, Paul D. & $10 / 1 / 2010-7 / 26 / 2012$ & United States & Received \\
\hline Shi, Yong & Su, Yi-Jiun Caton & $1 / 16 / 2012-1 / 15 / 2014$ & China & \\
\hline \multicolumn{5}{|l|}{ US Air Force Academy, Colorado Springs } \\
\hline Ayachitula, Rajani & Knize, Randall J. & $8 / 3 / 2012-8 / 2 / 2013$ & United States & \\
\hline Ghoreyshi, Mehdi & Cummings, Russell Mark & $8 / 11 / 2010-8 / 10 / 2013$ & United Kingdom & \\
\hline Porter, Christopher Odell & McLaughlin, Thomas E. & $11 / 1 / 2011-10 / 31 / 2013$ & United States & \\
\hline
\end{tabular}




\section{Table 3: Associates' Activities}

28 Associates ended tenure during the report period

22 months was the average tenure length

36 months was the longest

10 months was the shortest

22 submitted final reports

In the final reports, Associates indicated the following scholarly activity while on tenure.

33 Articles published in refereed journals

1 Patent applications

14 International presentations

131 Domestic presentations

4 Awards

After ending their tenure, Associates indicated their future plans as follows:

1 Permanent position at the NRC host agency

6 Contract or temporary position at the NRC host agency

0 Research/administrative position with another U.S. government agency

0 Research/administrative position with foreign government agency

10 Research/teaching at US college/university

1 Research/teaching position at a foreign college or university

1 Research/administrative position in private industry in the U.S.

0 Research/administrative position in private industry outside of the U.S.

0 Research/administrative position with a non-profit

0 Self-employed/consulting

2 Postdoctoral Research

0 Other

1 No information provided

In their final reports, Associates were asked to evaluate certain aspects of their experiences on a scale of 1 (low) to 10 (high). The average rating for each item follows:

9.0 Short-term value (lab)-Development of knowledge, skills, and research productivity at lab

8.9 Long-term value (career)-How your Research Associateship affected your career to date

8.9 Laboratory Support-Equipment, funding, orientation, safety \& health training, etc.

9.1 Adviser Mentoring-Quality of mentoring from the Research Adviser

9.0 LPR Support-Quality of administrative support from the LPR

8.9 NRC Support-Quality of administrative support from the NRC 


\section{Table 4: Summary of Associate Research}

\begin{tabular}{|c|c|c|}
\hline \multicolumn{1}{|c|}{ Associate } & Tenure Dates \\
\hline Alleyne, Andrew & $\mathbf{6 / 8 / 2 0 1 1 - 6 / 7 / 2 0 1 2}$ \\
\hline 1 & $\begin{array}{l}\text { Developed a hierarchical approach to controlling Thermal Management Systems (TMS's) within complex air } \\
\text { vehicles. Hierarchical approach is preferred method for handling distributed loads and storage }\end{array}$ \\
\hline 2 & \begin{tabular}{l} 
Initiated research on diagnostics and health management using hierarchical framework. \\
\hline 3
\end{tabular} & $\begin{array}{l}\text { Created modeling software to analyze Vapor Cycle Systems as part of TMS's. Enables the study of transient } \\
\text { thermal phenomena. }\end{array}$
\end{tabular}

Anderson, Eric 11/2/2009-5/1/2012

1 Assisted in establishment of the Small Engine Research Laboratory (SERL) at AFRL to develop IC engine technology.

2 Constructed and tested rotary ball valve for Pulsed Detonation Engine use, with substantial improvements in volumetric efficiency.

3 Developed computational code to compute heat transfer rates to pulsed detonation engine tube walls, found thermal barrier coating increased detonation tube wall temperatures.

4 Demonstrated prechamber as knock mitigation technique, enabling full load operation down with a 60 octane PRF blend in a spark ignition engine.

5 Demonstrated intercooler, optimized ignition timing, direct injection, and to reduce the octane requirement of the Rotax 914 from 100 to 87.

\section{Beier, Hope}

1/4/2010-11/16/2012

1 Developed a multiplex stimulated Raman scattering imaging system.

2 Improved the spectral resolution of multiplex coherent Raman scattering spectra.

3 Used coherent Raman scattering to measure the temperature of aqueous solutions with submicron resolution.

4 Monitored the kinetics of ion influx into biological cells using a high-speed imaging system.

5 Developed a system to aquire low-frequency Raman scattering spectra of biological molecules and compare to $\mathrm{THz}$ resonances.

\section{Chakravarty, Uttam}

10/1/2010-8/13/2012

1 Biologically inspired wings of micro munition vehicles (MMVs) were constructed with membrane, attached to the metallic/composite reinforced structures.

2 Finite element models were developed for the modal characteristics of the flexible wings of MMVs and validated by experimental and analytical results.

3 The effects of added mass, damping, and aerodynamic loads on the modal characteristics (natural frequencies and mode shapes) of the wings were investigated.

4 The wings were vibrated in vacuum and in air for investigating the effects of added mass and damping on their modal characteristics.

5 Aerodynamic loads were estimated from the wind-tunnel test data, where the angle of attack of the wings and freestream velocity of air are varied.

\section{Comfort, Kristen}

\section{8/2/2010-8/1/2012}

1 Identified a disruption in EGF dependent signal transduction by silver, gold, and iron oxide nanoparticles.

2 Elucidated combinatorial bioeffects on a cellular, protein, and genomic level following concurrent exposure to nanoparticles and a static magnetic field.

3 Evaluated the photothermal capability of gold nanorods during NIR laser irradiation and correlated the resultant heat production to nanorod aspect ratio.

4 Discovered the impact of biologically relevant fluids on the photothermal efficiency of gold nanorods and successfully linked the diminution of thermal production to a solution-induced nanorod agglomeration phenomenon.

5 Developed and implemented a new nano-bioeffect paradigm targeting lower, occupational exposure levels of nanomaterials.

\section{Fillery, Scott}

\section{1/5/2009-1/4/2012}

1 Dielectric breakdown strength in insulating materials in heavily dependent on the population of defects. Hence, control over the size, shape and orientation of inclusion fillers can significantly impact the high electric field behavior.

2 Introduction of inorganic inclusions, in the form of low permititivity platelets, aligned to frustrate propagation of a failure path, show significant improvements in dielectric breakdown strength.

3 Attachment of polymeric structures to the nanoparticle surface, while positively promoting an improved nanocomposite dispersion, does not provide an enhancement to dielectric breakdown strength. 
4 Improvements to capacitor energy density, when utilizing nanocomposite motifs, requires a delicate balance, increasing material polarizability while staunching deletrious defects that result in premature breakdown under applied fields.

5 Biomaterials, such as silk, show significant versatility, stemming from the large phase space of chain comformation. Highly crystalline chain conformations show improvements to dielectric breakdown strength of $150 \%$.

\section{Kanel, Sushil}

8/2/2010-8/1/2012

1 Synthesized nanomaterials (NMs) such as silver nanoparticles (AgNPs) and nanoscale zerovalent iron (nZVI) and $\mathrm{Ni}$ and Pd coated nZVI.

2 Remediation of carbontetrachloride(CT) by $\mathrm{nZVI}$ and bimetallic(Ni and $\mathrm{Pd}) \mathrm{nZVI}$ is investigated and found that $\mathrm{nZVI}$ and Bimetallic $\mathrm{nZVI}$ has fast Kinetics to react $\mathrm{CT}$. We found the highest efficiency ever reported in literature.

3 Fate and transport of AgNP was studied and found that AgNP transport differently at different pHs through porous media.

4 AgNPs and Ag ion showed different transport pattern through porous media.

\section{Martin, Jennifer}

11/1/2010-10/31/2012

1 Designed and utilized an aptamer selection for cortisol with a tunable stringency component integrated into the method. Found that more stringent conditions evolved the pool toward a single sequence dominating $45 \%$ of the final sequenced pool.

2 Developed equilibrium dialysis protocols for testing dissociation constants of aptamer/small molecule target binding. Confirmed a low micromolar Kd of a cortisol sequence.

3 Modified conditions to enable a $\sim 30 \mathrm{nM}$ limit of detection for cortisol the identified cortisol aptamer with a gold nanoparticle assay (serum cortisol $200-450 \mathrm{nM}$ ).

4 Developed a method for testing aptamer/target interactions with custom DNA microarrays. Studied structural properties of aptamer/target binding (buffer conditions, purity, fluorescence reporting scheme, distance from chip surface).

5 Identified potential thrombin binding aptamers, each of which contained a sequence motif similar to the known 15mer thrombin binding aptamer.

\section{McClung, Amber}

7/1/2009-2/13/2012

1 Established and validated the appropriate digital image correlation system, laser extensometer, high temperature grips, and environmental chamber for thermomechanical evaluation of shape memory polymers.

2 Thermal stability of shape memory polymers determined with thermogravimetric analysis (TGA) and differential scanning calorimetry (DSC).

3 Appropriate post-cure cycles established for multiple shape memory polymers based on the preliminary TGA and DSC results.

4 The path-dependent axial behavior of both Veriflex-E and a BMI-based SMP were evaluated using dynamic mechanical analysis (DMA) and axial tensile tests.

5 The shape memory response of Veriflex-E was evaluated using DMA and axial tensile tests.

6 The strain rate dependence of Veriflex-E was evaluated using axial tensile tests.

7 Shape memory hybrids combining SMPs and SMAs were created and evaluated.

\section{McConney, Michael 9/1/2009-8/17/2012}

1 Developed a new fabrication technique to create polymer stabilized cholesteric liquid crystals that enables high contrast optical filters to be made.

2 Made an cholesteric optical filter that induces high contrast (hyper-reflectivity) when exposed to heat or to light.

3 Made an cholesteric optical filter that which is high contrast and the wavelength of the filter changes when exposed to heat or light.

4 Developed an electrically tunable cholesteric liquid crystal.

5 Developed a novel CW laser from a polymer stabilized cholesteric liquid crystal.

\section{McDonald, Jonathan 1/18/2011-6/29/2012}

1 Derived discrete representation of the Ricci tensor for Piecewise-flat manifolds.

2 Used our discrete Ricci tensor to provide a geometric discretization of Richard Hamilton's Ricci flow equations on piecewise-flat manifolds.

3 Used discrete exterior calculus (DEC) to develop an inherently discrete analysis of curvature on simplicial geometries.

4 Applied techniques from Persistent Homology and quantum theory to demonstrate how quantum computations can be viewed as foliations of hypersurfaces whose geometry is determined by the correlation information between qubits.

5 Demonstrated the geometric view of quantum computation for 1D quantum cellular automata.

\section{O'Connor, Alan}

9/12/2011-7/31/2012

1 Demonstrated convergence of a distributed multi-agent system for agreeing on a collective sensing action when 
there is uncertainty about the target dynamical model.

2 Computed an analytical formula for the Cramer-Rao Lower Bound on range and velocity estimation variance and its dependece on the emitted radar pulse-train length. This result was confirmed for a stationary target using an Sband radar.

3 Quantified the benefit of feedback control of radar pulse-train length. Showed that the actively controlled approach achieved a $14 \%$ reduction in tracking error and dwell-time cost for constant velocity targets compared to the best constant policy.

4 Developed detector/tracker for asteroids moving in image sequences. This was an application of cognitive-based data-association algorithms developed by my advisor. Demonstrated improved performance for data with occlusions of objects of interest.

\section{Rider, Keith 7/18/2011-7/17/2012}

1 Measured particle deposition rates from helium droplet beam to compare with calculations.

2 Designed and build magnesium and perfluoropolyether sources.

3 Performed TPD/TPR experiments on magnesium and perfluoropolyether thin films.

4 Performed DSC/TGA experiments on magnesium and perfluoropolyether bulk materials.

5 Assisted with other experiments (XRD, SEM) of these and other materials.

\section{Sanders, Nathaniel}

8/1/2011-6/30/2012

1 Developed a heating reactor for gas-phase molecules to be interfaced with molecular beam, mass spectrometer.

2 Developed models for the pyrolysis of endothermic fuel simulant $n$-hexane under deoxygenated, low pressure conditions.

3 Introduced a novel class of Boron Nitride-based nanomaterials as catalysts to modify distribution of reaction intermediates.

4 Was able to differentiate classes of catalytic activity, and identify commonalities in catalytic behavior.

5 Developed a supercritical sample reaction chamber to be safely integrated to instrument for future work.

\section{Seletskiy, Denis}

\section{0/1/2010-7/26/2012}

1 High sensitivity spectroscopic methods developed.

2 Using methods above, local cooling to $110 \mathrm{~K}$ has been measured, in agreement with the model.

3 Bulk cooling to $119 \mathrm{~K}$ has been demonstrated.

4 Laser cooling model has been extended to include effects of saturation.

5 Cooling by 80 degrees has been demonstrated inside of a optically-pumped semiconductor laser cavity.

\section{Smith, Matthew}

\section{6/1/2010-6/30/2012}

1 Created novel self-oscillating (BZ) gels based on the biomacromolecule gelatin and synthetic polymer p(AAm-coAPMA).

2 Developed chemistries for effectively postfunctionalizing these gels with a Ru metal catalyst.

3 Charcterized chemical and mechanical behavior of BZ gelatin as a function of reactant concentration, gel size.

4 Demonstrated gel printing and ink stamping techniques for effective patterning of catalyst, made first heterogeneous gels.

5 Demonstrated conditions for synchronized, coupled oscillations between active patches, laid foundation for modular design.

\section{Voccola, Kaitlyn}

\section{9/15/2011-9/14/2012}

1 For a polarimetric SAR system consisting of orthogonally polarized dipoles, we found a way to circumvent the standard assumption/approximation that the polarization properties of the transmitted waves remain constant throughout the flight trajectory.

2 Completed numerical experiments comparing current polarimetric SAR imaging with our coupled polarimetric imaging approach for extended targets in clutter and found that it improved image signal-to-clutter ratio and meansquared error.

3 Developed forward model and imaging operator for a correlation based SAR imaging technique for targets and volume scattering clutter. Developed resolution analysis for the imaging scheme and found improvements over standard imaging.

4 Created a clutter minimization technique based on avoiding certain pairs of correlated data which requires no knowledge of the clutter present in the scene of interest.

5 Developed MATLAB code to simulate correlated SAR data and implement the correlation imaging scheme. It was found that clutter mitigation was successful for a variety of targets and for a variety of antenna trajectories.

\section{Wang, Peng} 10/1/2009-8/3/2012

1 Joint Spectrum Allocation and Scheduling in Multi-Radio Multi-Channel Cognitive Radio Wireless Networks; Throughput Optimization for Cognitive Radio Network with Slowly Varying Channels.

2 Capacity Optimization of MIMO Links with Interference: Derives the approximate theoretical capacity formula for MIMO links with interference through SVD. An Integer Programming algorithm is proposed to solve the capacity 
problem.

3 Resource Allocation in MIMO-based Ad Hoc Networks: Solves the problem of joint routing, scheduling, power control and bit rate selection with the goal of maximizing the system throughput that satisfies the given end-to-end traffic demands.

4 Throughput Optimization of Cognitive Radio Networks: The optimal solution provides a theoretical upper bound of throughput for cognitive radio networks. Also, derives a theoretical upper bound when greedy solution is used to solve the MWIS problem.

5 Throughput Optimization for Cognitive Radio Network with Slowly Varying Channels: Study the effect of aggregate delay; compare the optimal solution and the approximation solution, the centralized solution and distributed solution.

$\mathrm{Wu}$, Thomas

9/1/2010-8/14/2012

1 Investigated design methodologies for aircraft synchronous generator, including main machine, exciter and pilot exciter.

2 Developed linear and nonlinear electrical models for aircraft sunchronous generator.

3 Developed lumped element thermal and mechanical models for aircraft synchronous generaor.

4 Updated nonlinear electromechanical actuator model.

5 Started to work on generator testing.

Yang, Chi

6/22/2010-6/21/2012

1 Developed optically pumped mid-infrared in-plane DBR semiconductor lasers, reached the record power of $3 \mathrm{~W}$ in a $7 \mathrm{~nm}$ spectral range.

2 Realized the first unstable resonator diode laser at $2 \mu \mathrm{m}$ wavelength as precursor to unstable resonator quantum cascade lasers.

Yen, Chun-Wan 8/15/2011-9/28/2012

1 Introducing Gold Nanoparticles into PEDOT:PSS Layer.

2 Introducing Gold Nanoparticles into Active Layer.

3 Modifying the metallic electrode/active layer interface through nano-imprint patterning.

\section{Zunoubi, Mohammad}

8/1/2011-7/31/2012

1 Designed a Graphic Precessing Unit (GPU) high-performance computing system with a compute power of 15 Teraflops/s.

2 Implemented the first multiple computational tools for the analysis of coupled propagation equations for the UltraShort Laser Pulse (USPL) propagation.

3 Implemented the first multiple computational tools for the propagation of USPL in atmosphere and its interaction with matters.

4 Developed the massively parallel version of the above tool on GPUs to help speeding up the computation times by a factor of 70 over the convetional CPU tools. 
Advisers to the Nation on Science, Engineering, and Medicine

National Research Council

\section{Research Associateship Programs}

\section{FINAL REPORT}

1) Associate Last or Family Name

First Name

M.I.

Andrew

G

Alleyne

2) FORWARDING Address (to which your tax statement will be mailed)

FORWARDING Phone(s) and E-Mail (if known)

Home Phone:

Residence or Institution

Alt. Phone: 217-244-9993

Street

City, State Zip Urbana, IL, 61801

3) Today's Date

May 16, 2012

4) Host Agency

AFRL

(e.g., AFRL)

5) Name of Laboratory NRC Adviser (and USMA Mentor, if applicable)

Kirk Yerkes

6) TITLE OF RESEARCH PROPOSAL

Distributed Hybrid Thermal Management Systems for High Performane Aircraft Cooling Systems

7) SUMMARY OF RESEARCH DURING TENURE Itemize significant findings in concise form, utilizing key concepts/words.

1) Developed a hierarchical approach to controlling Thermal Management Systems (TMS's) within complex air vehicles. Hierarchical approach is preferred method for handling distributed loads and storage

2) Initiated research on diagnostics and health management using hierarchical framework

3) Created modeling software to analyze Vapor Cycle Systems as part of TMS's. Enables the study of transient thermal phenomena

4)

5)

(USMA Davies Fellow: please add summary of teaching, including classes taught.)

8) RESEARCH IN PROGRESS Describe in no more than 100 words.

Merging the modeling framework with the control framework. Create an actual system model with realistic components to design hierarchical controller and test in simulation

9) PUBLICATIONS AND PAPERS RESULTING FROM NRC ASSOCIATESHIP RESEARCH

Provide complete citations: author(s), title, full name of journal, volume number, page number(s), and year of publication.

a) Publications in peer-reviewed journals

b) Books, book chapters, other publications

c) Manuscripts in preparation, manuscripts submitted

Transient Thermal Systems, in preparation for ASME Dynamic Systems and Control

10) PATENT OR COPYRIGHT APPLICATIONS RESULTING FROM NRC ASSOCIATESHIP RESEARCH

Provide titles, inventors, and dates of applications.

11) PRESENTATIONS AT SCIENTIFIC MEETINGS OR CONFERENCES

Provide complete references: author(s), title, abstract/proceeding citation, meeting name and location.

International (e.g., High-Speed Propulsion) ctorate / Department 
Domestic

A Dynamic Modeling Toolbox fo Air Vehicle Vapor Cycle Systems, SAE Power Systems Conference, Phoenix AZ,Oct 30-Nov 1,2012 .

Experimental Load Emulation for Multi-Evaporator Air Conditioning and Refrigeration Systems, 14 ${ }^{\text {th }}$ International Refrigeration and Air Conditioning Conference, Purdue University, West Lafayette, IN, July 16-19, 2012

12) SEMINARS OR LECTURES DELIVERED AT UNIVERSITIES AND/OR INSTITUTES Include dates, names and locations of seminars.

Transient Thermal Systems Modeling and Control, University of Cincinnati, ME Dept, Jan 27, 2012

Transient Thermal Systems Modeling and Control, University of California, Irvine, ME Dept, March 9, 2012

Transient Thermal Systems Modeling and Control, University of Michigan, Controls Systems Seminar, March 30, 2012

Transient Thermal Systems Modeling and Control, University of California, San Diego, ME Dept, April 6, 2012

Transient Thermal Systems Modeling and Control, Rutgers University, MAE Dept, April 11, 2012

13) PROFESSIONAL AWARDS RECEIVED DURING TENURE

14) POST-TENURE POSITION / JOB TITLE

Professor

15) NAME AND ADDRESS OF POST-TENURE POSITION / JOB ORGANIZATION

Mechanical Science and Engineering, University of Illinois at Urbana-Champaign

16) POST-TENURE POSITION STATUS / CATEGORY Please indicate only one.

Permanent position at the NRC host agency

Contract or temporary position at the NRC host Agency

Abbreviate Host Laboratory/Center

Research/Administrative position with another U.S.government agency

$\square$ Research/Administrative position with a foreigngovernment agency

$\bigotimes$ Research/teaching position at a U.S. college or university

Research/teaching position at a foreign college or university $\square$ Research/administration position in private industry in the U.S.

Research/administration position in private industry outside of the U.S.

$\square$ Research/administration position with a non profit

$\square$ Self-employed/consulting

$\square$ Postdoctoral research

$\square$ Other (Please specify, possible)

$\square$ No information provided

17) APPRAISAL OF RESEARCH ASSOCIATESHIP PROGRAM

On a scale of 1 - 10 (poor - excellent), please rate the following:

SHORT TERM VALUE

7 Development of knowledge, skills, and research productivity

Comments

It was good to know more specifics of the people and problems here at the lab. I did not pick up new skills but I did get to see how they may be applicable in various domains.

LONG TERM VALUE

6 How the NRC Associateship award affected your career to date

Comments

The NRC Associateship award has had a neutral effect on my career to date. It will be more interesting to see how it affects my career in the future.

LAB SUPPORT

9 Quality of support from the Laboratory--equipment, funding, orientation, safety and health guidelines, etc.

Comments

I have had everything that I've needed.

ADVISER/MENTOR SUPPORT

3 Quality of mentoring from the Laboratory NRC Adviser (USMA Mentor, if applicable)

Comments

There was little contact between the mentor and myself on research related topics over the course of the year.

LPR SUPPORT

9 Quality of administrative support from the Laboratory (e.g., NIST, NRL, IWR, FHWA) NRC Program $\underline{\text { Representative (LPR) }}$ Comments

I think the admin support was very good. Things were turned around in a timely fashion. The LPR even came up with some admin solutions that were out of the box for the Educational Partnership Agreement we created. 
9 Quality of administrative support. Please assess respective NRC aspects (e.g., moving company, insurance, Omega, payroll, coordinator, travel, etc.)

Comments

Very good.

18) PLEASE PROVIDE ANY SUGGESTIONS FOR PROGRAM IMPROVEMENT.

Please do NOT scan to PDF. Send the Final Report as MSWord document via e-mail to your NRC Program Coordinator No handwritten signature required; Asha Davis: $\quad$ adavis@nas.edu but you may upload a scanned signature file below:

Linda Sligh: Isligh@nas.edu

Jason Thornhill: jthornhill@nas.edu

Peggy Wilson: pwilson@nas.edu

Suzanne White: swhite@nas.edu 
Advisers to the Nation on Science, Engineering, and Medicine

\section{Research Associateship Programs}

National Research Council

\section{FINAL REPORT}

1) Associate Last or Family Name

First Name

Eric

FORWARDING Phone(s) and E-Mail (if known)

Home Phone:

Alt. Phone:

Preferred E-mail: eric.anderson.ctr@wpafb.af.mil

Street

City, State Zip Centerville, OH 45459

3) Today's Date

April 30, 2012

4) Host Agency

AFRL

(e.g., AFRL)

5) Name of Laboratory NRC Adviser (and USMA Mentor, if applicable)

Dr. Joseph Zelina

6) TITLE OF RESEARCH PROPOSAL

Knock Mitigation Techniques to Enable SI Engine Operation on Low Octane Fuels

7) SUMMARY OF RESEARCH DURING TENURE Itemize significant findings in concise form, utilizing key concepts/words.

1) Assisted in establishment of the Small Engine Research Laboratory (SERL) at AFRL to develop IC engine technology.

2) Constructed and tested rotary ball valve for Pulsed Detonation Engine use, with substantial improvements in volumetric efficiency.

3) Developed computational code to compute heat transfer rates to pulsed detonation engine tube walls, found thermal barrier coating increased detonation tube wall temperatures.

4) Demonstrated prechamber as knock mitigation technique, enabling full load operation down with a 60 octane PRF blend in a spark ignition engine.

5) Demonstrated intercooler, optimized ignition timing, direct injection, and to reduce the octane requirement of the Rotax 914 from 100 to 87.

(USMA Davies Fellow: please add summary of teaching, including classes taught.)

\section{8) RESEARCH IN PROGRESS Describe in no more than 100 words.}

Continuing research includes development of a prechamber optimized for the Rotax 914 combution chamber geometry. We are also an optically accessible single cylinder engine for studying direct injection and prechamber ignition in the Rotax 914. This engine will enable visualization of fuel sprays in a firing or motored engine with high speed video, laser induced fluorescence, or particle imaging velocimetry techniques. Flame development with the prechamber can be observed by recording natural flame luminosity and chemiluminescence.

\section{9) PUBLICATIONS AND PAPERS RESULTING FROM NRC ASSOCIATESHIP RESEARCH}

Provide complete citations: author(s), title, full name of journal, volume number, page number(s), and year of publication.

a) Publications in peer-reviewed journals

W.P. Attard, H. Blaxill, E.K. Anderson, P. Litke, "Knock Limit Extension with a Gasoline Fueled Pre-Chamber Jet Igniter in a Modern Vehicle Powertrain,’ SAE Paper No. 2012-01-1143

J. Karnesky, E. Anderson, F. Schauer, J. Hoke, “Pulsed Detonation Engines in the Choked Flame Regime,” Proceedings of the 50th AIAA Aerospace Sciences Meeting, January 9-12, 2012, Nashville, Tennessee.

b) Books, book chapters, other publications

N/A

c) Manuscripts in preparation, manuscripts submitted

N/A 
Provide titles, inventors, and dates of applications.

N/A

11) PRESENTATIONS AT SCIENTIFIC MEETINGS OR CONFERENCES

Provide complete references: author(s), title, abstract/proceeding citation, meeting name and location.

International

E.K. Anderson, J.L. Hoke, F.R. Schauer, "Study of a Thermal Barrier Coating in a Pulsed Detonation Engine," Proceedings of the ASME 2010 IMECE, November 12-18 2010, Vancouver, British Columbia.

Domestic

E. Anderson, A. Brown, J. Baranski, J. Hoke, P. Litke, F. Schauer, "Performance of Low Octane Fuels in a Rotax 914 Engine with Advanced Knock Mitigation Strategies," Proceedings of the 47th AIAA/ASME/SAE/ASEE Joint Propulsion Conference \& Exhibit, July 31-August 3, 2011, San Diego, California.

E. Anderson, C. Stevens, J Hoke, F. Schauer, “Ball Valve Pulsed Detonation Engine,’ Proceedings of the 49th AIAA Aerospace Sciences Meeting, January 4-7, 2011, Orlando, Florida.

E. Anderson, J. Hoke, F. Schauer, "Novel Valving Technique for Pulse Detonation Engines," Proceedings of the 46th AIAA/ASME/SAE/ASEE Joint Propulsion Conference \& Exhibit, July 25-28, 2010, Nashville, Tennessee.

12) SEMINARS OR LECTURES DELIVERED AT UNIVERSITIES AND/OR INSTITUTES Include dates, names and locations of seminars. N/A

13) PROFESSIONAL AWARDS RECEIVED DURING TENURE

N/A

14) POST-TENURE POSITION / JOB TITLE

Research Engineer

15) NAME AND ADDRESS OF POST-TENURE POSITION / JOB ORGANIZATION

Innovative Scientific Solutions Inc., AFRL Contractor, my physical address: Building 71 Room 5, $7^{\text {th }}$ St, WPAFB, OH 45433

16) POST-TENURE POSITION STATUS / CATEGORY Please indicate only one.

Permanent position at the NRC host agency

$\bigotimes$ Contract or temporary position at the NRC host Agency

Abbreviate Host Laboratory/Center WPAFB

$\square$ Research/Administrative position with another U.S.government agency

Research/Administrative position with a foreigngovernment agency

Research/teaching position at a U.S. college or university

Research/teaching position at a foreign college or university

$\square$ Research/administration position in private industry in the U.S.

$\square$ Research/administration position in private industry outside of the U.S.

$\square$ Research/administration position with a non profit

$\square$ Self-employed/consulting

$\square$ Postdoctoral research

$\square$ Other (Please specify, possible)

$\square$ No information provided

17) APPRAISAL OF RESEARCH ASSOCIATESHIP PROGRAM

On a scale of 1 - 10 (poor - excellent), please rate the following:

SHORT TERM VALUE

8 Development of knowledge, skills, and research productivity

Comments

Working at AFRL/RZTC/SERL provided me with the opportunity to spend most of my time doing hands-on experimental research. I would have ranked this a full 10 with some additional guidance as to the overall goals of the laboratory would have been.

LONG TERM VALUE

8 How the NRC Associateship award affected your career to date

Comments

The accociateship allowed me to learn new skills in the Detonation Engine Research Facility as well as continue to learn IC engine testing and development. It also provided me the opportunity to teach at nearby universities. I would have ranked this a full 10 had $I$ been able to publish/present more frequently.

LAB SUPPORT

8 Quality of support from the Laboratory--equipment, funding, orientation, safety and health guidelines, etc.

Comments 
Since SERL was a new laboratory, funding and equipment for our laboratory has improved dramatically since I began my fellowship. I feel that we now have funding and equipment which enables us to produce quality data. I have had no problems with the safety and health guidelines followed here.

\section{ADVISER/MENTOR SUPPORT}

8 Quality of mentoring from the Laboratory NRC Adviser (USMA Mentor, if applicable)

Comments

I feel I could have used more interaction from my mentor. Most of my interaction on a day-to-day basis were with the non-NRC laboratory researchers. Additional input as to the expectations of the NRC would have been helpful.

\section{LPR SUPPORT}

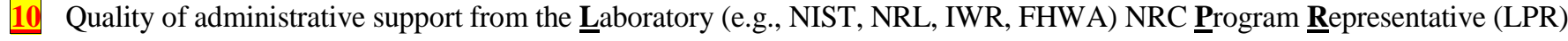
Comments

All of my needs from the LPR were met quickly.

\section{NRC SUPPORT}

10 Quality of administrative support. Please assess respective NRC aspects (e.g., moving company, insurance, Omega, payroll, coordinator, travel, etc.)

\section{Comments}

All of my needs in this area were met quickly. One area that is always tricky is figuring out income tax with the lack of official tax forms from NRC, but I understand that there are good reasons for NRC avoid providing 1099 or W-2 forms.

18) PLEASE PROVIDE ANY SUGGESTIONS FOR PROGRAM IMPROVEMENT.

As stated above, more mentor input and the income tax issue could be areas for improvement.

Please do NOT scan to PDF. Send the Final Report as MSWord document via e-mail to your NRC Program Coordinator

No handwritten signature required; $\quad$ Asha Davis: $\quad$ adavis@nas.edu

but you may upload a scanned $\quad$ Linda Sligh: $\quad$ Isligh@nas.edu

signature file below: $\quad$ Jason Thornhill: $\quad$ ithornhill@nas.edu

Peggy Wilson: pwilson@nas.edu

Suzanne White: swhite@nas.edu 
Advisers to the Nation on Science, Engineering, and Medicine

National Research Council

\section{Research Associateship Programs}

\section{FINAL REPORT}

1) Associate Last or Family Name

First Name

Beier

2) FORWARDING Address (to which your tax statement will be mailed)

Hope

M.I.

FORWARDING Phone(s) and E-Mail (if known)

Home Phone:

Residence or Institution (Residence)

Street

City, State Zip San Antonio, TX 78258

3) Today's Date

November 15, 2012

4) Host Agency

AFRL

(e.g., AFRL)

5) Name of Laboratory NRC Adviser (and USMA Mentor, if applicable)

Dr. Benjamin Rockwell

6) TITLE OF RESEARCH PROPOSAL

Stimulated Raman Scattering Imaging of Laser Induced Protein Denaturation

7) SUMMARY OF RESEARCH DURING TENURE Itemize significant findings in concise form, utilizing key concepts/words.

1) Developed a multiplex stimulated Raman scattering imaging system.

2) Improved the spectral resolution of multiplex coherent Raman scattering spectra.

3) Used coherent Raman scattering to measure the temperature of aqueous solutions with submicron resolution.

4) Monitored the kinetics of ion influx into biological cells using a high-speed imaging system.

5) Developed a system to aquire low-frequency Raman scattering spectra of biological molecules and compare to $\mathrm{THz}$ resonances.

(USMA Davies Fellow: please add summary of teaching, including classes taught.)

\section{8) RESEARCH IN PROGRESS Describe in no more than 100 words.}

My current research is focused on using techniques such as spontaneous and coherent Raman scattering, high-speed imaging, and confocal and multi-photon microscopy for the investigation of biological response to electromagnetic exposure. Of particular interest is exploration of effects or specific information that can be gained from low-frequency Raman techniques and using this technique as an indirect comparison to direct terahertz exposure.

\section{9) PUBLICATIONS AND PAPERS RESULTING FROM NRC ASSOCIATESHIP RESEARCH}

Provide complete citations: author(s), title, full name of journal, volume number, page number(s), and year of publication.

a) Publications in peer-reviewed journals

1. Beier HT, Roth CC, Tolstykh, GP, Ibey BL, Resolving the spatial kinetics of electric pulse-induced ion release, Biochemical and Biophysical Research Communications (2012), 423(4), 863-866.

2. Beier HT, Noojin GN, Rockwell BA, Remote, Label-Free Thermal Mapping using Coherent Anti-Stokes Raman Spectroscopy, Journal of Biomedical Optics (2012), $17(8), 080501$.

3. Beier HT, Noojin GN, Rockwell BA, Stimulated Raman Scattering Using a Single Femtosecond Oscillator with Flexibility for Imaging and Spectral Applications, Optics Express (2011), 19(20), 18885-18892.

b) Books, book chapters, other publications

c) Manuscripts in preparation, manuscripts submitted

1. Beier HT, Ibey BL, "Experimental Comparison of the High-Speed Imaging Performance of an EM-CCD and sCMOS Camera in a Dynamic Live-Celling Imaging Test Case.” in preparation.

2. Tolstykh GP, Beier HT, Roth CC, Thompson GT, Payne JA, Kuipers MA and Ibey BL. Activation of Intracellular Phosphoinositide Signaling after a Single 600 Nanosecond Electric Pulse, Biochemical and Biophysical Research Communications (2012), in internal review. 
10) PATENT OR COPYRIGHT APPLICATIONS RESULTING FROM NRC ASSOCIATESHIP RESEARCH

Provide titles, inventors, and dates of applications.

11) PRESENTATIONS AT SCIENTIFIC MEETINGS OR CONFERENCES

Provide complete references: author(s), title, abstract/proceeding citation, meeting name and location.

International

1. Beier HT, Roth CC, Tolstykh GP, Ibey BL "Resolving the spatial kinetics of nanosecond pulse-induced calcium release" Bioelectrics, Kumamoto, Japan, 2012

2. Tolstykh GP, Roth CC, Payne JA, Kuipers MA, Thompson GL, Beier HT, Ibey BL, "Activation of Intracellular Phosphoinositide Signaling after a Single Nanosecond Electric Pulse.’ Bioelectrics, Kumamoto, Japan, 2012

3. Tolstykh GP, Roth CC, Payne JA, Kuipers MA, Thompson GL, Beier HT, Ibey BL, "Activation of Intracellular Phosphoinositide Signaling after a Single Nanosecond Electric Pulse.” Gordons Research Conference - Bioelectrochemistry, Lucca, Italy, July 1-6, 2012

Domestic

1. Beier HT, Noojin GD, Rockwell BA, Coherent Raman Scattering for Localized Thermal Mapping, Proceedings of SPIE Volume 8221, SPIE Photonis West, San Francisco (2012).

2. Yakovlev V, Petrov GI, Noojin GD, Golovan LA, Beier HT, Thomas RJ, Rockwell BA, "Directed Raman Signal to a Detector.” CLEO: Science and Innovations, San Jose, CA, May 2012.

3. Beier HT, Noojin GD, Rockwell BA, “Stimulated Raman scattering using a photonic crystal fiber," SPIE Photonics West, San Francisco January 2011.

4. Lipscomb D, Echchgadda I, Ibey BL, Beier HT, Thomas RJ, Peralta X, Wilmink GJ, “Terahertz spectroscopy of dry, hydrated, and thermall denatured biological macromolecules," Proceedings of SPIE Volume 8221, SPIE Photonis West, San Francisco, (2012)

5. Beier HT, Coté GL, Meissner KE, Whispering-Gallery Mode Based Biosensing Using Quantum-Dot Embedded Microspheres, Proceedings of SPIE Volume 7575, SPIE Photonis West, San Francisco, (2010).

12) SEMINARS OR LECTURES DELIVERED AT UNIVERSITIES AND/OR INSTITUTES Include dates, names and locations of seminars.

1. Beier, HT “Optical Approaches for Chemical and Biological Sensing: Whispering Gallery Modes and Stimulated Raman Scattering” Seminar for UT-San Antonio Physics Department, February 2012 (Invited)

13) PROFESSIONAL AWARDS RECEIVED DURING TENURE

1. AF Section 219 Venture Funds: "Investigation of Directed-Energy-Induced Membrane Dynamics using Stimulated Emission Depletion Nanoscopy “, Role: PI, (September 2012)

2. Air Force Office of Scientific Research LRIR: “Activation of intracellular signaling pathways by nanosecond pulsed electric fields", Role: Co-PI, (Oct 2012-2015)

3. Air Force Office of Scientific Research LRIR Grant \#12RH01COR: "Probing Terahertz Resonances Using Visible and Near-Infrared Light through Low-Frequency Raman”A Role: PI, (Oct 2011-2014)

14) POST-TENURE POSITION / JOB TITLE

Research Biomedical Engineer

15) NAME AND ADDRESS OF POST-TENURE POSITION / JOB ORGANIZATION

Air Force Research Laboratory

711 Human Performance Wing

Bioeffects Division

4141 Petroleum Road

Fort Sam Houston, TX 78234

16) POST-TENURE POSITION STATUS / CATEGORY Please indicate only one.

$\triangle$ Permanent position at the NRC host agency

Contract or temporary position at the NRC host Agency

Abbreviate Host Laboratory/Center

Research/Administrative position with another U.S.government agency

Research/Administrative position with a foreigngovernment agency

Research/teaching position at a U.S. college or university

Research/teaching position at a foreign college or university $\square$ Research/administration position in private industry in the U.S.

$\square$ Research/administration position in private industry outside of the U.S.

Research/administration position with a non profit

$\square$ Self-employed/consulting

$\square$ Postdoctoral research

$\square$ Other (Please specify, possible)

No information provided 
On a scale of 1 - 10 (poor - excellent), please rate the following:

\section{SHORT TERM VALUE}

10 Development of knowledge, skills, and research productivity Comments

The NRC program gave me the opportunity to work in a laboratory with equipment and resources not typically available in an academic setting, with free reign to work on projects of my own choosing. I was able to work directly with and learn from other scientists and technicians with many years of true laboratory experience. I do not believe I could have gained experience of this magnitude in an university setting.

LONG TERM VALUE

10 How the NRC Associateship award affected your career to date

Comments

The NRC program gave me the opportunity to establish a research program and apply for and be awarded research grants as a principal investigator that I will continue to work on as a federal civilian employee. It gave me the opportunity to prove my capabilities to my mentors and led directly to an offer of employment.

LAB SUPPORT

10 Quality of support from the Laboratory--equipment, funding, orientation, safety and health guidelines, etc.

Comments

Support from the laboratory was outstanding. I was given unparalleled access to any equipment necessary for any experiment of my choosing, substantial start-up type funds to purchase any need supplies, my own laboratory space which I was subsequently allowed to upgrade as my space requirements increased, and access to technician support to help me meet my objectives. I was also given the opportunity to apply for additional research grants to expand my research program.

ADVISER/MENTOR SUPPORT

10 Quality of mentoring from the Laboratory NRC Adviser (USMA Mentor, if applicable)

Comments

I could not have asked for a more supportive mentor. He is always there to make sure I had everything I needed for my research program and as a member of the laboratory. He is always more than willing to go out of his way to solve any problem that I may have, whether with research, professionally, or personally.

LPR SUPPORT

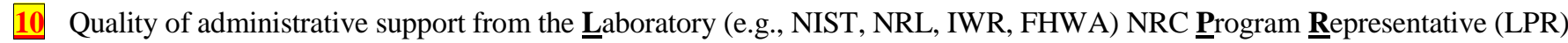
Comments

Support from the LPR was outstanding. He always made sure we had everything we needed in the laboratory. He was also extremely supportive in ensuring I was well-taken care of in terms of my research program and future career.

\section{NRC SUPPORT}

9 Quality of administrative support. Please assess respective NRC aspects (e.g., moving company, insurance, Omega, payroll, coordinator, travel, etc.)

Comments

Administrative support was typically excellent. I never had any issues with insurance, payroll, etc. Everyone in the NRC office was curteous and seemed willing to help. Travel reimbursment was a bit slow at times (up to two months) and sometimes required an over-abundance of justification; however, all issues were eventually resolved.

18) PLEASE PROVIDE ANY SUGGESTIONS FOR PROGRAM IMPROVEMENT.

Please do NOT scan to PDF. Send the Final Report as MSWord document via e-mail to your NRC Program Coordinator No handwritten signature required; Asha Davis: $\quad$ adavis@nas.edu but you may upload a scanned signature file below:

Linda Sligh: $\quad$ lsligh@ nas.edu

Jason Thornhill: ithornhill@nas.edu

Peggy Wilson: pwilson@nas.edu

Hope Beier

Suzanne White: swhite@nas.edu

Rev. July 2011

Proj/Act ID\# 
Advisers to the Nation on Science, Engineering, and Medicine

National Research Council

\section{Research Associateship Programs}

\section{FINAL REPORT}

1) Associate Last or Family Name

First Name

Uttam

FORWARDING Phone(s) and E-Mail (if known)

Home Phone:

Alt. Phone:

Preferred E-mail: uttamk@gatech.edu

Street Department of Mechanical Eng., 2000 Lakeshore Dr City, State Zip New Orleans, LA 70148

3) Today's Date

July 18, 2012
4) Host Agency

AFRL

(e.g., AFRL)

5) Name of Laboratory NRC Adviser (and USMA Mentor, if applicable)

Jess Willard Curtis

6) TITLE OF RESEARCH PROPOSAL

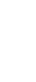

Experimental and Finite Element Modal Analysis of the Flexible Wings of Micro Munition Vehicles to August 13, 2012

Division / Directorate / Department

Munitions Directorate

(e.g., High-Speed Propulsion)
M.I.

$\mathbf{K}$
Dates of Tenure

from October 1, 2010

oratory or Center

Eglin AFB

(e.g., Wright Patterson AFB)

(e.g., Wright Patterson

7) SUMMARY OF RESEARCH DURING TENURE Itemize significant findings in concise form, utilizing key concepts/words.

1) Biologically inspired wings of micro munition vehicles (MMVs) were constructed with membrane, attached to the metallic/composite reinforced structures.

2) Finite element models were developed for the modal characteristics of the flexible wings of MMVs and validated by experimental and analytical results.

3) The effects of added mass, damping, and aerodynamic loads on the modal characteristics (natural frequencies and mode shapes) of the wings were investigated.

4) The wings were vibrated in vacuum and in air for investigating the effects of added mass and damping on their modal characteristics.

5) Aerodynamic loads were estimated from the wind-tunnel test data, where the angle of attack of the wings and freestream velocity of air are varied.

(USMA Davies Fellow: please add summary of teaching, including classes taught.)

8) RESEARCH IN PROGRESS Describe in no more than 100 words.

Biologically inspired hair receptors are designed for detecting the surrounding air flow characteristics of micro munition vehicles. Finite element model is developed for investigating the deformation, shear force, and bending moment distributions of the hair receptors at different fluid flow velocities, considering both steady and unsteady aerodynamics. Dynamic characteristics (natural frequencies and mode shapes) of the hair receptors are also investigated at the steady and unsteady air flow regimes.

9) PUBLICATIONS AND PAPERS RESULTING FROM NRC ASSOCIATESHIP RESEARCH

Provide complete citations: author(s), title, full name of journal, volume number, page number(s), and year of publication.

a) Publications in peer-reviewed journals

1) Uttam Kumar Chakravarty, "Vibration Characteristics of the Wings of Micro Air Vehicles," Journal of Aircraft 49(2) (2012) 644-650.

2) Uttam Kumar Chakravarty, "Modal Analysis of a Composite Wing of a Micro Air Vehicle," Journal of Aircraft 48(6) (2011) 2175-2178.

3) Uttam Kumar Chakravarty, and Roberto Albertani, “Modal Analysis of a Flexible Membrane Wing of Micro Air Vehicles," Journal of Aircraft 48(6) (2011) 1960-1967.

b) Books, book chapters, other publications 
1) Uttam K. Chakravarty, Benjamin T. Dickinson, Michael R. Hays, and William S. Oates, "Aeromechanics of an Electroactive Membrane Wing of Micro Air Vehicles," manuscript in preparation.

2) Michael R. Hays, Jeffrey Morton, Benjamin Dickinson, Uttam K. Chakravarty, and William S. Oates, "Aerodynamic Control of Micro Air Vehicle Wings using Electroactive Membranes,” Journal of Intelligent Materials Systems and Structures, submitted for publication.

3) Uttam Kumar Chakravarty, "On the resonance frequencies of a membrane of a dielectric elastomer," Journal of Intelligent Materials Systems and Structures, submitted for publication.

4) Uttam Kumar Chakravarty, "Analytical and Finite Element Modal Analysis of a Hyperelastic Membrane for Micro Air Vehicle Wings,” ASME Journal of Vibration and Acoustics, submitted for publication.

10) PATENT OR COPYRIGHT APPLICATIONS RESULTING FROM NRC ASSOCIATESHIP RESEARCH

Provide titles, inventors, and dates of applications.

11) PRESENTATIONS AT SCIENTIFIC MEETINGS OR CONFERENCES

Provide complete references: author(s), title, abstract/proceeding citation, meeting name and location.

International

1) Uttam Kumar Chakravarty, "Modal Analysis of Micro Air Vehicle Wings," 9th International Conference on Mechanical Engineering (published only the abstract); Dhaka, Bangladesh: December 18-20, 2011.

2) Uttam Kumar Chakravarty, "Experimental and Finite Element Modal Analysis of the Flexible Wings of Micro Air Vehicles," Proceedings of the International Conference on Mechanical, Industrial and Energy Engineering; Khulna, Bangladesh: December 23-24, 2010.

Domestic

1) Uttam Kumar Chakravarty, "Natural Frequencies and Mode Shapes of the Wings of Low-Reynolds-Number Flyers," Proceedings of the 53rd AIAA/ASME/ASCE/AHS/ASC Structures, Structural Dynamics, and Materials Conference; Honolulu, Hawaii: April 23-26, 2012.

2) Uttam Kumar Chakravarty, "Experimental and Finite Element Modal Analysis of the Flexible Wings of Micro Munition Vehicles," Proceedings of the Society for Experimental Mechanics Annual Conference \& Exposition on Experimental and Applied Mechanics; Uncasville, Connecticut: June 13-16, 2011.

3) Uttam Chakravarty, Crystal Pasiliao, and Eduardo Pasiliao, "Modal Analysis of Biologically Inspired Wings of LowReynolds-Number Flyers," ASME Applied Mechanics and Materials Conference (published only the abstract); Chicago, Illinois: May 31-June 2, 2011.

12) SEMINARS OR LECTURES DELIVERED AT UNIVERSITIES AND/OR INSTITUTES Include dates, names and locations of seminars.

1) Uttam Kumar Chakravarty, “Mechanics of Composite Structures for Aerospace Applications," Department of Mechanical Engineering, University of New Orleans, 2000 Lakeshore Dr, New Orleans, LA 70148: May 18, 2012.

2) Uttam Kumar Chakravarty, "Mechanics of Composite Structures for Aerospace Applications," Department of Aerospace Engineering, Embry-Riddle Aeronautical University, 600 S. Clyde Morris Blvd., Daytona Beach, FL 32114: March $26,2012$.

3) Uttam Kumar Chakravarty, “Finite Element Modal Analysis of Micro Air Vehicle Wings," University of Florida and Air Force Research Laboratory Summer Seminar Series; University of Florida, Research and Engineering Education Facility, Shalimar, FL 32579: August 10, 2011.

13) PROFESSIONAL AWARDS RECEIVED DURING TENURE

14) POST-TENURE POSITION / JOB TITLE

Assistant Professor

15) NAME AND ADDRESS OF POST-TENURE POSITION / JOB ORGANIZATION

Department of Mechanical Engineering, University of New Orleans, 2000 Lakeshore Dr, New Orleans, LA 70148

16) POST-TENURE POSITION STATUS / CATEGORY Please indicate only one.

Permanent position at the NRC host agency

Contract or temporary position at the NRC host Agency

Abbreviate Host Laboratory/Center

$\square$ Research/Administrative position with another U.S.government agency

Research/Administrative position with a foreigngovernment agency

$\bigotimes$ Research/teaching position at a U.S. college or university $\square$ Research/teaching position at a foreign college or university

Research/administration position in private industry in the U.S.

Research/administration position in private industry outside of the U.S.

$\square$ Research/administration position with a non profit

$\square$ Self-employed/consulting

$\square$ Postdoctoral research

Other (Please specify, possible) 
No information provided

17) APPRAISAL OF RESEARCH ASSOCIATESHIP PROGRAM

On a scale of 1 - 10 (poor - excellent), please rate the following:

SHORT TERM VALUE

$\square$ Development of knowledge, skills, and research productivity

Comments

10

LONG TERM VALUE

$\square$ How the NRC Associateship award affected your career to date Comments

10

LAB SUPPORT

Quality of support from the Laboratory--equipment, funding, orientation, safety and health guidelines, etc.

Comments

10

\section{ADVISER/MENTOR SUPPORT}

Quality of mentoring from the Laboratory NRC Adviser (USMA Mentor, if applicable)

Comments

10

LPR SUPPORT

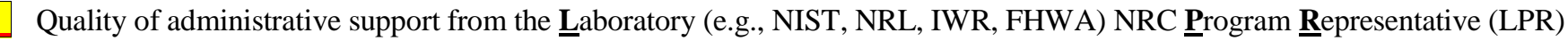
Comments

10

NRC SUPPORT

$\square$ Quality of administrative support. Please assess respective NRC aspects (e.g., moving company, insurance, Omega, payroll, coordinator, travel, etc.)

Comments

10

18) PLEASE PROVIDE ANY SUGGESTIONS FOR PROGRAM IMPROVEMENT.

Please do NOT scan to PDF. Send the Final Report as MSWord document via e-mail to your NRC Program Coordinator No handwritten signature required; but you may upload a scanned signature file below:

Asha Davis:

Linda Sligh:

Jason Thornhill: ithornhill@nas.edu

Peggy Wilson: pwilson@nas.edu

Suzanne White: swhite@nas.edu
Proj/Act ID\# 
Advisers to the Nation on Science, Engineering, and Medicine

National Research Council

\section{Research Associateship Programs}

\section{FINAL REPORT}

1) Associate Last or Family Name

First Name

M.I.

Kristen

$\mathbf{K}$

Comfort

2) FORWARDING Address (to which your tax statement will be mailed)

FORWARDING Phone(s) and E-Mail (if known)

Home Phone:

Residence or Institution Residence

Alt. Phone: 937-219-1800

Street

City, State Zip Beavercreek, OH 45434

3) Today's Date

July 15, 2012

4) Host Agency

AFRL

(e.g., AFRL)

5) Name of Laboratory NRC Adviser (and USMA Mentor, if applicable)

Dr. Saber M Hussain

6) TITLE OF RESEARCH PROPOSAL

Remote Actuation of Epidermal Growth Factor (EGF) Signal Transduction through a Nano-based Mechanism

7) SUMMARY OF RESEARCH DURING TENURE Itemize significant findings in concise form, utilizing key concepts/words.

1) Identified a disruption in EGF dependent signal transduction by silver, gold, and iron oxide nanoparticles.

2) Elucidated combinatorial bioeffects on a cellular, protein, and genomic level following concurrent exposure to nanoparticles and a static magnetic field.

3) Evaluated the photothermal capability of gold nanorods during NIR laser irradiation and correlated the resultant heat production to nanorod aspect ratio.

4) Discovered the impact of biologically relevant fluids on the photothermal efficiency of gold nanorods and successfully linked the diminution of thermal production to a solution-induced nanorod agglomeration phenomenon.

5) Developed and implemented a new nano-bioeffect paradigm targeting lower, occupational exposure levels of nanomaterials. (USMA Davies Fellow: please add summary of teaching, including classes taught.)

8) RESEARCH IN PROGRESS Describe in no more than 100 words.

Currently, a NIR dependent, remote release of EGF is being developed which utilizes gold nanorods of various aspect ratio as a platform. Gold nanorods are functionalized with carboxylated PEG and EGF molecules are conjugated to via a well documented EDC/NHS reaction. Successful creation of these EGF-nanorod conjugates will be verified by dynamic light scattering, UV-VIS, and SEM. These conjugates will then undergo NIR laser irradiation with the released EGF being collected, quantified, and correlated to the nanorod aspect ratio and the degree of solution heating. Following optimization, this release mechanism will be used to induce EGF signaling in vitro.

9) PUBLICATIONS AND PAPERS RESULTING FROM NRC ASSOCIATESHIP RESEARCH

Provide complete citations: author(s), title, full name of journal, volume number, page number(s), and year of publication.

a) Publications in peer-reviewed journals

Comfort, K.K.; Maurer, E.I.; Braydich-Stolle, L.K.; Hussain, S.M. Interference of Silver, Gold, and Iron Oxide

Nanoparticles on Epidermal Growth Factor Signal Transduction in Epithelial Cells. ACS Nano 2011, 5, 10000-10008.

Maurer, E.I.; Comfort, K.K.; Hussain, S.M.; Schlager, J.J.; Mukhopadhyay, S.M. Novel Platform Development using Assembly of Carbon Nanotube, Nanogold and Immobilized RNA Capture Element for Rapid, Selective Sensing of Bacteria. Sensors 2012, 12, 8135-8144.

b) Books, book chapters, other publications

Stacy, B.M.; Comfort, K.K.; Comfort, D.A.; Hussain, S.M. Controlled Synthesis of Gold Nanorods and their Biological Applications. In Preparation

c) Manuscripts in preparation, manuscripts submitted 
Comfort, K.K.; Maurer, E.I.; Hussain, S.M. The Biological Impact of Concurrent Exposure to Metallic Nanoparticles and a Static Magnetic Field on Keratinocytes. Submitted.

Comfort, K.K.; Speltz, J.; Stacy, B.M.; Dosser, L.; Hussain, S.M. The Differential Photothermal Ability of Gold Nanorods: Dependence on Aspect Ratio and Agglomeration Patterns. Submitted.

10) PATENT OR COPYRIGHT APPLICATIONS RESULTING FROM NRC ASSOCIATESHIP RESEARCH

Provide titles, inventors, and dates of applications.

11) PRESENTATIONS AT SCIENTIFIC MEETINGS OR CONFERENCES

Provide complete references: author(s), title, abstract/proceeding citation, meeting name and location.

International

Domestic

Comfort, K.K.; Maurer, E.I.; Braydich-Stolle, L.K. ; Hussain, S.M. Inhibition of EGF-Induced Signal Transduction by Low Levels of Silver, Gold, and Iron Oxide Nanoparticles Presentation given at Materials Research Society (MRS), November 29, 2011, Boston, MA (Oral Presentation)

12) SEMINARS OR LECTURES DELIVERED AT UNIVERSITIES AND/OR INSTITUTES Include dates, names and locations of seminars. Comfort, K.K. Bioengineering Experimental Techniques. Department of Bioengineering, University of Dayton, Dayton, $\mathrm{OH}$, July 19, 2011.

Comfort, K.K., Maurer, E.I., Hussain, S.M. From CME to Bioengineering with an Emphasis on Research. Department of Chemical Engineering, University of Dayton, Dayton, OH, March 21, 2012.

13) PROFESSIONAL AWARDS RECEIVED DURING TENURE

14) POST-TENURE POSITION / JOB TITLE

Postdoctoral Researcher

15) NAME AND ADDRESS OF POST-TENURE POSITION / JOB ORGANIZATION

Oak Ridge Institute for Science and Education, AFRL, Wright Patterson AFB, Dayton,OH

16) POST-TENURE POSITION STATUS / CATEGORY Please indicate only one.

Permanent position at the NRC host agency

$\triangle$ Contract or temporary position at the NRC host Agency

Abbreviate Host Laboratory/Center AFRL

$\square$ Research/administration position in private industry in the U.S.

Research/Administrative position with another U.S.government agency

Research/Administrative position with a foreigngovernment agency

Research/teaching position at a U.S. college or university

Research/teaching position at a foreign college or university

$\square$ Research/administration position in private industry outside of the U.S.

$\square$ Research/administration position with a non profit

$\square$ Self-employed/consulting

$\square$ Postdoctoral research

$\square$ Other (Please specify, possible)

$\square$ No information provided

17) APPRAISAL OF RESEARCH ASSOCIATESHIP PROGRAM

On a scale of 1 - 10 (poor - excellent), please rate the following:

\section{SHORT TERM VALUE}

9 Development of knowledge, skills, and research productivity

Comments

This was an excellent opportunity to expand my core knowledge base and skill set. Additionally, through the support I was provided, my NRC postdoctoral period was very productive, both professionally and research-based.

LONG TERM VALUE

8 How the NRC Associateship award affected your career to date Comments 
I feel that the prestige associated with an NRC post-doctoral fellow will significantly strengthen my prospects for my future career. Furthermore, the skills I aquired through this fellowship will be incorporated into and strengthen my highlighted qualifications for future employment opportunities.

LAB SUPPORT

9 Quality of support from the Laboratory--equipment, funding, orientation, safety and health guidelines, etc.

Comments

The support I received from Dr. Hussain's laboratory was phenominal. The equipment is state of the art and I was always provided with the materials and proper safety information that I needed to effectively perform my research. The multi-disciplinary approach Dr. Hussain has taken to his group was of a significant benefit to expanding my research capabilities and learning new laboratory skills.

ADVISER/MENTOR SUPPORT

10 Quality of mentoring from the Laboratory NRC Adviser (USMA Mentor, if applicable)

Comments

I received nothing buth the utmost level of support and encouragement from Dr. Hussain. He helped me grow as a scientist and a professional, while simultaneous introducing me to the Air Force environment. Furthermore, I always received the necessary funding for project completion and travel. Dr. Hussain has helped to direct me and provide advise for my future career path and what I have learned from him, I believe, will be invaluable in my future endeavors.

LPR SUPPORT

9 Quality of administrative support from the Laboratory (e.g., NIST, NRL, IWR, FHWA) NRC $\underline{\text { Program }} \underline{\text { Representative (LPR) }}$ Comments

Whenever I required assistance from Dr. Stone, such as travel authorization or fellowship renewals, these were always handled rapidly and in a very professional manner. Futhermore, he made himself very availabe at the beginning of my tenure to discuss my project and personally welcome me, which to me demonstrated his extreme investment in NRC fellows.

NRC SUPPORT

7 Quality of administrative support. Please assess respective NRC aspects (e.g., moving company, insurance, Omega, payroll, coordinator, travel, etc.)

Comments

On the whole, I perceived the NRC support to be very good and Ms. Linda Sligh was more than willing to help me or to put me in contact with the appropriate person. The reimbursement for travel process was fairly straight-forward and I received my reimbursement quickly. However, one concern I have is that I or my advisor were not informed that NRC changed their policy and no longer allowed for a $3^{\text {rd }}$ year renewal, not allowing for adequate time to search for a new position.

18) PLEASE PROVIDE ANY SUGGESTIONS FOR PROGRAM IMPROVEMENT.

1) Clearly outline if the renewal policies change to allow fellows adaquete time line up another position.

2) Transistion to per diem for meals instead of individual entry as this was a very time consuming process.

Please do NOT scan to PDF. Send the Final Report as MSWord document via e-mail to your NRC Program Coordinator No handwritten signature required; Asha Davis: $\quad$ adavis@nas.edu

but you may upload a scanned Linda Sligh: $\quad$ lsligh@nas.edu

signature file below:

Jason Thornhill: jthornhill@nas.edu

Peggy Wilson: pwilson@nas.edu

Kristen K Comfort

Suzanne White: swhite@nas.edu

Rev. July 2011

Proj/Act ID\# 
Advisers to the Nation on Science, Engineering, and Medicine

\section{Research Associateship Programs}

National Research Council

\section{FINAL REPORT}

1) Associate Last or Family Name

First Name

Fillery

2) FORWARDING Address (to which your tax statement will be mailed)

Residence or Institution Residence

Street

City, State Zip Beavercreek OH 45431

3) Today's Date

Scott

FORWARDING Phone(s) and E-Mail (if known)

Home Phone:

Alt. Phone: (720) 8548770

Preferred E-mail: sfillery@gmail.com

Dates of Tenure

from January 5, 2009

M.I.

$\mathbf{P}$

\begin{tabular}{c|c}
\multicolumn{2}{c}{} \\
\hline 4$)$ & Host Agency \\
AFRL & Laboratory or Center \\
(e.g., AFRL) & Wright Patterson AFB \\
(e.g., Wright Patterson AFB)
\end{tabular}

to January 4, 2012

Michael Durstock

6) TITLE OF RESEARCH PROPOSAL

Next Generation Polymer Nanocomposites: Implications to Capacitor Dielectrics and Energy Density

7) SUMMARY OF RESEARCH DURING TENURE Itemize significant findings in concise form, utilizing key concepts/words.

1) Dielectric breakdown strength in insulating materials in heavily dependent on the population of defects. Hence, control over the size, shape and orientation of inclusion fillers can significantly impact the high electric field behavior.

2) Introduction of inorganic inclusions, in the form of low permititivity platelets, aligned to frustrate propagation of a failure path, show significant improvements in dielectric breakdown strength.

3) Attachment of polymeric structures to the nanoparticle surface, while positively promoting an improved nanocomposite dispersion, does not provide an enhancement to dielectric breakdown strength.

4) Improvements to capacitor energy density, when utilizing nanocomposite motifs, requires a delicate balance, increasing material polarizability while staunching deletrious defects that result in premature breakdown under applied fields.

5) Biomaterials, such as silk, show significant versatility, stemming from the large phase space of chain comformation. Highly crystalline chain conformations show improvements to dielectric breakdown strength of $\mathbf{1 5 0 \%}$.

(USMA Davies Fellow: please add summary of teaching, including classes taught.)

\section{8) RESEARCH IN PROGRESS Describe in no more than 100 words.}

1. Investigation into the potential of $\mathrm{SiO} 2$ nanoparticles, functionalized with a polystyrene surface coverage, to provide an enhancement in dielectric breakdown strength. SiO2 nanoparticles provide an ideal platform, due to the low dielectric constant, thereby providing no significant field enhancement to the polymeric phase, as well as the large breadth of synthesis routes.

2. Completion of research into the silk films as potential dielectric materials. Final characterization of silk phase and electrical properties.

\section{9) PUBLICATIONS AND PAPERS RESULTING FROM NRC ASSOCIATESHIP RESEARCH}

Provide complete citations: author(s), title, full name of journal, volume number, page number(s), and year of publication.

a) Publications in peer-reviewed journals

Assemblies of titanium dioxide-polystyrene hybrid nanoparticles for dielectric applications, Tchoul M.N., Fillery S.P., Koerner H., Drummy L.F., Oyerokun F.T., Durstock M.F., Vaia R.A., vol. 22 (5), 1749-59 (2010)

b) Books, book chapters, other publications

c) Manuscripts in preparation, manuscripts submitted

Enhancement of Breakdown Strength Utilizing Nanolaminate Morphologies, S.P. Fillery, H. Koerner, E. Dunkerley, D.A. Schmidt, M.F. Durstock, R.A. Vaia, Submitted to ACS Applied Materials and Interfaces, November 2011 
BaTiO3 - Polystyrene Single Component Hybrid Nanodielectrics, S.P. Fillery, M. Tchoul, C.W. Beier, H. Koerner, L.F. Drummy, M.F. Durstock, R.L. Brutchey, R.A. Vaia, in preparation.

Morphology Investigations of Silk Thin Films: Dielectric Breakdown Strength”, S.P. Fillery, M.A. Dickerson, K. Martinick, H. Koerner, L.F. Drummy, M.F. Durstock, D.N. Kaplan, R. Naik, in preparation.

10) PATENT OR COPYRIGHT APPLICATIONS RESULTING FROM NRC ASSOCIATESHIP RESEARCH

Provide titles, inventors, and dates of applications.

11) PRESENTATIONS AT SCIENTIFIC MEETINGS OR CONFERENCES

Provide complete references: author(s), title, abstract/proceeding citation, meeting name and location.

International

Fillery S.P., Koerner H., Drummy L., Tchoul M., Beier C., Brutchey R., Dunkerley E., Schmidt D., Vaia R., High Inorganic Fraction Nanocomposites for Ultra-High Density Capacitors, Composites at Lake Louise, 2011, Lake Louise, Alberta, Canada

Domestic

Fillery S.P., Koerner H., Jacobs J.D., Narayanan V., Brandstetter S.S., Drummy L.F., Tchou1 M.N., Wang D., Horwath J.C., Schweickart D.L., Durstock M.F., Tan L-S., Dang T., Vaia R.A., Dielectric Strength and Corona Endurance of Polymer Nanocomposites, American Chemical Society Spring Meeting, 2009, Salt Lake City UT

Tchoul M.N., Fillery S.P., Koerner H., Drummy L.F., Oyerokun F.T., Durstock M.F., Vaia R.A., Nanostructured Assemblies for Extreme Power Devices, Materials Research Society Fall Meeting, 2009, Boston MA

Fillery S.P., Enlow J.O, Jakubiak R., Bunning T.J., Durstock M.F., Dieletric Characteristics of Nano-scale, Multilayered Polymer Films, Fabricated by Plasma Enhanced Chemical Vapor Deposition, Materials Research Society Fall Meeting, 2009, Boston MA

Fillery S.P., Koerner H., Dunkerley E., Schmidt D.A, Durstock M.F., Vaia R.A, Nano-scale Layered Approaches to Improving Breakdown Strength in Polymer-clay Nanocomposites, American Chemical Society Regional Meeting, 2010, Dayton OH

Fillery S.P., Beier C., Drummy L., Brutchey R., Durstock M.F., Vaia R.A., Increased Energy Storage through improved morpholgy and dispersion of surface functionalized BaTiO3, polyimide nanocomposites, Smart Materials, Intelligent Systems and Adaptive Structures Meeting, 2010, Philadelphia PA

Fillery S.P., Koerner H., Drummy L., Tchoul M., Beier C., Brutchey R., Dunkerley E., Schmidt D., Vaia R., Single Conponent Polymer Nanocomposites: Assemblies of polymer-nanoparticle hybrids, American Chemical Society Fall Meeting, 2011, Denver CO

12) SEMINARS OR LECTURES DELIVERED AT UNIVERSITIES AND/OR INSTITUTES Include dates, names and locations of seminars.

Scott P. Fillery, Maxim Tchoul, Hilmar Koerner, Lawrence F. Drummy, Erik Dunkerley, Christopher W. Beier , Daniel F. Schmidt, Richard L. Brutchey, Michael F. Durstock, Richard A. Vaia, Next Generation Polymer Nanocomposites: Implications to Dielectrics and Energy Storage, Colorado School of Mines, $4^{\text {th }}$ November 2010.

13) PROFESSIONAL AWARDS RECEIVED DURING TENURE

Arthur K. Doolittle Award, Most Outstanding Paper, Polymeric Materials Science and Engineering Division, American Chemical Society, Spring 2009.

Brandstetter S., Drummy L., Tchoul M., Fillery S.P., Horwath J., Schweickert D., Durstock M., Vaia R., "Dielectric Strength and Corona Endurance of Polymers and Nanocomposites with In-plane Lamellar Nano-structure’.

14) POST-TENURE POSITION / JOB TITLE

Technologist - Electronic Product Divsion

15) NAME AND ADDRESS OF POST-TENURE POSITION / JOB ORGANIZATION

WL Gore and Associates, 555 Paper Mill Rd., Newark, DE, 19711

16) POST-TENURE POSITION STATUS / CATEGORY Please indicate only one.

Permanent position at the NRC host agency $\square$ Research/Administrative position with another U.S.-

Contract or temporary position at the NRC host Agency

Abbreviate Host Laboratory/Center government agency

Research/Administrative position with a foreign- 
Research/teaching position at a U.S. college or university

Research/teaching position at a foreign college or university

$\bigotimes$ Research/administration position in private industry in the U.S.

Research/administration position in private industry outside of the U.S.

\section{7) APPRAISAL OF RESEARCH ASSOCIATESHIP PROGRAM}

On a scale of 1 - 10 (poor - excellent), please rate the following:

\section{SHORT TERM VALUE}

8 Development of knowledge, skills, and research productivity

Comments

The associateship program, in combination with the post doctoral position at AFRL/RX provided in-valuable support towards developing new skills and knowledge. Allowing me to broaden my knowledge and skills base, becoming a more productive research scientist. The opportunity presented a entirely new research area from which $I$ have developed skills that are intrinsic to my future position, as well as offering a new prespective of soft skills in proposal writing and communication skills.

\section{LONG TERM VALUE}

9 How the NRC Associateship award affected your career to date

Comments

In examining my productivity and maturity, the NRC associateship has a broader and complete effect on my research career, than my graduate studies. The NRC associateship and AFRL post doctoral position will provide a far greater influence in communication, experimental design and writing than any other opportunity to this date.

\section{LAB SUPPORT}

7 Quality of support from the Laboratory--equipment, funding, orientation, safety and health guidelines, etc.

\section{Comments}

The support for equipment and funding at AFRL/RXBN was outstanding. I found the level of bureaucracy to be understandable for a military organization, but at times did stunt productivity and prevent full investigation into particular research areas. Health and safety was a primary concern at the laboratory, handled well at both orientation and periodically throughout my tenure.

\section{ADVISER/MENTOR SUPPORT}

8 Quality of mentoring from the Laboratory NRC Adviser (USMA Mentor, if applicable)

\section{Comments}

The quality of mentoring at AFRL/RXBN was excellent. The door was always open, allowing for discussions of research and overarching projects direction. At the same time, there was space and support to pursuing differing ideas and concepts, not linearly related to the core mission.

\section{LPR SUPPORT}

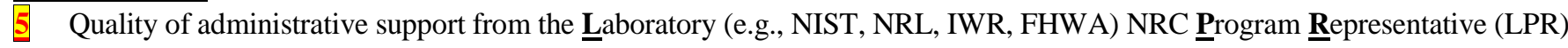
Comments

I only interfaced with the NRC Program Representative on official occasions, relating to travel requests and tenure extensions. As such, I can't reliably comment or rate the quality of support.

\section{NRC SUPPORT}

7 Quality of administrative support. Please assess respective NRC aspects (e.g., moving company, insurance, Omega, payroll, coordinator, travel, etc.)

\section{Comments}

The quality of support from the associateship administration was prompt and efficient. Questions relating to insurance, travel and changes to stipend were handled without delay.

18) PLEASE PROVIDE ANY SUGGESTIONS FOR PROGRAM IMPROVEMENT.

Please do NOT scan to PDF. Send the Final Report as MSWord document via e-mail to your NRC Program Coordinator No handwritten signature required; $\quad$ Asha Davis: $\quad$ adavis@nas.edu but you may upload a scanned signature file below:

$$
\text { Linda Sligh: } \quad \underline{\text { sligh@nas.edu }}
$$

Jason Thornhill: ithornhill@nas.edu

Peggy Wilson: pwilson@nas.edu

Suzanne White: $\underline{\text { swhite@nas.edu }}$ 
Advisers to the Nation on Science, Engineering, and Medicine

National Research Council

FINAL REPORT

1) Associate Last or Family Name

Kanel

2) FORWARDING Address (to which your tax statement will be mailed)

Residence or Institution

Street 2950 Hobson Way

City, State Zip Beavercreek, OH, 45433

3) Today's Date

July 31, 2012

First Name

Sushil

M.I.

FORWARDING Phone(s) and E-Mail (if known)

Home Phone: 6788601746

Alt. Phone: $9372553636 \times 4568$

Preferred E-mail: srkanel@gmail.com

Dates of Tenure

from August 2, 2010

August 1,
to
Division / Directorate / Department
AFIT
(e.g., High-Speed Propulsion)

Laboratory or Center

Wright Patterson AFB

(e.g., Wright Patterson AFB)

(e.g., AFRL)

(e.g., Wright Patterson

5) Name of Laboratory NRC Adviser (and USMA Mentor, if applicable)

Mark

Goltz

6) TITLE OF RESEARCH PROPOSAL

Fate and Transport of Nano Materials in the Subsurface Environment and their Application to Groundwater Remediation

7) SUMMARY OF RESEARCH DURING TENURE Itemize significant findings in concise form, utilizing key concepts/words.

1) Synthesized nanomaterials (NMs) such as silver nanoparticles (AgNPs) and nanoscale zerovalent iron (nZVI) and Ni and Pd coated nZVI

2) Remediation of carbontetrachloride(CT) by $n Z V I$ and bimetallic(Ni and Pd) $n Z V I$ is investigated and found that $n Z V I$ and Bimetallic nZVI has fast Kinetics to react CT. We found the highest efficiency ever reported in literature.

3) Fate and transport of AgNP was studied and found that AgNP transport differently at different pHs through porous media

4) AgNPs and Ag ion showed different transport pattern through porous media

5)

(USMA Davies Fellow: please add summary of teaching, including classes taught.)

8) RESEARCH IN PROGRESS Describe in no more than 100 words.

I was trying to use the study in column experiment, which resemples the real filed condition.

9) PUBLICATIONS AND PAPERS RESULTING FROM NRC ASSOCIATESHIP RESEARCH

Provide complete citations: author(s), title, full name of journal, volume number, page number(s), and year of publication.

a) Publications in peer-reviewed journals

Kanel, S. R., Clement, T.P., Barnett, M. O. and Goltz, M. N. Nano-Scale Hydroxyapatite: Synthesis, Two-Dimensional

Transport Experiments,and Application for Uranium Remediation. J of Nanotechnology (doi:10.1155/2011/462382), 2011.

b) Books, book chapters, other publications

Kanel, S. R., Su, C., Patel, U. and Agrawal, A. Nanoscale Multifunctional Materials: Science \& Applications Applications of Metal Nanoparticles in Environmental Cleanup, Eds: Mukhopadhyay S M., Wiley, London, UK, 2010.

Kanel S.R., Nepal D., Goltz M.N. Nanotechnology for water aned wastewater treatment, Eds: Surampalli, Tian C. Zhang, American Society of Civil Engineers, USA, 2013 (In preparation)

c) Manuscripts in preparation, manuscripts submitted

1. Jason Flory, Sushil R. Kanel, LeeAnn Racz, Christopher A. Impellitteri, Rendahandi G. Silva, Mark N. Goltz, Influence of pH on the Transport of Silver Nanoparticles in Saturated Porous Media: Laboratory Experiments and Modeling, submitted to $\mathrm{J}$ of Nanoparticle Research ( 2012).

2. McPherson A., Agrawal A., Danner K., Goltz N. M. and Kanel, S. R., Highly Efficient Degradation of Chlorinated Aliphatic Hydrocarbons by Caboxymethyl Cellulose Stabilized Bimetallic Palladium-Zero Valent Iron under Anoxic Conditions (In preparation to submit in Environ. Sci. and Tech.) 
3. Sushil R. Kanel1, Jason Flory Jessica Dagher, Ioana E. Pavel, LeeAnn Racz, Christopher A. Impeliteri, Craig Patterson, Rendahandi G. Silva and Mark N. Goltz, Fate and Transport of Silver Nanoparticles and Their Ions in Saturated Porous Media: Modeling and Experimental Validation, (In Preparation to submit in Environ. Sci. and Tech ).

4. Jessica Dagher, Sushil R. Kanel1, Ioana E. Pavel, LeeAnn Racz, Christopher A. Impeliteri, Craig Patterson, Rendahandi G. Silva and Mark N. GoltzFate and Transport of Different Size Silver Nanoparticles in Saturated Porous Media, ( In Preparation to submit in Environ. Sci. and Tech ).

5. Prakash Swarnakar, Sushil R. Kanel, Yuntong Jiang, Lei Kerr, Mark N. Goltz, Jonathan Levy, John Rakovan, Visible Light Activity of Silver Coated Titanium Dioxide Thin Film for Photocatalysis of Organic Compounds Using Natural Solar Light, (In preparation)

10) PATENT OR COPYRIGHT APPLICATIONS RESULTING FROM NRC ASSOCIATESHIP RESEARCH

Provide titles, inventors, and dates of applications.

11) PRESENTATIONS AT SCIENTIFIC MEETINGS OR CONFERENCES

Provide complete references: author(s), title, abstract/proceeding citation, meeting name and location.

International

Kanel S. R., Dagher J., Travis M., Pavel I., Racz L., Impeliteri C.A, Goltz M. N. Fate and transport of silver nanoparticles and silver ions in saturated porous media: laboratory experiments and modeling, ACS National Meeting and Exposition, 244th ACS National Meeting, Philadelphia, PA, August 19-23, 2012.

2. Dagher J., Kanel S. R., Meyerhoefe, A., Goltz M. N. and Pavel, I.E. Transport of Engineered Silver Nanoparticles through Saturated Porous Media,Wright State University, OH, June 1, 2012.

3. Kanel S. R., Flory J., Racz L., Goltz M. N. Road towards Sustainability: Understanding Silver Nanoparticle and Silver Ion Transport in Saturated Porous Media, World Environmental and Water Resource Congress, Albuquerdue NM, May 20-24, 2012.

4. Dagher J. M., Kanel S.R., Meyerhoefer A., Goltz M.N., and Pavel Sizemore I. E.; Transport of Engineered Silver Nanoparticles through Saturated Porous Media Celebration of Research, , Wright State University, Dayton, OH, April 13, 2012.

5. Meyerhoefer A., Dagher J. M., Kanel S. R., Goltz M.N., and Pavel Sizemore I. E. A Study of the Transport of Different Size Silver Nanoparticles in Saturated Porous Media Celebration of Research, , Wright State University, Dayton, OH, April $13,2012$.

6. Dagher J. M., Meyerhoefer A., Kanel S. R., Goltz M. N., and Pavel Sizemore I.E. A Study of the Transport of Different Size Silver Nanoparticles in Saturated Porous Media ACS local Meeting, Central State University, OH, April 3, 2012.

7. Kanel S. R., Flory J., Racz L., Impeliteri C.A, Nadagouda , M. Silva R. G., Huang J., Goltz M. N. Fate and transport of silver nanoparticles and related products in saturated porous media, ACS National Meeting and Exposition, San Diego CA, March 25-29, 2012.

8. McPherson A., Agrawal, A., Danner K., Goltz M. N., and Kanel S. R., Degradation of carbon tetrachloride by stabilized bimetallic palladium-zero-valent iron (Pd-nZVI) nanoparticles, ACS National Meeting and Exposition, San Diego CA, March 25-29, 2012.

9. Swarnakar P., Kanel S. R., Jiang Y., Kerr L., Goltz M.N., Levy, J., Rakovan, J. Visible Light Activity of Silver Coated Titanium Dioxide Thin Film for Photocatalysis of Organic Compounds Using Natural Solar Light. ACS National Meeting and Exposition, San Diego CA, March 25-29, 2012.

10. Kanel S. R., Flory, J., Pavel I.E., Meyerhoefer, A. and Goltz M. N. Fate and transport of silver nano particles (agnps) in saturated porous media, 243rd ACS National Meeting and Exposition, in Denver, CO, Aug. 28 - Sept. 1, 2011.

11. Kanel S. R., Danner K., McPherson A., Goltz M. N., Agrawal A. Degradation of carbon tetrachloride by nickel-modified nanoscale zerovalent iron stabilized with cme, 243rd ACS National Meeting and Exposition, in Denver, Co, Aug. 28 - Sept. 1, 2011. 
12. McPherson A., Kanel S. R., Danner K., Agrawal A., Goltz M. N. Degradation of carbon tetrachloride by stabilized bimetallic nanoscale zerovalent iron, 243rd ACS National Meeting and Exposition, in Denver, Co, Aug. 28 - Sept. 1, 2011.

13. Flory J., Kanel, S. R., Dagher J., Pavel, I.E., Racz L., Huang, J. and Goltz M. N. Transport of silver nano particles in saturated porous media and their prediction using mathematical model, , AFMS Medical Research Symposium in DC, W.DC., Aug. 02 - 04, 2011.

14. McPherson A., Kanel S. R., Danner K., Agrawal A., Goltz M. N. Degradation Of Carbon Tetrachloride Using SurfaceModified Nanoscale Iron, AEESP Education \& Research Conference, University of South Florida, Florida, July 10-12. 1, 2011.

15. Dagher J., Kanel S. R., Flory, J., Goltz M. N. and Pavel, I .E. Fate and Transport of Silver Nano Particles (AgNPs) in Saturated Porous Media, The 42nd Meeting of the ACS Central Region in Indianapolis, Indiana, June 8 -10, 2011.

16. Kanel S. R., and Goltz M. N. Fate and Transport of Nanoscale Silver Particles in Saturated Porous Media, Gordon Research Conference, in Waterville Valley, NH, May 29 - June 3, 2011, 2011.

17. Kanel S. R., Goltz M. N., Agrawal A. Fate and transport of nano materials and their application for soil and groundwater remediation, RemTEC Submit, in Chicago, IL, USA, May 16-19, 2011.

18. Vijwani H., Kanel S. R., Mukhopadhyay, S.M., Agrawal A. and Goltz M. N. Nanoscale hybrid Structures for Treatment of Chlorinated Organic Compounds, Ohio Innovation Submit, in Toledo, OH April 19-20, 2011.

19. Kanel S. R., Vijwani H., Mukhopadhyay, S.M., Agrawal A. and Goltz M. N. Treatment of chlorinated organic compounds by carbon nanotubes modified with nanoscale palladium metal, Spring ACS National Meeting and Exposition, in Anaheim, California, March 27-31, 2011.

20. Kanel S. R., Racz L, Huang J and Goltz M. N. Transport of Engineered Nanosilver Particles in Saturated Porous Media, Spring ACS National Meeting and Exposition, in Anaheim, California, March 27-31, 2011.

Domestic

12) SEMINARS OR LECTURES DELIVERED AT UNIVERSITIES AND/OR INSTITUTES Include dates, names and locations of seminars.

1. Kanel, S. R. Department of Civil Engineering, North Dekota State University: Engineered Iron Nano Materials: Fate, their Application in Groundwater Treatment and Transport: Research Presentation as a Guest Speaker, ND, May 3, 2012.

2. Kanel, S. R. Department of Engineering and Environmental Management, Air Force Institute of Technology

(AFIT)/ENV: Application and implication of Nanotechnology in our environment: Research Presentation as a Guest Speaker, Dayton, OH, 28th October, 2011.

3. Kanel, S. R. School of Chemical and Environmental Engineering, Toledo University: Engineered nano materials: fate, transport and their application in soil and water treatment: Research Presentation as a Guest Speaker, Toledo, OH, USA, 3rd May, 2011.

13) PROFESSIONAL AWARDS RECEIVED DURING TENURE

14) POST-TENURE POSITION / JOB TITLE

Research Scientist

15) NAME AND ADDRESS OF POST-TENURE POSITION / JOB ORGANIZATION

2950 Hobson Way, Beavercreek Oh 45433, AFIT-Wright Patterson AFB

16) POST-TENURE POSITION STATUS /CATEGORY Please indicate only one.

Permanent position at the NRC host agency

$\triangle$ Contract or temporary position at the NRC host Agency

Abbreviate Host Laboratory/Center

Research/Administrative position with another U.S.government agency

$\square$ Research/Administrative position with a foreigngovernment agency

$\square$ Research/teaching position at a U.S. college or university

Research/teaching position at a foreign college or university $\square$ Research/administration position in private industry in the U.S.

Research/administration position in private industry outside of the U.S.

$\square$ Research/administration position with a non profit

Self-employed/consulting

Postdoctoral research

$\square$ Other (Please specify, possible)

No information provided 
17) APPRAISAL OF RESEARCH ASSOCLATESHIP PROGRAM

On a scale of $1-10$ (poor - excellent), please rate the following:

SHORT TERM VALUE

Development of knowledge, skills, and research productivity Comments

10

LONG TERM VALUE

How the NRC Associateship award affected your career to date

Comments

10

LAB SUPPORT

Quality of support from the Laboratory--equipment, funding, orientation, safety and health guidelines, etc. Comments

10

\section{ADVISER/MENTOR SUPPORT}

Quality of mentoring from the Laboratory NRC Adviser (USMA Mentor, if applicable)

Comments

10

LPR SUPPORT

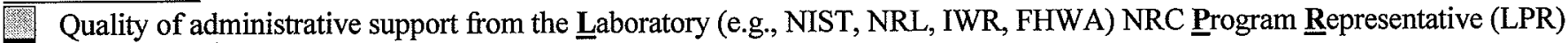
Comments

10

NRC SUPPORT

Quality of administrative support. Please assess respective NRC aspects (e.g., moving company, insurance, Omega, payroll, coordinator, travel, etc.)

\section{Comments}

10

18) PLEASE PROVIDE ANY SUGGESTIONS FOR PROGRAM IMPROVEMENT.

It would be nice to let the fellow to complete the three year tenure once hired.

Please do NOT scan to PDF. Send the Final Report as MSWord document via e-mail to your NRC Program Coordinator

No handwritten signature required; Asha Davis:

but you may upload a scanned Linda Sligh: Isligh@nas.edu

signature file below:

Sushil Kanel

Jason Thornhill: jthornhill@nas.edu

Peggy Wilson: pwilson@nas.edu

Suzanne White: swhite@nas.edu 
Advisers to the Nation on Science, Engineering, and Medicine

\section{Research Associateship Programs}

National Research Council

\section{FINAL REPORT}

1) Associate Last or Family Name

Martin

2) FORWARDING Address (to which your tax statement will be mailed)

First Name

M.I.

Jennifer

A

Residence or Institution

FORWARDING Phone(s) and E-Mail (if known)

Home Phone: :

Street

b)ityøgtat's ZlфtBeavercreek, OH 45431

October 29, 2012

4)

Host Agency

Laboratory or Center

Preferred E-mail: jennifer_a19@hotmail.com

Dates of Tenure

from November 1, 2010

to November 1, 2012

AFRL

(e.g., AFRL)

Wright Patterson AFB

(e.g., Wright Patterson AFB)

Mentor, if applicable)

5) Name of Laboratory NRC Adviser (and USMA Mentor, if app
Dr. Morley Stone Dr. Nancy Kelley-

6) TITLE OF RESEARCH PROPOSAL

Loughnane

\section{DNA MICROARRAYS TO IMPROVE THE APTAMER SELECTION PROCESS FOR ON-CHIP APPLICATIONS}

7) SUMMARY OF RESEARCH DURING TENURE Itemize significant findings in concise form, utilizing key concepts/words.

1) Designed and utilized an aptamer selection for cortisol with a tunable stringency component integrated into the method. Found that more stringent conditions evolved the pool toward a single sequence dominating $45 \%$ of the final sequenced pool.

2) Developed equilibrium dialysis protocols for testing dissociation constants of aptamer/small molecule target binding.

Confirmed a low micromolar Kd of a cortisol sequence.

3) Modified conditions to enable a $\sim 30 \mathrm{nM}$ limit of detection for cortisol the identified cortisol aptamer with a gold nanoparticle assay (serum cortisol $\sim 200-450 \mathrm{nM}$ ).

4) Developed a method for testing aptamer/target interactions with custom DNA microarrays. Studied structural properties of aptamer/target binding (buffer conditions, purity, fluorescence reporting scheme, distance from chip surface).

5) Identified potential thrombin binding aptamers, each of which contained a sequence motif similar to the known 15-mer thrombin binding aptamer.

(USMA Davies Fellow: please add summary of teaching, including classes taught.)

8) RESEARCH IN PROGRESS Describe in no more than 100 words.

We are looking at testing the binding of several more cortisol aptamer candidates, and further decreasing the LOD of the AuNP detection assay to enable saliva-based detection ( 10-25 $\mathrm{nM})$. We are also working on confirming binding of the microarray potential thrombin aptamers by capillary electrophoresis and surface plasmon resonance methods.

9) PUBLICATIONS AND PAPERS RESULTING FROM NRC ASSOCIATESHIP RESEARCH

Provide complete citations: author(s), title, full name of journal, volume number, page number(s), and year of publication.

a) Publications in peer-reviewed journals

b) Books, book chapters, other publications

c) Manuscripts in preparation, manuscripts submitted

- Martin, J., Chushak, Y., Chavez, J., Hagen, J., Kelley-Loughnane, N., “Tunable Aptamer Selection and Gold

Nanoparticle Detection of Cortisol" (2012) in preparation

- Martin, J., Chushak, Y., Chavez, J., Hagen, J., Kelley-Loughnane, N., "DNA Microarrays for Aptamer Identification and Structural Characterization" (2012) Technical Note, internal review

10) PATENT OR COPYRIGHT APPLICATIONS RESULTING FROM NRC ASSOCIATESHIP RESEARCH

Provide titles, inventors, and dates of applications. 
11) PRESENTATIONS AT SCIENTIFIC MEETINGS OR CONFERENCES

Provide complete references: author(s), title, abstract/proceeding citation, meeting name and location.

International

Domestic

- Gordon Research Conference (Newport, RI) 2011- "Small-molecule Aptamer Selection for Detection of Cortisol" Jennifer A. Martin, Jorge Chavez, Yaroslav Chushak, and Nancy Kelley-Loughnane

- Chemical and Biological Defense Science and Technology Conference (Las Vegas) 2011- "Combination of In Silico Oligonucleotide Library Design and Microarray Screening for High Throughput Selection of Aptamers" Yaroslav Chushak, Jennifer A. Martin, Jorge L. Chávez, Morley O. Stone, and Nancy Kelley-Loughnane

12) SEMINARS OR LECTURES DELIVERED AT UNIVERSITIES AND/OR INSTITUTES Include dates, names and locations of seminars.

- RH Biotronics Update (Dayton, OH) 2011- Presented "Human Effectiveness Directorate: Bio-X Biotronics Review" (with J. Hagen)

- RX Biotechnology Review (Dayton, OH) 2012- Presented "In silico and High-throughput Microarray Selection of Biological Recognition Elements" (with Y. Chushak)

- RH Biotronics Update (Dayton, OH) 2012- Presented "Human Effectiveness Directorate: Bio-X Biotronics Review" (with J. Hagen)

13) PROFESSIONAL AWARDS RECEIVED DURING TENURE

14) POST-TENURE POSITION / JOB TITLE

Research Associate, Henry Jackson Foundation

15) NAME AND ADDRESS OF POST-TENURE POSITION / JOB ORGANIZATION

711 HPW/RHXBC

2510 Fifth St.

Area B Bldg. 840

WPAFB, OH 45433-7913

16) POST-TENURE POSITION STATUS / CATEGORY Please indicate only one.

$\square$ Permanent position at the NRC host agency

$\triangle$ Contract or temporary position at the NRC host Agency

Abbreviate Host Laboratory/Center RHXBC

Research/Administrative position with another U.S.government agency

Research/Administrative position with a foreigngovernment agency

Research/teaching position at a U.S. college or university

Research/teaching position at a foreign college or university $\square$ Research/administration position in private industry in the U.S.

Research/administration position in private industry outside of the U.S.

Research/administration position with a non profit

$\square$ Self-employed/consulting

Postdoctoral research

$\square$ Other (Please specify, possible)

No information provided

17) APPRAISAL OF RESEARCH ASSOCIATESHIP PROGRAM

On a scale of 1 - 10 (poor - excellent), please rate the following:

SHORT TERM VALUE

10 Development of knowledge, skills, and research productivity Comments

LONG TERM VALUE

8 How the NRC Associateship award affected your career to date Comments

\section{LAB SUPPORT}

9 Quality of support from the Laboratory--equipment, funding, orientation, safety and health guidelines, etc. Comments 
9 Quality of mentoring from the Laboratory NRC Adviser (USMA Mentor, if applicable) Comments

\section{LPR SUPPORT}

9 Quality of administrative support from the Laboratory (e.g., NIST, NRL, IWR, FHWA) NRC $\underline{\text { Program }} \underline{\text { Representative (LPR) }}$ Comments

\section{NRC SUPPORT}

5 Quality of administrative support. Please assess respective NRC aspects (e.g., moving company, insurance, Omega, payroll, coordinator, travel, etc.)

Comments

It was difficult to receive feedback or any response related to moving expenses. Responses for payroll, travel, etc. were efficient.

18) PLEASE PROVIDE ANY SUGGESTIONS FOR PROGRAM IMPROVEMENT.

It would be nice to have an orientation at the beginning of the program for all related aspects of the program. If $I$ hadn't met current/former NRC researchers, I wouldn't have known anything about estimated taxes. Otherwise, I think it is a fantastic opportunity and I really appreciated and enjoyed the experience.

Please do NOT scan to PDF. Send the Final Report as MSWord document via e-mail to your NRC Program Coordinator No handwritten signature required; $\quad$ Asha Davis: $\quad$ adavis@nas.edu but you may upload a scanned signature file below:

Linda Sligh: $\quad$ lsligh@ nas.edu

Jason Thornhill: ithornhill@nas.edu

Peggy Wilson: pwilson@nas.edu

Suzanne White: swhite@nas.edu 
Advisers to the Nation on Science, Engineering, and Medicine

Research Associateship Programs

National Research Council

FINAL REPORT

1) Associate Last or Family Name

First Name

M.I.

Amber

J.W.

McClung

2) FORWARDING Address (to which your tax statement will be mailed)

FORWARDING Phone(s) and E-Mail (if known)

Home Phone:

Residence or Institution

Alt. Phone: 765-409-4733

Street 8334 Thorncliff Drive

City, State Zip San Antonio, TX 78250

3) Today's Date

January 27, 2012

4) Host Agency

AFRL

Laboratory or Center

(e.g., AFRL)

Wright Patterson AFB

(e.g., Wright Patterson AFB)

Preferred E-mail: mcclunga2@asme.org

Dates of Tenure

from June 1, 2009

to February 13, 2012

5) Name of Laboratory NRC Adviser (and USMA Mentor, if applicable)

Jeffery Baur

6) TITLE OF RESEARCH PROPOSAL

Characterization of the Path-Dependent Behavior of Reinforced Shape Memory Polymers for Adaptive (Morphing) Skins

7) SUMMARY OF RESEARCH DURING TENURE Itemize significant findings in concise form, utilizing key concepts/words.

1) Established and validated the appropriate digital image correlation system, laser extensometer, high temperature grips, and environmental chamber for thermomechanical evaluation of shape memory polymers.

2) Thermal stability of shape memory polymers determined with thermogravimetric analysis (TGA) and differential scanning calorimetry (DSC).

3) Appropriate post-cure cycles established for multiple shape memory polymers based on the preliminary TGA and DSC results.

4) The path-dependent axial behavior of both Veriflex-E and a BMI-based SMP were evaluated using dynamic mechanical analysis (DMA) and axial tensile tests.

5) The shape memory response of Veriflex-E was evaluated using DMA and axial tensile tests.

6) The strain rate dependence of Veriflex-E was evaluated using axial tensile tests.

7) Shape memory hybrids combining SMPs and SMAs were created and evaluated.

(USMA Davies Fellow: please add summary of teaching, including classes taught.)

8) RESEARCH IN PROGRESS Describe in no more than 100 words.

1) Constitutive models are under development and will be validated with both Matlab and with Abaqus finite element software.

2) Expanded manufacturing and evalutation of shape memory hybrids is in the planning stages.

3) Novel shape memory polymers that have the potential for higher transition temperatures and are processable into composites are being synthesized and evaluated.

9) PUBLICATIONS AND PAPERS RESULTING FROM NRC ASSOCIATESHIP RESEARCH

Provide complete citations: author(s), title, full name of journal, volume number, page number(s), and year of publication.

a) Publications in peer-reviewed journals

McClung, A.J.W., Tandon, G.P., and Baur, J.W. "Deformation Rate-, Hold Time-, and Cycle-Dependent Shape Memory

Performance of Veriflex-E Resin.” In Press Mechanics of Time-Dependent Materials.

McClung, A.J.W., Tandon, G.P., and Baur, J.W. "Strain Rate- and Temperature-Dependent Tensile Properties of an Epoxy-Based, Thermosetting, Shape Memory Polymer (Veriflex-E)." In Press Mechanics of Time-Dependent Materials.

McClung, A.J.W., Tandon, G.P., Goecke, K.E., and Baur, J.W. "Non-Contact Technique for Characterizing Full-Field Surface Deformation of Shape Memory Polymers at Elevated and Room Temperatures." Polymer Testing 30 (2011) 140149. 
b) Books, book chapters, other publications

c) Manuscripts in preparation, manuscripts submitted

McClung, A.J.W. and Baur, J. "Performance and Temperature-Dependent Tensile Properties of Novel Bismaleimide Based Shape Memory Polymers." In preparation.

Shumaker, J., McClung, A.J.W., and Baur, J.W. "A Novel Approach to Synthesizing Polyaspartimide-Urea Based Shape Memory Polymers.” In preparation for submission to Polymer.

McClung, A.J.W., Tandon, G.P., and Baur, J.W. "Relaxation and Recovery Behavior of an Epoxy Based Shape Memory Polymer Resin." In preparation.

Cheng, L., Torres, Y., Lee, K.M., McClung, A.J.W., Baur, J.W., White, T., Oates, W. "Photomechanical Bending Mechanics of Polydomain Azobenzene Liquid Crystal Polymer Network Films." In preparation for submission to the Journal of Applied Physics.

10) PATENT OR COPYRIGHT APPLICATIONS RESULTING FROM NRC ASSOCIATESHIP RESEARCH

Provide titles, inventors, and dates of applications.

“A Novel Approach to Synthesizing Polyaspartimide-Urea Based Shape Memory Polymers," Shumaker, J., McClung, A.J.W., Mathyss, S., and Baur, J., 2011

11) PRESENTATIONS AT SCIENTIFIC MEETINGS OR CONFERENCES

Provide complete references: author(s), title, abstract/proceeding citation, meeting name and location.

International

Domestic

McClung, A.J.W., Tandon, G.P., Baur, J.W., and Foster, D.C. "Status of Shape Memory Polymers for Aerospace Applications." SPIE Smart Structures/NDE, San Diego, California, March 11 - 15, 2011. Abstract.

McClung, A.J.W., Tandon, G.P., and Baur, J.W. "Relaxation and Recovery Behavior of an Epoxy Based Shape Memory Polymer Resin." Society for Experimental Mechanics Annual Conference \& Exposition on Experimental and Applied Mechanics, Costa Mesa, California, June 11 - 14, 2012. Proceedings.

McClung, A.J.W., Shumaker, J.A., and Baur, J.W. “Bismaleimide Based Shape Memory Polymers: Comparison to Commercial Shape Memory Polymers.” ASME Smart Materials, Adaptive Structures and Intelligent Systems, Scottsdale, Arizona, September 18-21, 2011. Proceedings.

McClung, A.J.W., Tandon, G.P., and Baur, J.W. "Fatigue Cycling of Shape Memory Polymer Resin." Society for Experimental Mechanics Annual Conference \& Exposition on Experimental and Applied Mechanics, Uncasville, Connecticut, June 13 - 16, 2011. Proceedings.

McClung, A.J.W., Shumaker, J.A., Baur, J.W., Reed, S.D., and Matthys, S.A. "Bismaleimide Based Shape Memory Polymers: Correlation Between Chemical Composition and Mechanical Properties." 52nd AIAA/ASME/ASCE/AHS/ASC Structures, Structural Dynamics and Materials Conference, Denver, Colorado, April 4 - 7, 2011. Proceedings.

McClung, A.J.W., Tandon, G.P., Goecke, K.E., and Baur, J.W. "Non-Contact Technique for Characterizing Full-Field Surface Deformation of Shape Memory Polymers." ASME Smart Materials, Adaptive Structures and Intelligent Systems, Philadelphia, Pennsylvania, September 28 - October 1, 2010. Proceedings.

McClung, A.J.W., Tandon, G.P., and Baur, J.W. "The Strain Rate- and Temperature-Dependent Mechanical Behavior of Veriflex-E in Tension." ASME Smart Materials, Adaptive Structures and Intelligent Systems, Philadelphia, Pennsylvania, September 28 - October 1, 2010. Proceedings.

Torres, Y., McClung, A.J.W., Oates, B., and White, T. "Photoresponsive Azobenzene Liquid Crystal Polymer Networks: In Situ Photogenerated Stress Measurement." ASME Smart Materials, Adaptive Structures and Intelligent Systems, Philadelphia, Pennsylvania, September 28 - October 1, 2010. Proceedings.

Shumaker, J.A., McClung, A. J.W., Matthys, S.A., and Baur, J.W. "Novel Approach to Synthesizing PolyaspartimidePolyurea Based Shape Memory Polymers." Central Regional Meeting of the American Chemical Society, Dayton, Ohio, June 16-19, 2010. Abstract 
McClung, A.J.W., Tandon, G.P., Foster, D.C., and Baur, J.W. "Influence of Post-Cure and Repeated Cycling on Thermomechanical Characterization of Shape Memory Polymers and Composites." Society for the Advancement of Material and Process Engineering Spring Meeting, Seattle, Washington, May 17 - 20, 2010. Proceedings.

Peel, L.D., Baur, J.W., Phillips, D., and McClung, A.J.W. "The Effect of Scaling on the Performance of Elastomer Composite Actuators.” SPIE Smart Structures/NDE, San Diego, California, March 7 - 11, 2010. Proceedings.

12) SEMINARS OR LECTURES DELIVERED AT UNIVERSITIES AND/OR INSTITUTES Include dates, names and locations of seminars. "Shape Memory Polymers for Aerospace Structural Applications." St. Mary's University, San Antonio, Texas, November 28, 2011

“Adaptive and Multifunctional Materials.” Mound Laser and Photonics Center, Dayton, Ohio, June 21, 2011

"Shape Memory Polymers for Morphing Aircraft Structures." 3rd Annual Society for the Advancement of Material and Process Engineering Dinner, University of Dayton, Dayton, Ohio, March 16, 2011

13) PROFESSIONAL AWARDS RECEIVED DURING TENURE

14) POST-TENURE POSITION / JOB TITLE

Assistant Professor of Mechanical Engineering

15) NAME AND ADDRESS OF POST-TENURE POSITION / JOB ORGANIZATION

St. Mary's University, San Antonio, TX

16) POST-TENURE POSITION STATUS / CATEGORY Please indicate only one.

Permanent position at the NRC host agency

Contract or temporary position at the NRC host Agency

Abbreviate Host Laboratory/Center

$\square$ Research/Administrative position with another U.S.government agency

$\square$ Research/Administrative position with a foreigngovernment agency

$\bigotimes$ Research/teaching position at a U.S. college or university

Research/teaching position at a foreign college or university $\square$ Research/administration position in private industry in the U.S.

Research/administration position in private industry outside of the U.S.

$\square$ Research/administration position with a non profit

$\square$ Self-employed/consulting

$\square$ Postdoctoral research

$\square$ Other (Please specify, possible)

$\square$ No information provided

17) APPRAISAL OF RESEARCH ASSOCIATESHIP PROGRAM

On a scale of $1-10$ (poor - excellent), please rate the following:

SHORT TERM VALUE

9 Development of knowledge, skills, and research productivity

Comments

I was exposed to many new areas of technical expertise.

LONG TERM VALUE

6 How the NRC Associateship award affected your career to date

Comments

This is difficult to judge. An answer might be easier to give if looking back in several years than it is right now.

LAB SUPPORT

10 Quality of support from the Laboratory--equipment, funding, orientation, safety and health guidelines, etc. Comments

\section{ADVISER/MENTOR SUPPORT}

10 Quality of mentoring from the Laboratory NRC Adviser (USMA Mentor, if applicable)

Comments

Time is an issue with the successful Advisers. In my opinion NRC should do something to provide suplemental mentoring/career broadening assistance.

LPR SUPPORT

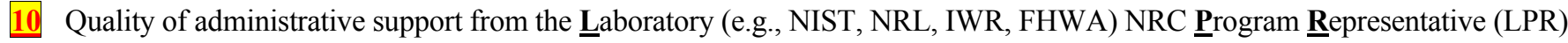
Comments 


\section{NRC SUPPORT}

9 Quality of administrative support. Please assess respective NRC aspects (e.g., moving company, insurance, Omega, payroll, coordinator, travel, etc.)

Comments

Travel started off rough, but was a 10 by the end of tenure.

18) PLEASE PROVIDE ANY SUGGESTIONS FOR PROGRAM IMPROVEMENT.

Some sort of support needs to be in place for career development. This was a great opportunity to do research but it seems to lead to a bit of a dead end as far as the next career step. The top candidates already know how to do research, what we need even more is development of other skills and connections to create a pathway forward.

Please do NOT scan to PDF. Send the Final Report as MSWord document via e-mail to your NRC Program Coordinator

No handwritten signature required; but you may upload a scanned signature file below:
Asha Davis:

Linda Sligh: $\quad \underline{\text { Isligh } @ \text { nas.edu }}$

Jason Thornhill: jthornhill@nas.edu

Peggy Wilson: pwilson@nas.edu

Suzanne White: swhite@nas.edu
Proj/Act ID\# 
Advisers to the Nation on Science, Engineering, and Medicine

National Research Council

\section{Research Associateship Programs}

\section{FINAL REPORT}

1) Associate Last or Family Name

First Name

Michael

FORWARDING Phone(s) and E-Mail (if known)

Home Phone:

Alt. Phone: 515-231-4059

E-mail: mcconney@gmail.com

City, State Zip Beavercreek, Oh, 45434

3) Today's Date

August 22, 2011

4) Host Agency

AFRL

(e.g., AFRL)

5) Name of Laboratory NRC Adviser (and USMA Mentor, if applicable)

Timothy J. Bunning

6) TITLE OF RESEARCH PROPOSAL

"Advanced Light Responsive Liquid Crystal Elastomers"

7) SUMMARY OF RESEARCH DURING TENURE Itemize significant findings in concise form, utilizing key concepts/words.

1) Developed a new fabrication technique to create polymer stabilized cholesteric liquid crystals that enables high contrast optical filters to be made

2) Made an cholesteric optical filter that induces high contrast (hyper-reflectivity) when exposed to heat or to light

3) Made an cholesteric optical filter that which is high contrast and the wavelength of the filter changes when exposed to heat or light

4) Developed an electrically tunable cholesteric liquid crystal

5) Developed a novel CW laser from a polymer stabilized cholesteric liquid crystal

(USMA Davies Fellow: please add summary of teaching, including classes taught.)

8) RESEARCH IN PROGRESS Describe in no more than 100 words.

Currently working on photo-responsive liquid crystalline polymers. More specifically this includes designing and patterning the mesogenic monomers before polymerization to create a material with the desired photo-induced actuation.

9) PUBLICATIONS AND PAPERS RESULTING FROM NRC ASSOCIATESHIP RESEARCH

Provide complete citations: author(s), title, full name of journal, volume number, page number(s), and year of publication.

a) Publications in peer-reviewed journals

ME McConney, MM Duning, LV Natarajan, AA Voevodin, VP Tondiglia, TJ White, TJ Bunning, Molecular Crystals and Liquid Crystals 559: 115-126 (2012)

A Muñoz, ME McConney, T Kosa, P Luchette, L Sukhomlinova, TJ White, TJ Bunning, B Taheri. Optics Letters 37: 2904-2906 (2012)

ME McConney, TJ White, VP Tondiglia, LV Natarajan, LV Natarajan, DK Yang, TJ Bunning. Soft Matter 8:312-323 (2012)

R Kattumenu, CH Lee, L Tian, ME McConney, S Singamaneni, Journal of Material Chemistry 21: 15218-15223 (2012)

ME McConney, VP Tondiglia, JM Hurtubise, LV Natarajan, TJ White, TJ Bunning. Advanced Materials 23: 1453-1457 (2011)

ME McConney, VP Tondiglia, JM Hurtubise, TJ White, TJ Bunning. Chemical Communications 47: 505-507 (2011)

TJ White, ME McConney, TJ Bunning. Journal of Materials Chemistry 20: 9832-9847 (2010) 
b) Books, book chapters, other publications

c) Manuscripts in preparation, manuscripts submitted

ME McConney, VP Tondiglia, LV Natarajan, TJ White, TJ Bunning. "Electrically Induced Reflective Color Changes in Polymer Stabilized Cholesterics" (In Preparation)

10) PATENT OR COPYRIGHT APPLICATIONS RESULTING FROM NRC ASSOCIATESHIP RESEARCH

Provide titles, inventors, and dates of applications.

11) PRESENTATIONS AT SCIENTIFIC MEETINGS OR CONFERENCES

Provide complete references: author(s), title, abstract/proceeding citation, meeting name and location.

International

McConney, M.E., Duning, M., Natarajan, L.V., Tondiglia, V.P., Bailey, C., White, T.J., and Bunning, T.J., 'Dynamic Coloration Enabled by Polymer Stabilized Cholesteric Liquid Crystals", CIMTEC 4th International Conference on Smart Materials, Structures, and Systems, Montecatini Terme Italy, June, 2012. (invited)

Lee, K.M., Tondiglia, V., Natarajan, L., McConney, M., Bailey, C., White, T., and Bunning, T., "Dynamic Coloration Effects in Negative Dielectric Anisotropy Cholesteric Liquid Crystals”, International Meeting on Information Display (IMID), Seoul Korea, August, 2012.

Taheri, B., Munoz, A., McConney, M.E., Kosa, T., Luchette, P., Sukhomlinova, L., White, T.J., and Bunning, T.J., “CW mirrorless lasing in cholesteric liquid crystals”, International Liquid Crystal Conference (ILCC), Mainz Germany, August, 2012

Bunning, T.J., White, T.J., McConney, M.E., Tabiryan, N.V., Serak, S., Hrozhyk, U., bailey, C., Natarajan, L.V., Tondiglia, "Dynamic Coloration and Cholesteric Liquid Crystals", Optics of Liquid Crystals, Yerevan, Armenia, Sept. 25-31, 2011. (invited)

Bunning, T.J., White, T.J., McConney, M.E., Hurtubise, J., Natarajan, L.V., Tondiglia, V.P., "Dynamic Hyper-reflective Cholesteric Liquid Crystals using Spatially Polymer Templated Structures”, Liquid Crystal Photonics, Spain, September, 2010. (invited)

Domestic

White, T.J., McConney, M.E., Cazzell, S.A., Duning, M., Hurtubise, J., Natarajan, L., Tondiglia, V., and Bunning, T.J., “Responsive Liquid Crystal Polymer Network Architectures: Towards Color Tuning”, Polymer Network Group Conference, Jackson Hole WY, August, 2012. (invited)

Bunning, T.J., Bailey, C.A., McConney, M.E., Yang, D.-k., Natarajan, L., Tondiglia, V., and White, T.J., "Novel electro-optic effects in negative dielectric polymer stabilized cholesteric liquid crystals", SPIE Optics+Photonics, San Diego CA, August, 2012. (invited)

McConney, M.E., Duning, M., Natarajan, L.V., Tondiglia, V.P., White, T.J., and Bunning, T.J., "Helicoidally structure gels undergoing order-disorder phase transitions", American Chemical Society National Meeting, San Diego CA, April, 2012.

Taheri, B., Munoz, A., McConney, M.E., Kosa, T., Luchette, P., Sukhomlinova, L., White, T.J., and Bunning, T.J., “CW mirrorless lasing in cholesteric liquid crystals", SPIE Photonics West, San Francisco CA, January, 2012. (invited)

Natarajan, L.V., McConney, M.E., Duning, M., Tondiglia, V.P., White, T.J., and Bunning, T.J., "Thermally responsive polymer/liquid crystal gels exhibiting large scale color changing in cholesterics", SPIE Photonics West, San Francisco CA, January, 2012. (invited)

McConney, M.E., Duning, M., Natarajan, L., Tondiglia, V.P., White, T.J., Bunning, T.J., "Responsive Polymer/Liquid Crystal Nanocomposites enabling Large Scale Coloration Changes”, 2011 Fall Materials Research Society Meeting, Boston MA, December, 2011.

Duning, M., Voevodin, A., McConney, M., Natarajan, L., Tondiglia, V.P., White, T.J., Bunning, T.J., “Structure/property relationships of Responsive LC Gels", 2011 Fall Materials Research Society Meeting, Boston MA, December, 2011. 
Bunning, T.J., McConney, M.E., Duning, M.D., Voevodin, A., Natarajan, L.V., Tondiglia, V.P., White, T.J., “Thermal Responsive Gels based on Order/Disorder Transitions in Liquid Crystal Fluids”, 2011 Fall Materials Research Society Meeting, Boston MA, December, 2011.

Bunning, T.J., McConney, M.E., Hurtubise, J., Duning, M., Natarajan, L.V, Tondiglia, V., and White, T.J., "Dynamic Selective Reflection Properties in Cholesteric Liquid Crystals", International Stimuli Responsive Materials Conference, Hattiesburg, MS, October 24-25, 2011. (invited)

Bunning, T.J., McConney, M.E., Hurtubise, J., Duning, M., Natarajan, L.V, Tondiglia, V., and White, T.J., "Dynamic Selective Reflection Properties in Cholesteric Liquid Crystals", 2011 SPIE Optics and Photonics National Meeting, San Diego, CA, August, 2011. (invited)

Lee, K.M., McConney, M.E., Natarajan, L.V., Tondiglia, V., White, T.J., and Bunning, T.J., "Liquid Crystal/Polymer Composites as Novel Responsive Motifs", 2011 Nano Science and Technology Institute, Boston, MA, June, 2011. (invited)

Bunning, T., McConney, M., Hurtubise, J., Tondiglia, V., White, T., "A mechanistic study of a thermoresponsive polymer in a liquid crystal solvent”, APS Annual Meeting, Dallas, TX, March, 2011.

McConney, M., Hurtubise, ., Tondiglia, V., White, T., Bunning, T., "The unique behavior of chiral template polymers swollen with liquid crystals", APS Annual Meeting, Dallas, TX, March, 2011.

White, T.J., McConney, M.E., Natarajan, L.V., Tondiglia, V.P., and Bunning, T.J. "Novel Light Directed Effects in Cholesteric Liquid Crystals”, 2010 Pacifichem Meeting, Honolulu, HI, December, 2010.

Bunning, T.J., White, T.J., McConney, M.E., Hurtibise, J., Tabiryan, N.V., Serak, S.V., Natarajan, L.V., andTondiglia, V.P., "Dynamic Cholesteric Liquid Crystals Using Spatially Templated Polymer Structures", 2010 Pacifichem Meeting, Honolulu, HI, December, 2010. (invited)

McConney, M.E., Hurtubise, J., Tondiglia, V.P., Natarajan, L.V., White, T.J., and Bunning, T.J., "Interactions Between Cholesteric Templated Polymers and Liquid Crystals", 2010 Materials Research Society Fall Meeting, Boston, MA, December, 2010.

Bunning, T.J., White, T.J., McConney, M.E., Hurtibise, J., Tabiryan, N.V., Serak, S.V., Natarajan, L.V., andTondiglia, V.P., "Dynamic Cholesteric Liquid Crystals Using Spatially Templated Polymer Structures", 2010 Materials Research Society Fall Meeting, Boston, MA, December, 2010. (invited)

McConney, M.E., White, T.J., Tondiglia, V.P., Natarajan, L.V., Hurtubise, J., and Bunning, T.J. “Thermally tunable hyperreflective filters", SPIE Optics+Photonics, San Diego, CA, August, 2010. (invited)

ME McConney, JM Hurtubise, TJ White, VP Tondiglia, LV Natarajan, TJ Bunning. Interactions between Cholesteric Templated Polymers and Liquid Crystals. Materials Research Society Meeting, Fall 2010.

TJ Bunning, TJ White, ME McConney, JM Hurtubise, N Tabiryan, S Serak, LV Natarajan, VP Tondiglia. Dynamic Cholesteric Liquid Crystals Using Spatially Polymer Templated Structures. Materials Research Society Meeting, Fall 2010.

ME McConney, TJ White, J Hurtubise, VP Tondiglia, LV Natarajan, TJ Bunning. Tunable Hyper-reflective Filters. Central Regional Meeting of American Chemical Society (CeRMACS), 2010.

12) SEMINARS OR LECTURES DELIVERED AT UNIVERSITIES AND/OR INSTITUTES Include dates, names and locations of seminars.

13) PROFESSIONAL AWARDS RECEIVED DURING TENURE

14) POST-TENURE POSITION / JOB TITLE

Contractor at AFRL-RX/ Scientist III

15) NAME AND ADDRESS OF POST-TENURE POSITION / JOB ORGANIZATION

3005 Hobson Way, Bldng 654, RM 70

Materials and Manufacturing Directorate AFRL

WPAFB, OH, 45434 
16) POST-TENURE POSITION STATUS / CATEGORY Please indicate only one.

$\square$ Permanent position at the NRC host agency

$\triangle$ Contract or temporary position at the NRC host Agency

Abbreviate Host Laboratory/Center

Research/Administrative position with another U.S.government agency

$\square$ Research/Administrative position with a foreigngovernment agency

Research/teaching position at a U.S. college or university

Research/teaching position at a foreign college or university $\square$ Research/administration position in private industry in the U.S.

Research/administration position in private industry outside of the U.S.

Research/administration position with a non profit

$\square$ Self-employed/consulting

$\square$ Postdoctoral research

$\square$ Other (Please specify, possible)

$\square$ No information provided

17) APPRAISAL OF RESEARCH ASSOCIATESHIP PROGRAM

On a scale of 1 - 10 (poor - excellent), please rate the following:

SHORT TERM VALUE

10 Development of knowledge, skills, and research productivity

Comments

LONG TERM VALUE

10 How the NRC Associateship award affected your career to date Comments

\section{LAB SUPPORT}

10 Quality of support from the Laboratory--equipment, funding, orientation, safety and health guidelines, etc.

\section{Comments}

\section{ADVISER/MENTOR SUPPORT}

10 Quality of mentoring from the Laboratory NRC Adviser (USMA Mentor, if applicable)

\section{Comments}

\section{LPR SUPPORT}

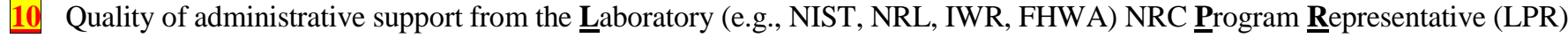
Comments

\section{NRC SUPPORT}

10 Quality of administrative support. Please assess respective NRC aspects (e.g., moving company, insurance, Omega, payroll, coordinator, travel, etc.)

\section{Comments}

18) PLEASE PROVIDE ANY SUGGESTIONS FOR PROGRAM IMPROVEMENT.

Please do NOT scan to PDF. Send the Final Report as MSWord document via e-mail to your NRC Program Coordinator No handwritten signature required; Asha Davis: $\quad$ adavis@ nas.edu but you may upload a scanned Linda Sligh: $\quad$ lsligh@nas.edu signature file below:

Jason Thornhill: jthornhill@nas.edu

Peggy Wilson: pwilson@nas.edu

Suzanne White: swhite@nas.edu 
Advisers to the Nation on Science, Engineering, and Medicine

National Research Council

\section{Research Associateship Programs}

\section{FINAL REPORT}

1) Associate Last or Family Name

First Name

M.I.

Jonathan

$\mathbf{R}$

McDonald

2) FORWARDING Address (to which your tax statement will be mailed)

FORWARDING Phone(s) and E-Mail (if known)

Home Phone:

Residence or Institution Residence

Alt. Phone:

Street

City, State Zip Belmont, MA 02478

3) Today's Date

June 21, 2012

4) Host Agency

AFRL

(e.g., AFRL)

5) Name of Laboratory NRC Adviser (and USMA Mentor, if applicable)

Paul M Alsing

6) TITLE OF RESEARCH PROPOSAL

A Discrete Geometric Approach to Characterizing Quantum Computations

7) SUMMARY OF RESEARCH DURING TENURE Itemize significant findings in concise form, utilizing key concepts/words.

1) Derived discrete representation of the Ricci tensor for Piecewise-flat manifolds

2) Used our discrete Ricci tensor to provide a geometric discretization of Richard Hamilton's Ricci flow equations on piecewise-flat manifolds

3) Used discrete exterior calculus (DEC) to develop an inherently discrete analysis of curvature on simplicial geometries

4) Applied techniques from Persistent Homology and quantum theory to demonstrate how quantum computations can be viewed as foliations of hypersurfaces whose geometry is determined by the correlation information between qubits.

5) Demonstrated the geometric view of quantum computation for 1D quantum cellular automata.

(USMA Davies Fellow: please add summary of teaching, including classes taught.)

8) RESEARCH IN PROGRESS Describe in no more than 100 words.

We are currently studying the numeric behavior of simplicial Ricci flow and the role of diffeomorphisms. We are also investiagting the geometric foundations of multi-partite entanglement (through measures such as information area).

\section{9) PUBLICATIONS AND PAPERS RESULTING FROM NRC ASSOCIATESHIP RESEARCH}

Provide complete citations: author(s), title, full name of journal, volume number, page number(s), and year of publication.

a) Publications in peer-reviewed journals

P M Alsing, J R McDonald, W A Miller, "The simplicial Ricci tensor, " Class . Quantum Gra.v. 28 (2011) 155007

b) Books, book chapters, other publications

J R McDoanld, Paul M. Alsing, Howard A. Blair, "A geometric view of quantum cellular automata," in Quantum Information and Computation X, eds. Eric Donkor, Andrew R. Pirich, Howard E. Brandt, Proceedings of SPIE 8400, 84000S (2012).

P M Alsing, J R McDonald, “Nonlocality, entanglement witnesses, and supra-correlations,” in Quantum Information and Computation X, eds. Eric Donkor, Andrew R. Pirich, Howard E. Brandt, Proceedings of SPIE 8400, 84000Y (2012).

c) Manuscripts in preparation, manuscripts submitted

P M Alsing, J R McDonald, W A Miller, X Wang, "Simplicial Ricci Flow"

J R McDonald, W A Miller, X Wang, "On exterior calculus and curvature in piecewise-flat manifolds"

S Ray, C Tison, M A Corne, J R McDonald, W A Miller, "Simplicial Ricci Flow on Discretizations of the 2- and 3spheres" 
10) PATENT OR COPYRIGHT APPLICATIONS RESULTING FROM NRC ASSOCIATESHIP RESEARCH

Provide titles, inventors, and dates of applications.

N/A

11) PRESENTATIONS AT SCIENTIFIC MEETINGS OR CONFERENCES

Provide complete references: author(s), title, abstract/proceeding citation, meeting name and location.

International

Domestic

J R McDonald, "Hybrid Measures and Discrete Exterior Calculus," ${ }^{\text {th }}$ Gulf Coast Gravity Meeting, Florida Atlantic University, Boca Raton, FL 16 May 2011

J R McDonald, "The Simplicial Ricci Tensor," East Coast Gravity Meeting, Syracuse University, Syracuse, NY , 22 April 2012

J R McDoanld, Paul M. Alsing, Howard A. Blair, “A geometric view of quantum cellular automata,” at Quantum Information and Computation X, SPIE Defense, Security, and Sensing, Baltimore, MD, April 2012

12) SEMINARS OR LECTURES DELIVERED AT UNIVERSITIES AND/OR INSTITUTES Include dates, names and locations of seminars.

"Geometric Discretizations and Piecewise-flat manifolds," Naval Research Laboratory, Washington, DC, 28 Mar 2011

13) PROFESSIONAL AWARDS RECEIVED DURING TENURE

14) POST-TENURE POSITION / JOB TITLE

Postdoctoral Researcher

15) NAME AND ADDRESS OF POST-TENURE POSITION / JOB ORGANIZATION

Department of Mathematics, Harvard University, One Oxford St, Cambridge, MA

16) POST-TENURE POSITION STATUS / CATEGORY Please indicate only one.

Permanent position at the NRC host agency

Contract or temporary position at the NRC host Agency

Abbreviate Host Laboratory/Center

Research/Administrative position with another U.S.government agency

$\square$ Research/Administrative position with a foreigngovernment agency

Research/teaching position at a U.S. college or university

Research/teaching position at a foreign college or university

17) APPRAISAL OF RESEARCH ASSOCIATESHIP PROGRAM

On a scale of 1 - 10 (poor - excellent), please rate the following:

SHORT TERM VALUE

8 Development of knowledge, skills, and research productivity

Comments

LONG TERM VALUE

8 How the NRC Associateship award affected your career to date

Comments

\section{LAB SUPPORT}

7 Quality of support from the Laboratory--equipment, funding, orientation, safety and health guidelines, etc. Comments

Obtaining proper equipment/computers to perform research adequately could sometimes be slow and stall some aspects of the research. 
ADVISER/MENTOR SUPPORT

10 Quality of mentoring from the Laboratory NRC Adviser (USMA Mentor, if applicable)

Comments

\section{LPR SUPPORT}

8 Quality of administrative support from the Laboratory (e.g., NIST, NRL, IWR, FHWA) NRC $\underline{\text { Program }} \underline{\text { Representative (LPR) }}$ Comments

There was very little interaction between NRC associates and the LPR. However, they were always helpful when needed and getting forms signed/approved was quick and effortless.

NRC SUPPORT

9 Quality of administrative support. Please assess respective NRC aspects (e.g., moving company, insurance, Omega, payroll, coordinator, travel, etc.)

Comments

Very helpful and always knowledgeable about processes and requirements.

18) PLEASE PROVIDE ANY SUGGESTIONS FOR PROGRAM IMPROVEMENT.

Please do NOT scan to PDF. Send the Final Report as MSWord document via e-mail to your NRC Program Coordinator

No handwritten signature required; but you may upload a scanned signature file below:

Id\#
Asha Davis: $\quad$ adavis@ nas.edu

Linda Sligh: $\quad \underline{\text { sligh@nas.edu }}$

Jason Thornhill: ithornhill@nas.edu

Peggy Wilson: pwilson@nas.edu

Suzanne White: swhite@nas.edu

Rev. July 2011
Proj/Act ID\# 
Advisers to the Nation on Science, Engineering, and Medicine

National Research Council

\section{Research Associateship Programs}

\section{FINAL REPORT}

1) Associate Last or Family Name

First Name

M.I.

O'Connor

2) FORWARDING Address (to which your tax statement will be mailed)

Alan

C

Residence or Institution Residence

Street

City, State Zip Arlington, MA 02474

3) Today's Date

FORWARDING Phone(s) and E-Mail (if known)

Home Phone:

Alt. Phone:

Preferred E-mail: alan.c.oconnor@gmail.com

Dates of Tenure

from September 12, 2011

4) Host Agency

AFRL

(e.g., AFRL)

5) Name of Laboratory NRC Adviser (and USMA Mentor, if applicable)

Leonid

Perlovsky

6) TITLE OF RESEARCH PROPOSAL

Integrating Prior Knowledge and Sensor Data for Active Sensing

7) SUMMARY OF RESEARCH DURING TENURE Itemize significant findings in concise form, utilizing key concepts/words.

1) Demonstrated convergence of a distributed multi-agent system for agreeing on a collective sensing action when there is uncertainty about the target dynamical model.

2) Computed an analytical formula for the Cramer-Rao Lower Bound on range and velocity estimation variance and its dependece on the emitted radar pulse-train length. This result was confirmed for a stationary target using an S-band radar.

3) Quantified the benefit of feedback control of radar pulse-train length. Showed that the actively controlled approach achieved a $14 \%$ reduction in tracking error and dwell-time cost for constant velocity targets compared to the best constant policy.

4) Developed detector/tracker for asteroids moving in image sequences. This was an application of cognitive-based dataassociation algorithms developed by my advisor. Demonstrated improved performance for data with occlusions of objects of interest.

5)

(USMA Davies Fellow: please add summary of teaching, including classes taught.)

N/A

8) RESEARCH IN PROGRESS Describe in no more than 100 words.

Am currently investigating the use of multipath propagation information in passive location of RF emitters. The active sensing aspect of this project has to do with the fact that the quality of information depends on the position and velocity of the mobile sensor. Having some prior knowledge of the position of the emitter permits an optimization sensor trajectory and thus of future measurements.

9) PUBLICATIONS AND PAPERS RESULTING FROM NRC ASSOCIATESHIP RESEARCH

Provide complete citations: author(s), title, full name of journal, volume number, page number(s), and year of publication.

a) Publications in peer-reviewed journals

None completed yet.

b) Books, book chapters, other publications

A. O'Connor, "Multi-agent system for target-adaptive radar tracking," Proc. SPIE, vol. 8408, 2012.

A. O'Connor, R. Vela, and L. LoMonte, "Target-adaptive radar pulse-train optimization," Proc. IEEE Antennas and

Propagation Symp., 2012.

T. Allen, A. O'Connor, and I. Ternovskiy, "Improved near-Earth object detection using dynamic logic," Proc. SPIE, vol. 8408, 2012.

A. O'Connor, R. Ilin, T. Allen, and I. Ternovskiy, "Detection and tracking of near-Earth objects using a cognitive hierarchical data-association model," to appear in Proc. IEEE NAECOM, 2012.

c) Manuscripts in preparation, manuscripts submitted 
A. O'Connor, P. Setlur, and N. Devroye, "Single-antenna localization of RF emitters using multipath exploitation," in preparation.

A. O'Connor, R. Ilin, I. Ternovskiy, and L. Perlovsky, "Learning hierarchical concept models," in preparation.

A. O'Connor, T. Allen, and I. Ternovskiy, "Improved near-Earth object detection using dynamic logic," in preparation.

10) PATENT OR COPYRIGHT APPLICATIONS RESULTING FROM NRC ASSOCIATESHIP RESEARCH

Provide titles, inventors, and dates of applications.

N/A

11) PRESENTATIONS AT SCIENTIFIC MEETINGS OR CONFERENCES

Provide complete references: author(s), title, abstract/proceeding citation, meeting name and location.

International

A. O'Connor, "Measurement of a Markov jump process by hypothesis tests," Intl Conference on Control and Automation, Santiago, Chile, Dec. 2011.

Domestic

A. O'Connor, "Measurement of a Markov jump process: when is it too costly?" IEEE Control and Decision Conference, Orlando, FL, Dec. 2011.

A. O'Connor, "Multi-agent system for target-adaptive radar tracking," SPIE Defence, Sensing, and Security, Baltimore, MD, Apr. 2012.

A. O'Connor, R. Vela, and L. LoMonte, "Target-adaptive radar pulse-train optimization," IEEE Antennas and Propagation Symposium, Chicago, IL, July, 2012.

A. O'Connor, R. Ilin, T. Allen, and I. Ternovskiy, "Detection and tracking of near-Earth objects using a cognitive hierarchical data-association model," IEEE NAECOM, Fairborn, OH, July, 2012.

12) SEMINARS OR LECTURES DELIVERED AT UNIVERSITIES AND/OR INSTITUTES Include dates, names and locations of seminars.

"Integrating prior knowledge and data for intelligent adaptive sensors," MIT Lincoln Laboratory, Lexington, MA, March, 2012.

"Research on Dynamic Logic and adaptive radar," Air Force Research Laboratory, Wright-Patterson AFB, OH, May, 2012.

13) PROFESSIONAL AWARDS RECEIVED DURING TENURE

N/A

14) POST-TENURE POSITION / JOB TITLE

Technical Staff

15) NAME AND ADDRESS OF POST-TENURE POSITION / JOB ORGANIZATION

Lincoln Laboratory

Massachusetts Institute of Technology

244 Wood Street

Lexington, MA 02420-9108

16) POST-TENURE POSITION STATUS / CATEGORY Please indicate only one.

Permanent position at the NRC host agency

Contract or temporary position at the NRC host Agency

Abbreviate Host Laboratory/Center

Research/Administrative position with another U.S.government agency

Research/Administrative position with a foreigngovernment agency

$\bigotimes$ Research/teaching position at a U.S. college or university

Research/teaching position at a foreign college or university

$\square$ Research/administration position in private industry in the U.S.

$\square$ Research/administration position in private industry outside of the U.S.

$\square$ Research/administration position with a non profit

$\square$ Self-employed/consulting

Postdoctoral research

$\square$ Other (Please specify, possible)

$\square$ No information provided

17) APPRAISAL OF RESEARCH ASSOCIATESHIP PROGRAM

On a scale of 1 - 10 (poor - excellent), please rate the following:

SHORT TERM VALUE

Development of knowledge, skills, and research productivity

Comments

7

$\underline{\text { LONG TERM VALUE }}$ 
How the NRC Associateship award affected your career to date

Comments

9

LAB SUPPORT

Quality of support from the Laboratory--equipment, funding, orientation, safety and health guidelines, etc.

Comments

5

ADVISER/MENTOR SUPPORT

Quality of mentoring from the Laboratory NRC Adviser (USMA Mentor, if applicable)

Comments

7

LPR SUPPORT

Quality of administrative support from the Laboratory (e.g., NIST, NRL, IWR, FHWA) NRC Program $\underline{\text { Representative (LPR) }}$ Comments

6

NRC SUPPORT

Quality of administrative support. Please assess respective NRC aspects (e.g., moving company, insurance, Omega, payroll, coordinator, travel, etc.)

\section{Comments}

10

18) PLEASE PROVIDE ANY SUGGESTIONS FOR PROGRAM IMPROVEMENT.

Please do NOT scan to PDF. Send the Final Report as MSWord document via e-mail to your NRC Program Coordinator No handwritten signature required; but you may upload a scanned signature file below:

Asha Davis: $\quad$ adavis@nas.edu

Linda Sligh: $\quad$ Isligh@nas.edu

Jason Thornhill: ithornhill@nas.edu

Peggy Wilson: $\quad$ pwilson@nas.edu

Suzanne White: swhite@nas.edu 
Advisers to the Nation on Science, Engineering, and Medicine

National Research Council

\section{Research Associateship Programs}

\section{FINAL REPORT}

1) Associate Last or Family Name

First Name

M.I.

Rider

2) FORWARDING Address (to which your tax statement will be mailed)

Keith

B

Residence or Institution Residence

FORWARDING Phone(s) and E-Mail (if known)

Home Phone:

Street

City, State Zip Prospect, VA 23960

3) Today's Date

July 17, 2012

4) Host Agency

AFRL

(e.g., AFRL)

5) Name of Laboratory NRC Adviser (and USMA Mentor, if applicable)

C. Michael Lindsay

6) TITLE OF RESEARCH PROPOSAL

Energetic Nanocluster Thin Films

7) SUMMARY OF RESEARCH DURING TENURE Itemize significant findings in concise form, utilizing key concepts/words.

1) Measured particle deposition rates from helium droplet beam to compare with calculations

2) Designed and build magnesium and perfluoropolyether sources

3) Performed TPD/TPR experiments on magnesium and perfluoropolyether thin films

4) Performed DSC/TGA experiments on magnesium and perfluoropolyether bulk materials

5) Assisted with other experiments (XRD, SEM) of these and other materials

(USMA Davies Fellow: please add summary of teaching, including classes taught.)

\section{8) RESEARCH IN PROGRESS Describe in no more than 100 words.}

The next phase of this research project will be charaterizing materials made with the helium droplet method using the baseline chemistry that was established with the thin film studies. Knowing the TPD behavior of the thin films should make it much easier to understand the behavior of the more complex core-shell particles made with the helium droplet beam.

9) PUBLICATIONS AND PAPERS RESULTING FROM NRC ASSOCIATESHIP RESEARCH

Provide complete citations: author(s), title, full name of journal, volume number, page number(s), and year of publication.

a) Publications in peer-reviewed journals

none

b) Books, book chapters, other publications

none

c) Manuscripts in preparation, manuscripts submitted

Physical and Chemical Properties of Iodine (V) Oxide Films

B.K. Little,* M.B. Bogle, J.C. Nittinger, R.C. Fantasia, S.B. Emery, K.B. Rider, and C.M. Lindsay

J. Mat. Chem.

Superfluid Helium Droplet Assembled Nanocluster Films: Cluster Formation and Deposition Rates

S.B. Emery, K.B. Rider, B.K. Little, and C.M. Lindsay

J. Phys. Chem. C

Magnesium Cluster Films Grown by Superfluid Helium Nanodroplets

S.B. Emery, K.B. Rider, B.K. Little, and C.M. Lindsay

Appl. Phys. Lett.

Thermochemical Measurements of a Magnesium-Perfluoropolyether Pyrolant
Munitions

(e.g., High-Speed Propulsion) 
Keith B. Rider, Brian Little, Samuel Emery, C. Michael Lindsay

Propellants, Explosives, Pyrotechnics

10) PATENT OR COPYRIGHT APPLICATIONS RESULTING FROM NRC ASSOCIATESHIP RESEARCH

Provide titles, inventors, and dates of applications.

none

11) PRESENTATIONS AT SCIENTIFIC MEETINGS OR CONFERENCES

Provide complete references: author(s), title, abstract/proceeding citation, meeting name and location.

International

none

Domestic

Keith B. Rider, Samuel B. Emery, Brian K. Little, and C. Michael Lindsay, Magnesium-Perfluoropolyether Reactions Studied by TPD/TPR, AFOSR Contractor's Meeting, Arlington, VA, 5/21 to 5/24/2012

12) SEMINARS OR LECTURES DELIVERED AT UNIVERSITIES AND/OR INSTITUTES Include dates, names and locations of seminars. none

13) PROFESSIONAL AWARDS RECEIVED DURING TENURE

none

14) POST-TENURE POSITION / JOB TITLE

Associate professor of Chemistry

15) NAME AND ADDRESS OF POST-TENURE POSITION / JOB ORGANIZATION

Longwood University, 201 High St., Farmville, VA 23909

16) POST-TENURE POSITION STATUS / CATEGORY Please indicate only one.

Permanent position at the NRC host agency

Contract or temporary position at the NRC host Agency

Abbreviate Host Laboratory/Center

$\square$ Research/administration position in private industry in the U.S.

Research/Administrative position with another U.S.government agency

Research/Administrative position with a foreigngovernment agency

$\bigotimes$ Research/teaching position at a U.S. college or university

Research/teaching position at a foreign college or university

$\square$ Research/administration position in private industry outside of the U.S.

$\square$ Research/administration position with a non profit

$\square$ Self-employed/consulting

Postdoctoral research

$\square$ Other (Please specify, possible)

$\square$ No information provided

17) APPRAISAL OF RESEARCH ASSOCIATESHIP PROGRAM

On a scale of 1 - 10 (poor - excellent), please rate the following:

SHORT TERM VALUE

9 Development of knowledge, skills, and research productivity

Comments

I got a lot of work done in a very short time. It was a very intense year.

LONG TERM VALUE

10 How the NRC Associateship award affected your career to date

Comments

My associateship will probably win me my promotion to full professor.

LAB SUPPORT

9 Quality of support from the Laboratory--equipment, funding, orientation, safety and health guidelines, etc.

Comments

ADVISER/MENTOR SUPPORT

9 Quality of mentoring from the Laboratory NRC Adviser (USMA Mentor, if applicable) Comments 


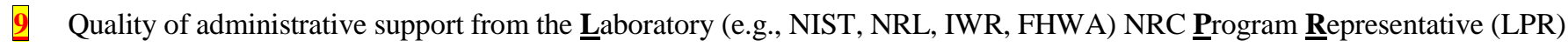
Comments

NRC SUPPORT

9 Quality of administrative support. Please assess respective NRC aspects (e.g., moving company, insurance, Omega, payroll, coordinator, travel, etc.)

Comments

We had very good experiences with Azar Storage, Omega Travel, and the NRC payroll office

18) PLEASE PROVIDE ANY SUGGESTIONS FOR PROGRAM IMPROVEMENT.

Please do NOT scan to PDF. Send the Final Report as MSWord document via e-mail to your NRC Program Coordinator

No handwritten signature required; but you may upload a scanned signature file below:
Asha Davis: $\quad$ adavis@nas.edu

Linda Sligh: lsligh@nas.edu

Jason Thornhill: jthornhill@nas.edu

Peggy Wilson: pwilson@nas.edu

Suzanne White: swhite@nas.edu

Rev. July 2011
Proj/Act ID\# 
Advisers to the Nation on Science, Engineering, and Medicine

National Research Council

\section{Research Associateship Programs}

\section{FINAL REPORT}

1) Associate Last or Family Name

First Name

M.I.

Nathaniel

$\mathbf{L}$

Sanders

2) FORWARDING Address (to which your tax statement will be mailed)

FORWARDING Phone(s) and E-Mail (if known)

Home Phone:

Residence or Institution Residence

Alt. Phone: 765-426-5982

Street

City, State Zip Sunnyvale, CA 94087

3) Today's Date

June 26, 2012

4) Host Agency

AFRL

(e.g., AFRL)

5) Name of Laboratory NRC Adviser (and USMA Mentor, if applicable)

Christopher

Bunker

6) TITLE OF RESEARCH PROPOSAL

In-situ Detection of Pyrolysis Intermediates in Supercritical Hydrocarbon

7) SUMMARY OF RESEARCH DURING TENURE Itemize significant findings in concise form, utilizing key concepts/words.

1) Developed a heating reactor for gas-phase molecules to be interfaced with molecular beam, mass spectrometer.

2) Developed models for the pyrolysis of endothermic fuel simulant $n$-hexane under deoxygenated, low pressure conditions.

3) Introduced a novel class of Boron Nitride-based nanomaterials as catalysts to modify distribution of reaction intermediates.

4) Was able to differentiate classes of catalytic activity, and identify commonalities in catalytic behavior.

5) Developed a supercritical sample reaction chamber to be safely integrated to instrument for future work.

(USMA Davies Fellow: please add summary of teaching, including classes taught.)

\section{8) RESEARCH IN PROGRESS Describe in no more than 100 words.}

Currently, we are preparing multiple manuscripts for publication, the first of which thoroughly describes the foundational characterization of pyrolysis reaction intermediates in the gas-phase which we found to produce reaction mechanisms which produced unique intermediates of potential importance. The second manuscript describes work investigating the behavior of a new class of BN-based nanomaterials which display unique, low-temperature calaytic activity in driving the intermediate, and product ion distribution towards useful, endothermic fuel products of potential use in the AFRL. Now, having layed the groundwork and characterized a novel catalysts, a supercritical source will be integrated for the second phase of work.

\section{9) PUBLICATIONS AND PAPERS RESULTING FROM NRC ASSOCIATESHIP RESEARCH}

Provide complete citations: author(s), title, full name of journal, volume number, page number(s), and year of publication.

a) Publications in peer-reviewed journals

b) Books, book chapters, other publications

c) Manuscripts in preparation, manuscripts submitted

Nathaniel L. Sanders, William K. Lewis, Kevin Kuchta, and Christopher E. Bunker "Characterization of n-Hexane Pyrolysis Intermediates Using a Molecular Beam Mass Spectrometer" Manuscript in preparation.

Nathaniel L. Sanders, William K. Lewis, Yi Lin, John Connell, K.A. Shiral Fernando, and Christopher Bunker

"Characterization of BN and Metal-BN Catalyzed Pyrolysis of n-Hexane" Manuscript in preparation.

10) PATENT OR COPYRIGHT APPLICATIONS RESULTING FROM NRC ASSOCIATESHIP RESEARCH

Provide titles, inventors, and dates of applications. 
11) PRESENTATIONS AT SCIENTIFIC MEETINGS OR CONFERENCES

Provide complete references: author(s), title, abstract/proceeding citation, meeting name and location.

International

Domestic

Nathaniel L. Sanders, William K. Lewis, Christopher E. Bunker, Kevin Kuchta, Sean Pawlowski, Yi Lin, and John Connell "Pyrolysis of Gas-Phase and Supercritical Hydrocarbons in a Molecular Beam Mass Spectrometer" Poster Presentation at the American Society for Mass Spectrometry Conference, Vancouver, BC Canada, 2012.

Nathaniel L. Sanders, William K. Lewis, Christopher E. Bunker, Kevin Kuchta, Yi Lin, John Connell. 'Pyrolysis of Gas Phase Hydrocarbons in a Molecular Beam Mass Spectrometer". Poster Presentation at the Air Force Office of Scientific Research Molecular Dynamics Program Review, Arlington VA, 2012.

12) SEMINARS OR LECTURES DELIVERED AT UNIVERSITIES AND/OR INSTITUTES Include dates, names and locations of seminars.

13) PROFESSIONAL AWARDS RECEIVED DURING TENURE

14) POST-TENURE POSITION/JOB TITLE

Research and Development Scientist / R \& D Researcher

15) NAME AND ADDRESS OF POST-TENURE POSITION / JOB ORGANIZATION

Agilent Technologies, Inc. Santa Clara, CA 95051

16) POST-TENURE POSITION STATUS / CATEGORY Please indicate only one.

Permanent position at the NRC host agency $\$ Research/administration position in private industry in the U.S.

Contract or temporary position at the NRC host Agency

Abbreviate Host Laboratory/Center

$\square$ Research/administration position in private industry outside of

Research/Administrative position with another U.S.government agency

$\square$ Research/Administrative position with a foreigngovernment agency

Research/teaching position at a U.S. college or university

Research/teaching position at a foreign college or university the U.S.

$\square$ Research/administration position with a non profit

$\square$ Self-employed/consulting

$\square$ Postdoctoral research

$\square$ Other (Please specify, possible)

$\square$ No information provided

17) APPRAISAL OF RESEARCH ASSOCIATESHIP PROGRAM

On a scale of 1 - 10 (poor - excellent), please rate the following:

SHORT TERM VALUE

8 Development of knowledge, skills, and research productivity

Comments

The position allowed me to broaden and stretch my research skills, by allowing me to approach the research from a new perspective (physical chemistry as opposed to analytical chemistry). Also, by taking full responsibility for the direction and progress of the project it was necessary that I work more efficiently and evaluate potential project directions more critically than in the past.

\section{LONG TERM VALUE}

8 How the NRC Associateship award affected your career to date

Comments

The award was definitely a positive contribution to my resume. The job has allowed me to network with and develop new research connections which I would like to take advantage of in the future. It has given me an appreciation for the program in developing the careers of young scientists, and introducing them to the research environment in which close interactions occur between university and government laboratories.

LAB SUPPORT

10 Quality of support from the Laboratory--equipment, funding, orientation, safety and health guidelines, etc. Comments

The host lab provided for every possible need on a timely basis. I couldn't speak more highly of the manner in which they helped to facilitate my associateship.

ADVISER/MENTOR SUPPORT

9 Quality of mentoring from the Laboratory NRC Adviser (USMA Mentor, if applicable) Comments 
My adviser did an excellent job in his role as a mentor. Our discussions regarding the work was challenging and insightful, often giving me the opportunity to think of new approaches to perform studies and present results. I believe any young scientist would benefit tremendously from working in Dr. Bunker's lab.

\section{LPR SUPPORT}

9 Quality of administrative support from the Laboratory (e.g., NIST, NRL, IWR, FHWA) NRC Program $\underline{\text { Representative (LPR) }}$

\section{Comments}

Dr. Rivir was extremely helpful in accomodating my administrative needs, as well as enthusiastic in support of my, and my host laboratory research goals and accomplishments.

\section{NRC SUPPORT}

9 Quality of administrative support. Please assess respective NRC aspects (e.g., moving company, insurance, Omega, payroll, coordinator, travel, etc.)

\section{Comments}

The support I received from the NRC was very helpful and always communicated back to me in a timely manner. I felt that they were extremely reliable, and I'm grateful for my time there. I would highly recommend the experience to anyone considering the opportunity.

18) PLEASE PROVIDE ANY SUGGESTIONS FOR PROGRAM IMPROVEMENT.

Please do NOT scan to PDF. Send the Final Report as MSWord document via e-mail to your NRC Program Coordinator

No handwritten signature required; but you may upload a scanned signature file below:
Asha Davis: Linda Sligh:
Jason Thornhill: jthornhill@nas.edu
Peggy Wilson:
Suzanne White:
adavis@nas.edu
Isligh@nas.edu
pwilson@nas.edu
swhite@nas.edu 
Advisers to the Nation on Science, Engineering, and Medicine

\section{Research Associateship Programs}

National Research Council

\section{FINAL REPORT}

1) Associate Last or Family Name

First Name

Denis

FORWARDING Phone(s) and E-Mail (if known)

Home Phone:

Alt. Phone:

Preferred E-mail: dvsunm@gmail.com

Street

City, State Zip Albuquerque, NM 87123

3) Today's Date

August 1, 2012

\begin{tabular}{c|c} 
Host Agency & Laboratory or Center \\
AFRL & Kirtland AFB \\
(e.g., AFRL) & (e.g., Wright Patterson AFB) \\
5) Name of Laboratory NRC Adviser (and USMA Mentor, if applicable)
\end{tabular}

Dr. Paul LeVan

6) TITLE OF RESEARCH PROPOSAL

Laser Refrigeration

7) SUMMARY OF RESEARCH DURING TENURE Itemize significant findings in concise form, utilizing key concepts/words.

1) High sensitivity spectroscopic methods developed

2) Using methods above, local cooling to $110 \mathrm{~K}$ has been measured, in agreement with the model

3) Bulk cooling to $119 \mathrm{~K}$ has been demonstrated

4) Laser cooling model has been extended to include effects of saturation

5) Cooling by 80 degrees has been demonstrated inside of a optically-pumped semiconductor laser cavity.

(USMA Davies Fellow: please add summary of teaching, including classes taught.)

8) RESEARCH IN PROGRESS Describe in no more than 100 words.

Understanding of parasitic heating effects that limit cooling; cooling below $100 \mathrm{~K}$; improving intra laser cavity cooling to reach sub-100 $\mathrm{K}$ regime.

9) PUBLICATIONS AND PAPERS RESULTING FROM NRC ASSOCIATESHIP RESEARCH

Provide complete citations: author(s), title, full name of journal, volume number, page number(s), and year of publication.

a) Publications in peer-reviewed journals

1) D.V. Seletskiy, M.P. Hehlen, R.I. Epstein, M. Sheik-Bahae “Cryogenic Optical Refrigeration” Advances in Optics and Photonics 4, 78-107 (2012);

2) D.V Seletskiy, S.D Melgaard, R.I Epstein, A. Di Lieto, M. Tonelli, M.Sheik-Bahae, 'Precise Determination of Minimum Achievable Temperature for Solid-State Optical Refrigeration”, Journal of Luminescence published online, (2011);

3) D.V. Seletskiy, M.P. Hasselbeck, J.G. Cederberg, A. Katzenmeyer, M.E. Toimil-Molares, F. Léonard, A.A. Talin, M.

Sheik-Bahae, "Efficient terahertz emission from InAs nanowires", Physical Review B 84, 115421 (2011);

4) D.V. Seletskiy, S.D. Melgaard, R.I. Epstein, A. Di Lieto, M. Tonelli, M. Sheik-Bahae, "Local laser cooling of Yb:YLF to 110 K", Optics Express, 19, 18229-18236 (2011);

5) M. Tiwari, D.V. Seletskiy, V.M. Kenkre, "Resonance Effects in the Nonabiabatic Nonlinear Quantum Dimer", European Physics Journal B 81, 147-153 (2011).

b) Books, book chapters, other publications

c) Manuscripts in preparation, manuscripts submitted

S. Melgaard, D. Seletskiy, M. Tonelli, A. Di Lieto, M. Sheik-Bahae "Laser cooling to 119 K", Optics Letters (in preparation)

10) PATENT OR COPYRIGHT APPLICATIONS RESULTING FROM NRC ASSOCIATESHIP RESEARCH

Provide titles, inventors, and dates of applications. 
11) PRESENTATIONS AT SCIENTIFIC MEETINGS OR CONFERENCES

Provide complete references: author(s), title, abstract/proceeding citation, meeting name and location.

International

1) D. V. Seletskiy, C-Y Li, M. P. Hasselbeck, J. G. Cederberg, A. M. Katzenmeyer, M. E. Toimil-Molares, F. Léonard, A. A. Talin, M. Sheik-Bahae, "Strong THz emission from low-energy acoustic-like surface plasmons in InAs nanowires" Proc. SPIE, 8260, 826012 (2012);

2) C-Y Li, Denis V. Seletskiy, Jeffrey G. Cederberg, Mansoor Sheik-Bahae, "Detection of ultrafast THz pulses via electroabsorption in coupled asymmetric quantum wells", Proc. SPIE, 8260, 826021 (2012).;

3) S. D. Melgaard, D. V. Seletskiy, A. Di Lieto, M. Tonelli and M. Sheik-Bahae, "High sensitivity spectroscopic and thermal characterization of cooling efficiency for optical refrigeration materials", Proc. SPIE 8275, 827504 (2012);

4) D.V. Seletskiy, S. D. Melgaard and M. Sheik-Bahae, "Thermal imaging with high spatial and temperature resolution", Proc. SPIE 8275, 82750H (2012);

5) S.D. Melgaard, J. Trevino, D. V. Seletskiy and M. Sheik-Bahae, "Novel photon blockade schemes for thermal link applications", Proc. SPIE 8275, 82750I (2012);

6) M. Ghasemkhani, D. V. Seletskiy and M. Sheik-Bahae, "Polarization-resolved optical metrology for noncontact thermometry", Proc. SPIE 8275, 82750J (2012);

7) J. V. Moloney, G. Balakrishnan, M. Sheik-Bahae, "Intracavity laser cooling using a VECSEL", Proc. SPIE 8275, 827505 (2012);

8) M. Ghasemkhani, D. V. Seletskiy, M. Sheik-Bahae, "Sensitive thermal reflectance measurement for laser cooling applications", Proc. SPIE 7951, 79510J (2011).

9) S. D. Melgaard, D. V. Seletskiy, A. Di Lieto, M. Tonelli, M. Sheik-Bahae, "Experimental evidence for laser cooling of Yb:YLF to 120 Kelvin", Proc. SPIE 7951, 795105 (2011).

10) D. V. Seletskiy, R. I. Epstein, M. Sheik-Bahae, “Progress toward sub-100 Kelvin operation of an optical cryocooler", Proc. SPIE 7951, 795103 (2011).

11) A. Albrecht, D. V. Seletskiy, C. Hains, J. Cederberg, A. Di Lieto, M. Tonelli, G. Balakrishnan, M. Sheik-Bahae,

“Intracavity Laser Cooling Using a VECSEL", CLEO (San Jose, May 6-11, 2012), paper QTh4E.1

12) C.-Y. Li, D. V. Seletskiy, J. G. Cederberg, M. Sheik-Bahae, “Quantum-Well Electro-Absorption Sampling for Broadband THz Detection”, CLEO (San Jose, May 6-11, 2012), paper QTu1H.8

13) S. D. Melgaard, D. V. Seletskiy, A. DiLieto, M. Tonelli, M. Sheik-Bahae, “Optical Refrigeration to NIST Cryogenic Temperature at 123K", CLEO (San Jose, May 6-11, 2012), paper QTh4E.3

14) M. Ghasemkhani, D. V. Seletskiy, M. Sheik-Bahae, "Polarization-resolved optical metrology for noncontact thermometry", Photonics West (San Francisco, Jan 21-26, 2012) paper 8275-18.

15) S. Melgaard, D. Seletskiy, A. Di Lieto, M. Tonelli, M. Sheik-Bahae, "High sensitivity spectroscopic and thermal characterization of cooling efficiency for optical refrigeration materials”, Photonics West (San Francisco, Jan 21-26, 2012) paper 8275-3.

16) A.R. Albrecht, D.V. Seletskiy, A. Di Lieto, M. Tonelli, M. Sheik-Bahae, "Intracavity laser cooling using a VECSEL", Photonics West (San Francisco, Jan 21-26, 2012) paper 8275-4.

17) D.V. Seletskiy, J. Trevino, S.D. Melgaard, M. Sheik-Bahae, "Novel photon blockade schemes for thermal link applications", Photonics West (San Francisco, Jan 21-26, 2012), paper 8275-17.

18) D.V. Seletskiy, S.D. Melgaard, Mansoor Sheik-Bahae, “Thermal imaging with high spatial and temperature resolution", Photonics West (San Francisco, Jan 21-26, 2012), paper 8275-11.

19) D.V. Seletskiy, C.-Y. Li, J.G. Cederberg, A. Katzenmeyer, E. Morales, F. Leonard, A. Talin, M. Sheik-Bahae, "Strong THz emission from low-energy acoustic-like surface plasmons in InAs nanowires", Photonics West (San Fran, Jan 21-26, 2012), paper 8260-12.

20) C.-Y. Li, D.V. Seletskiy, J.G. Cederberg, M. Sheik-Bahae, "Detection of ultrafast THz pulses via electro-absorption in coupled asymmetric quantum wells", Photonics West (San Francisco, Jan 21-26, 2012), paper 8260-21.

21) D. Seletskiy, M. Hasselbeck, C.-Y. Li, J. Cederberg, A. Katzenmeyer, M. Toimil-Molares, F. Leonard, A. Talin, M. SheikBahae,'Efficient THz Emission from the Acoustic Surface Plasmons in InAs Nanowires", Nonlinear Optics Meeting (Kauai, HI, Jul. 17-22 2011), paper NMC2.

22) Mansoor Sheik-Bahae, Denis Seletskiy, "Lasers Running in Reverse: Optical Refrigeration below NIST-Cryogenics", Nonlinear Optics Meeting (Kauai, HI, Jul. 17-22 2011), paper NME1.

23) D. Seletskiy, S. Melgaard, A. Di Lieto, M. Tonelli, M. Sheik-Bahae, “Cryogenic Optical Refrigeration”, 16th International Conference on Luminescence and Optical Spectroscopy of Condensed Matter (Ann Arbor, MI Jun. 27 - Jul. 12011 ), paper MG4.

24) S. Melgaard, D. Seletskiy, A. Di Lieto, M. Tonelli, M. Sheik-Bahae, "High Sensitivity Optical Refrigeration Spectroscopy: Local Cooling of Yb:YLF Crystal to 110 K”, QELS (Baltimore, MD May 1-6, 2011), paper QWI4.

25) D. Seletskiy, M. Hasselbeck, C.-Y Li, J. Cederberg, A. Katzenmeyer, M. Toimil-Molares, F. Leonard, A. Talin, M. SheikBahae, "THz Acoustic Plasmons in InAs Nanowires“, QELS (Baltimore, MD May 1-6, 2011) paper QWH1. 
26) M. Ghasemkhani, D. V. Seletskiy, M. Sheik-Bahae, "Sensitive thermal reflectance measurement for laser cooling applications", Photonics West (San Francisco, CA Jan. 22-27, 2011) paper 7951-18.

27) S. D. Melgaard, D. V. Seletskiy, A. Di Lieto, M. Tonelli, M. Sheik-Bahae, "Experimental evidence for laser cooling of Yb:YLF to 120 Kelvin", Photonics West (San Francisco, CA Jan. 22-27, 2011) paper 7951-4.

28) D. V. Seletskiy, R. I. Epstein, M. Sheik-Bahae, "Progress toward sub-100 Kelvin operation of an optical cryocooler", Photonics West (San Francisco, CA, 22-27 Jan. 2011) paper 7951-2.

Domestic

12) SEMINARS OR LECTURES DELIVERED AT UNIVERSITIES AND/OR INSTITUTES Include dates, names and locations of seminars.

“Optical Refrigeration: From Laboratory Curiosity to Efficient Cryocoolers”, AFRL, Kirtland AFB, NM (Jul. 2012)

13) PROFESSIONAL AWARDS RECEIVED DURING TENURE

National Science Foundation International Research Fellowship

14) POST-TENURE POSITION / JOB TITLE

Junior Group Leader

15) NAME AND ADDRESS OF POST-TENURE POSITION / JOB ORGANIZATION

Universität Konstanz, Fachbereich Physik/LS Leitenstorfer, Fach M 696, 78457 Konstanz, Deutschland

16) POST-TENURE POSITION STATUS / CATEGORY Please indicate only one.

Permanent position at the NRC host agency

Contract or temporary position at the NRC host Agency

Abbreviate Host Laboratory/Center

$\square$ Research/administration position in private industry in the U.S.

Research/Administrative position with another U.S.government agency

Research/Administrative position with a foreigngovernment agency

$\square$ Research/teaching position at a U.S. college or university

$\bigotimes$ Research/teaching position at a foreign college or university

Research/administration position in private industry outside of the U.S.

$\square$ Research/administration position with a non profit

$\square$ Self-employed/consulting

$\square$ Postdoctoral research

$\square$ Other (Please specify, possible)

$\square$ No information provided

17) APPRAISAL OF RESEARCH ASSOCIATESHIP PROGRAM

On a scale of 1 - 10 (poor - excellent), please rate the following:

SHORT TERM VALUE

10 Development of knowledge, skills, and research productivity

Comments

LONG TERM VALUE

10 How the NRC Associateship award affected your career to date Comments

\section{LAB SUPPORT}

9 Quality of support from the Laboratory--equipment, funding, orientation, safety and health guidelines, etc. Comments

It would be great if NRC could allocate some of the small equipment/lab supplies/ money for the researchers

\section{ADVISER/MENTOR SUPPORT}

10 Quality of mentoring from the Laboratory NRC Adviser (USMA Mentor, if applicable)

Comments

It was a pleasure working with Dr. Paul Le Van, he showed the right ammount of guidance as well as given freedom to pursue my own research ambitions.

\section{LPR SUPPORT}

10 Quality of administrative support from the Laboratory (e.g., NIST, NRL, IWR, FHWA) NRC Program $\underline{\text { Representative (LPR) }}$

Comments

Great support

\section{NRC SUPPORT}

10 Quality of administrative support. Please assess respective NRC aspects (e.g., moving company, insurance, Omega, payroll, coordinator, travel, etc.) 


\section{Comments}

Great support by all the staff members, especially Linda Sligh

18) PLEASE PROVIDE ANY SUGGESTIONS FOR PROGRAM IMPROVEMENT.

Please do NOT scan to PDF. Send the Final Report as MSWord document via e-mail to your NRC Program Coordinator

No handwritten signature required; but you may upload a scanned signature file below:
Asha Davis: $\quad$ adavis@nas.edu

Linda Sligh: $\quad$ lsligh@nas.edu

Jason Thornhill: jthornhill@nas.edu

Peggy Wilson: pwilson@nas.edu

Suzanne White: swhite@nas.edu
Proj/Act ID\# 
Advisers to the Nation on Science, Engineering, and Medicine

National Research Council

\section{Research Associateship Programs}

\section{FINAL REPORT}

1) Associate Last or Family Name

First Name

M.I.

Matthew

$\mathbf{L}$

Smith

2) FORWARDING Address (to which your tax statement will be mailed)

FORWARDING Phone(s) and E-Mail (if known)

Home Phone:

Residence or Institution

Alt. Phone:

Street

City, State Zip Holland, MI 49423

3) Today's Date

July 3, 2012

4) Host Agency

AFRL

Laboratory or Center

Wright Patterson AFB

(e.g., AFRL)

(e.g., Wright Patterson AFB)

Preferred E-mail: msmith@hope.edu

Dates of Tenure

from June 1, 2010

to June 30, 2012

Division / Directorate / Department

Materials and Manufacturing Directorate (e.g., High-Speed Propulsion)

5) Name of Laboratory NRC Adviser (and USMA Mentor, if applicable)

Richard A. Vaia

6) TITLE OF RESEARCH PROPOSAL

Mechanical quantification of model parameters during oscillation in catalytically active hydrogels

7) SUMMARY OF RESEARCH DURING TENURE Itemize significant findings in concise form, utilizing key concepts/words.

1) Created novel self-oscillating (BZ) gels based on the biomacromolecule gelatin and synthetic polymer p(AAm-co-APMA)

2) Developed chemistries for effectively postfunctionalizing these gels with a Ru metal catalyst

3) Charcterized chemical and mechanical behavior of BZ gelatin as a function of reactant concentration, gel size

4) Demonstrated gel printing and ink stamping techniques for effective patterning of catalyst, made first heterogeneous gels

5) Demonstrated conditions for synchronized, coupled oscillations between active patches, laid foundation for modular design (USMA Davies Fellow: please add summary of teaching, including classes taught.)

8) RESEARCH IN PROGRESS Describe in no more than 100 words.

Demonstrating effective stamping in p(AAm-co-APMA) gels. Will use mechanical design principles to demonstrate amplified nonlinear motion driven by autonomous coupled oscillations.

9) PUBLICATIONS AND PAPERS RESULTING FROM NRC ASSOCIATESHIP RESEARCH

Provide complete citations: author(s), title, full name of journal, volume number, page number(s), and year of publication.

a) Publications in peer-reviewed journals

1) M.L. Smith, K. Heitfeld, C. Slone, R.A. Vaia. Autonomic Hydrogels Through Postfunctionalization of Gelatin. Accepted Chem. Mater. 2012.

2) K.M. Lee, M.L. Smith, H. Koerner, N. Tabiryan, R.A. Vaia, T.J. Bunning, T.J. White, Photodriven, Flexural-Torsional

Oscillation of Glassy Azobenzene Liquid Crystal Polymer Networks. Adv. Func. Mater. 21(15):2913-2918, 2011

b) Books, book chapters, other publications

1) M.L. Smith, K. Heitfeld, M. Tchoul, R.A. Vaia. Chemical Wave Characterization of Self-Oscillating Gelatin and

Polyacrylamide Gels. Proceedings of SPIE, 7975, 79750A, 2011

2) R.A. Vaia, M.L. Smith, K. Heitfeld. New Biomimetic Gel Chemistries may Refine Device Designs. SPIE Newsroom,

2011, DOI: 10.1117/2.1201102.003514.

c) Manuscripts in preparation, manuscripts submitted

1) M.L. Smith, C. Slone, K. Heitfeld, R.A. Vaia. Design and Fabrication of Composite Natural Gels with Autonomic Response. In Preparation.

2) H. Koerner, R. Strong, M.L. Smith, H. Wang, L.-S. Tan, K.M. Lee, T. White, R.A. Vaia. Polymer Design for High Temperature Shape Memory: Low Crosslink Density Polyimides. Submitted, 2012.

3) M. L. Smith, K. M. Lee, R. A. Vaia, T. J. White. Optical polarization and material alignment coupled deformations in anisotropic, photoresponsive liquid-crystal polymer cantilevers. In Preparation. 
10) PATENT OR COPYRIGHT APPLICATIONS RESULTING FROM NRC ASSOCIATESHIP RESEARCH

Provide titles, inventors, and dates of applications.

11) PRESENTATIONS AT SCIENTIFIC MEETINGS OR CONFERENCES

Provide complete references: author(s), title, abstract/proceeding citation, meeting name and location.

International

Domestic

1) M. L. Smith, C. Slone, K. Heitfeld, R. A. Vaia, “Hybrid BioGels: Amplification and Synchronicity through Composite Design." US-Japan Workshop on Advances in Organic/Inorganic Hybrid Materials, Ann Arbor, Michigan, May 2012 (poster).

2) M. L. Smith, C. Slone, K. Heitfeld, R. Kramb, R. A. Vaia, “'Coupling Chemomechanical Oscillators: Patterning BZ Hydrogels." Materials Research Society Fall Meeting, Boston, Massachusetts, December 2011 (oral presentation). 3) M. L. Smith, K. M. Lee, H. Koerner, R. A. Vaia, T. J. Bunnung, T. J. White, "'Tuning the Photoinduced Motion of Azobenzene Liquid Crystal Polymer Cantilevers." ASME Applied Mechanics and Materials Conference, Chicago, Illinois, May 2011 (oral presentation).

4) M. L. Smith, K. Heitfeld, R. Kramb, M. Tchoul, D. Gallagher, R. Vaia, “Chemomechanical Characterization of Autonomic Polyacrylamide Gels," American Physical Society March Meeting, Dallas, Texas, March 2011 (oral presentation).

12) SEMINARS OR LECTURES DELIVERED AT UNIVERSITIES AND/OR INSTITUTES Include dates, names and locations of seminars.

1) January 2012, Photoresponsive and Self-Oscillating Materials: Creating Building Blocks for Adaptive Structures, Washington and Lee University, Virginia.

2) February 2012, Photoresponsive and Self-Oscillating Materials: Creating Building Blocks for Adaptive Structures, Hope College, Michigan.

13) PROFESSIONAL AWARDS RECEIVED DURING TENURE

14) POST-TENURE POSITION / JOB TITLE

Assistant Professor of Engineering

15) NAME AND ADDRESS OF POST-TENURE POSITION / JOB ORGANIZATION

Hope College, 27 Graves Place, Holland, MI 49423

16) POST-TENURE POSITION STATUS / CATEGORY Please indicate only one.

Permanent position at the NRC host agency

Contract or temporary position at the NRC host Agency

Abbreviate Host Laboratory/Center

Research/Administrative position with another U.S.government agency

Research/Administrative position with a foreigngovernment agency

$\bigotimes$ Research/teaching position at a U.S. college or university

Research/teaching position at a foreign college or university

$\square$ Research/administration position in private industry in the U.S.

$\square$ Research/administration position in private industry outside of the U.S.

$\square$ Research/administration position with a non profit

$\square$ Self-employed/consulting

$\square$ Postdoctoral research

$\square$ Other (Please specify, possible)

$\square$ No information provided

17) APPRAISAL OF RESEARCH ASSOCIATESHIP PROGRAM

On a scale of 1 - 10 (poor - excellent), please rate the following:

SHORT TERM VALUE

10 Development of knowledge, skills, and research productivity Comments

\section{LONG TERM VALUE}

10 How the NRC Associateship award affected your career to date Comments

\section{LAB SUPPORT}

10 Quality of support from the Laboratory--equipment, funding, orientation, safety and health guidelines, etc. 


\section{Comments}

\section{ADVISER/MENTOR SUPPORT}

10 Quality of mentoring from the Laboratory NRC Adviser (USMA Mentor, if applicable) Comments

\section{LPR SUPPORT}

10 Quality of administrative support from the Laboratory (e.g., NIST, NRL, IWR, FHWA) NRC Program $\underline{\text { Representative (LPR) }}$ Comments

\section{NRC SUPPORT}

10 Quality of administrative support. Please assess respective NRC aspects (e.g., moving company, insurance, Omega, payroll, coordinator, travel, etc.)

\section{Comments}

18) PLEASE PROVIDE ANY SUGGESTIONS FOR PROGRAM IMPROVEMENT.

I was extremely satisfied with my time as an NRC Associate, this has been an exceptional opportunity for me for career growth. Overall $I$ think the program is in a good position.

Please do NOT scan to PDF. Send the Final Report as MSWord document via e-mail to your NRC Program Coordinator

No handwritten signature required;

but you may upload a scanned signature file below:
Asha Davis:

Linda Sligh:

Jason Thornhill: jthornhill@nas.edu

Peggy Wilson:

Suzanne White: adavis@nas.edu

lsligh@nas.edu

pwilson@nas.edu

swhite@nas.edu

Rev. July 2011

Proj/Act ID\# 
Advisers to the Nation on Science, Engineering, and Medicine

National Research Council

\section{Research Associateship Programs}

\section{FINAL REPORT}

1) Associate Last or Family Name

First Name

M.I.

Voccola

2) FORWARDING Address (to which your tax statement will be mailed)

Kaitlyn

$\mathbf{E}$

Residence or Institution

Street

City, State Zip Fort Collins, CO 80525

3) Today's Date

September 14, 2012

4) Host Agency

AFRL

(e.g., AFRL)

5) Name of Laboratory NRC Adviser (and USMA Mentor, if applicable)

Muralidhar Rangaswamy

6) TITLE OF RESEARCH PROPOSAL

Polarimetric Synthetic-Aperture Radar Correlation Imaging

7) SUMMARY OF RESEARCH DURING TENURE Itemize significant findings in concise form, utilizing key concepts/words.

1) For a polarimetric SAR system consisting of orthogonally polarized dipoles, we found a way to circumvent the standard assumption/approximation that the polarization properties of the transmitted waves remain constant throughout the flight trajectory

2) Completed numerical experiments comparing current polarimetric SAR imaging with our coupled polarimetric imaging approach for extended targets in clutter and found that it improved image signal-to-clutter ratio and mean-squared error.

3) Developed forward model and imaging operator for a correlation based SAR imaging technique for targets and volume scattering clutter. Developed resolution analysis for the imaging scheme and found improvements over standard imaging.

4) Created a clutter minimization technique based on avoiding certain pairs of correlated data which requires no knowledge of the clutter present in the scene of interest

5) Developed MATLAB code to simulate correlated SAR data and implement the correlation imaging scheme. It was found that clutter mitigation was successful for a variety of targets and for a variety of antenna trajectories.

(USMA Davies Fellow: please add summary of teaching, including classes taught.)

In addition I mentored two summer students in the lab on two separate research projects. One on extending my polarimetric imaging scheme for more complicated targets and a second on developing Cramer-Rao type bounds for bounded estimators.

\section{8) RESEARCH IN PROGRESS Describe in no more than 100 words.}

Currently I am finishing the proof to analytically show why my imaging technique minimizes clutter effects on the image. I am preparing a manuscript to submit to SIAM Journal on Imaging Sciences for the end of the month. After the proof is finished for standard SAR imaging I am working on generalizing the result for polarimetric SAR imaging. In addition during my tenure I developed a second technique for estimating the correlation or covariance matrix of a scene of interest using reproducing kernel Hilbert space techniques. I will compare this technique with the first method developed during my tenure at the lab.

9) PUBLICATIONS AND PAPERS RESULTING FROM NRC ASSOCIATESHIP RESEARCH

Provide complete citations: author(s), title, full name of journal, volume number, page number(s), and year of publication.

a) Publications in peer-reviewed journals

K. Voccola, M. Cheney, B. Yazici, "Polarimetric SAR Imaging for Extended Targets in Clutter," IEEE Radar Conference 2012, pp: 281 - 286, 2012.

b) Books, book chapters, other publications

c) Manuscripts in preparation, manuscripts submitted 
K. Voccola, M. Cheney, B. Yazici, "Polarimetric Synthetic-Aperture Imaging for Extended Targets in Clutter, " invited paper, to appear in Inverse Problems Special Issue on Radar Imaging, submitted May 2012.

K. Voccola, "Synthetic-Aperture Correlation Imaging," in preparation for SIAM Journal on Imaging Sciences, September 2012.

10) PATENT OR COPYRIGHT APPLICATIONS RESULTING FROM NRC ASSOCIATESHIP RESEARCH

Provide titles, inventors, and dates of applications.

11) PRESENTATIONS AT SCIENTIFIC MEETINGS OR CONFERENCES

Provide complete references: author(s), title, abstract/proceeding citation, meeting name and location.

International

Domestic

K. Voccola, M. Cheney, and B. Yazici, "Polarimetirc Synthetic-Aperture Imaging for Extended Targets in Clutter," AFOSR Electromagnetics Contractors Meeting, San Antonio, TX

K. Voccola, M. Cheney, and B. Yazici, "Polarimetirc Synthetic-Aperture Imaging for Extended Targets in Clutter," February Fourier Talks, University of Maryland, College Park, MD.

K. Voccola, M. Cheney, and B. Yazici, "Polarimetirc SAR Imaging for Extended Targets in Clutter," IEEE Radar Conference, Atlanta, GA.

K. Voccola, M. Cheney, and B. Yazici, "Polarimetirc Synthetic-Aperture Imaging for Extended Targets in Clutter," SIAM Conference on Imaging Sciences, Philadelphia, PA.

12) SEMINARS OR LECTURES DELIVERED AT UNIVERSITIES AND/OR INSTITUTES Include dates, names and locations of seminars.

K. Voccola, "Polarimetric and Correlation Synthetic Aperture Radar Imaging," AFRL RYAP Technical Seminar, WrightPatterson Air Force Base, Ohio.

13) PROFESSIONAL AWARDS RECEIVED DURING TENURE

14) POST-TENURE POSITION / JOB TITLE

Postdoctoral Research Fellow

15) NAME AND ADDRESS OF POST-TENURE POSITION / JOB ORGANIZATION

Department of Mathematics, Colorado State University, 101 Weber Building, CSU, Fort Collins, CO 80523-1874

16) POST-TENURE POSITION STATUS / CATEGORY Please indicate only one.

Permanent position at the NRC host agency

Contract or temporary position at the NRC host Agency

Abbreviate Host Laboratory/Center

Research/Administrative position with another U.S.government agency

Research/Administrative position with a foreigngovernment agency

$\bigotimes$ Research/teaching position at a U.S. college or university

Research/teaching position at a foreign college or university $\square$ Research/administration position in private industry in the U.S.

Research/administration position in private industry outside of the U.S.

$\square$ Research/administration position with a non profit

Self-employed/consulting

Postdoctoral research

$\square$ Other (Please specify, possible)

No information provided

17) APPRAISAL OF RESEARCH ASSOCIATESHIP PROGRAM

On a scale of 1 - 10 (poor - excellent), please rate the following:

SHORT TERM VALUE

10 Development of knowledge, skills, and research productivity

Comments

The associateship gave me the opportunity to spend focused time on gaining knowledge in my research area and allowed me to get my thesis work published quickly. It is so helpful for a young scientist to have this time post grad school to get settled as a researcher without other responsibilities to distract from our intellectual development.

LONG TERM VALUE

10 How the NRC Associateship award affected your career to date Comments 
The Associateship gave me a chance to travel to many conferences and network with many in my field. It also gave me the ability to consider and see first hand certain career possibilities. In addition I was able to try my hand at mentoring at the lab during the summer which helped me to decide to continue in academia and work with students.

LAB SUPPORT

8 Quality of support from the Laboratory--equipment, funding, orientation, safety and health guidelines, etc.

Comments

The lab has a lack of MATLAB licenses which affected my ability to start my numerical experiments in a timely manner, this is a general lab issue though, not specific to myself and my situation.

\section{ADVISER/MENTOR SUPPORT}

9 Quality of mentoring from the Laboratory NRC Adviser (USMA Mentor, if applicable)

Comments

Dr. Rangaswamy was very helpful in sharing his knowledge of radar and general career development advice. There was a mismatch between our interests but this was expected as he was not the original mentor I applied to work with.

\section{LPR SUPPORT}

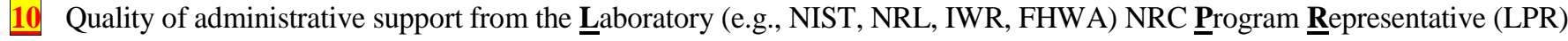
Comments

Also Sam Rosengarten and Joanne Maurice at AFRL were very helpful.

\section{NRC SUPPORT}

10 Quality of administrative support. Please assess respective NRC aspects (e.g., moving company, insurance, Omega, payroll, coordinator, travel, etc.)

\section{Comments}

Linda was great at answering my questions quickly and in a helpful manner. Everything was easy to figure out and it made the move very simple.

18) PLEASE PROVIDE ANY SUGGESTIONS FOR PROGRAM IMPROVEMENT.

Please do NOT scan to PDF. Send the Final Report as MSWord document via e-mail to your NRC Program Coordinator

No handwritten signature required; but you may upload a scanned signature file below:
Asha Davis:

Linda Sligh:

Jason Thornhill: jthornhill@nas.edu

Peggy Wilson: pwilson@nas.edu

Suzanne White: swhite@nas.edu 
Advisers to the Nation on Science, Engineering, and Medicine

National Research Council

Research Associateship Programs

FINAL REPORT

1) Associate Last or Family Name

First Name

WANG

2) FORWARDING Address (to which your tax statement will be mailed)

PENG

Residence or Institution

Street

City, State Zip Wilmington, DE 19809

3) Today's Date

July 25, 2012

4) Host Agency

AFRL

Laboratory or Center

ROME

(e.g., AFRL)

(e.g., Wright Patterson AFB)

FORWARDING Phone(s) and E-Mail (if known)

Home Phone:

Alt. Phone:

Preferred E-mail: wpyr2001@yahoo.com

Dates of Tenure

from October 1, 2009

to August 3, 2012

Division / Directorate / Department

INFORMATION

(e.g., High-Speed Propulsion)

5) Name of Laboratory NRC Adviser (and USMA Mentor, if applicable)

Michael Medley

6) TITLE OF RESEARCH PROPOSAL

Joint Spectrum Allocation and Scheduling in Multi-Radio Multi-Channel Cognitive Radio Wireless Networks; Throughput

Optimization for Cognitive Radio Network with Slowly Varying Channels

7) SUMMARY OF RESEARCH DURING TENURE Itemize significant findings in concise form, utilizing key concepts/words.

1) Throughput Optimization for Cognitive Radio Networks with Multi-Radio Multi-Channel: Extends the optimal scheduling algorithm developed in $\mathrm{my} \mathrm{PhD}$ thesis to solve the joint spectrum allocation and scheduling problem and obtains the optimal solution.

2) Capacity Optimization of MIMO Links with Interference: Derives the approximate theoretical capacity formula for MIMO links with interference through SVD. An Integer Programming algorithm is proposed to solve the capacity problem.

3) Resource Allocation in MIMO-based Ad Hoc Networks: Solves the problem of joint routing, scheduling, power control and bit rate selection with the goal of maximizing the system throughput that satisfies the given end-to-end traffic demands.

4) Throughput Optimization of Cognitive Radio Networks: The optimal solution provides a theoretical upper bound of throughput for cognitive radio networks. Also, derives a theoretical upper bound when greedy solution is used to solve the MWIS problem.

5) Throughput Optimization for Cognitive Radio Network with Slowly Varying Channels: Study the effect of aggregate delay; compare the optimal solution and the approximation solution, the centralized solution and distributed solution.

(USMA Davies Fellow: please add summary of teaching, including classes taught.)

8) RESEARCH IN PROGRESS Describe in no more than 100 words.

The proposed projects have been finished. Now we are working on the test bed development of cognitive radio network. We are interested in implementing a Frequency Hopping system (i.e. Bluetooth) with GNU Radio and USRP. We modify the hardware through FPGA programming to achieve two goals. One is the frequency hopping mechanism which has been finished. The second one is to implement a time slot transmit protocol where each packet is transmitted at the beginning of each time slot. Currently we are working on the second part which can be done soon.

\section{9) PUBLICATIONS AND PAPERS RESULTING FROM NRC ASSOCIATESHIP RESEARCH}

Provide complete citations: author(s), title, full name of journal, volume number, page number(s), and year of publication.

a) Publications in peer-reviewed journals

b) Books, book chapters, other publications

- Peng Wang, John Matyjas and Michael Medley. Throughput Optimization of Cognitive Radio Networks. Globecom 2011 (Houseton, TX).

- Peng Wang, John Matyjas and Michael Medley. Resource Allocation in MIMO-based Ad Hoc Networks. CISS 2011

(Baltimore, MD).

- Peng Wang, John Matyjas and Michael Medley. Capacity Optimization of MIMO Links with Interference. IEEE ICC

2011 (Kyoto, Japan). 
- Peng Wang, John Matyjas and Michael Medley. Joint Spectrum Allocation and Scheduling in Multi-Radio Multi-

Channel Cognitive Radio Wireless Networks. IEEE Sarnoff 2010 (Princeton 2010).

c) Manuscripts in preparation, manuscripts submitted

- Peng Wang, John Matyjas and Michael Medley. Performance Analysis of Greedy Suboptimal Solution for POMDP based OSA in Cognitive Radio Networks. (in preparation).

10) PATENT OR COPYRIGHT APPLICATIONS RESULTING FROM NRC ASSOCIATESHIP RESEARCH

Provide titles, inventors, and dates of applications.

11) PRESENTATIONS AT SCIENTIFIC MEETINGS OR CONFERENCES

Provide complete references: author(s), title, abstract/proceeding citation, meeting name and location.

International

- Peng Wang, John Matyjas and Michael Medley. Capacity Optimization of MIMO Links with Interference. IEEE ICC 2011 (Kyoto, Japan).

Domestic

- Peng Wang, John Matyjas and Michael Medley. Throughput Optimization of Cognitive Radio Networks. Globecom 2011 (Houseton, TX).

- Peng Wang, John Matyjas and Michael Medley. Resource Allocation in MIMO-based Ad Hoc Networks. CISS 2011

(Baltimore, MD).

- Peng Wang, John Matyjas and Michael Medley. Joint Spectrum Allocation and Scheduling in Multi-Radio Multi-Channel Cognitive Radio Wireless Networks. IEEE Sarnoff 2010 (Princeton 2010).

12) SEMINARS OR LECTURES DELIVERED AT UNIVERSITIES AND/OR INSTITUTES Include dates, names and locations of seminars.

13) PROFESSIONAL AWARDS RECEIVED DURING TENURE

14) POST-TENURE POSITION / JOB TITLE

Research Associate

15) NAME AND ADDRESS OF POST-TENURE POSITION / JOB ORGANIZATION

Army Reseach Lab, Aberdeen Proving Ground, MD

16) POST-TENURE POSITION STATUS / CATEGORY Please indicate only one.

Permanent position at the NRC host agency

Contract or temporary position at the NRC host Agency

Abbreviate Host Laboratory/Center

Research/Administrative position with another U.S.government agency

$\square$ Research/Administrative position with a foreigngovernment agency

$\square$ Research/teaching position at a U.S. college or university

$\square$ Research/teaching position at a foreign college or university

17) APPRAISAL OF RESEARCH ASSOCIATESHIP PROGRAM

On a scale of 1 - 10 (poor - excellent), please rate the following:

SHORT TERM VALUE

8 Development of knowledge, skills, and research productivity

Comments

Cooperate with senior researchers to publish and present papers in conferences, and do projects to improve the skills of software and hardware.

LONG TERM VALUE

8. How the NRC Associateship award affected your career to date

Comments

Research experiences provided by NRC program are helpful in finding a position in DOD industry. 
8 Quality of support from the Laboratory--equipment, funding, orientation, safety and health guidelines, etc.

Comments

Lab provides the required equipments, safe and confortable working environment, and a pretty good library.

ADVISER/MENTOR SUPPORT

9 Quality of mentoring from the Laboratory NRC Adviser (USMA Mentor, if applicable)

Comments

Adviser provides helpful suggestions, and discuss the research with me frequently.

LPR SUPPORT

8 Quality of administrative support from the Laboratory (e.g., NIST, NRL, IWR, FHWA) NRC Program $\underline{\text { Representative (LPR) }}$

Comments

LPR signes the documents in time.

NRC SUPPORT

8 Quality of administrative support. Please assess respective NRC aspects (e.g., moving company, insurance, Omega, payroll, coordinator, travel, etc.)

Comments

NRC processes my travel authorization form and travel reinburse request in time, and answers my questions patiently.

18) PLEASE PROVIDE ANY SUGGESTIONS FOR PROGRAM IMPROVEMENT.

Please do NOT scan to PDF. Send the Final Report as MSWord document via e-mail to your NRC Program Coordinator No handwritten signature required; $\quad$ Asha Davis: $\quad$ adavis@nas.edu

but you may upload a scanned signature file below:

Linda Sligh: $\quad$ Isligh@nas.edu

Jason Thornhill: jithornhill@nas.edu

Peggy Wilson: pwilson@nas.edu

Suzanne White: swhite@nas.edu

Rev. July 2011

Proj/Act ID\# 
Advisers to the Nation on Science, Engineering, and Medicine

National Research Council

\section{Research Associateship Programs}

\section{FINAL REPORT}

1) Associate Last or Family Name

First Name

Wu

2) FORWARDING Address (to which your tax statement will be mailed)

Thomas Xinzhang

Residence or Institution

FORWARDING Phone(s) and E-Mail (if known)

Home Phone:

Street

City, State Zip Oviedo, FL 32765

3) Today's Date

August 14, 2012

4) Host Agency

AFRL

(e.g., AFRL)

5) Name of Laboratory NRC Adviser (and USMA Mentor, if applicable)

Dr. Kerk Yerkes

6) TITLE OF RESEARCH PROPOSAL

Advanced Modeling of Aircraft Synchronous Generator System

7) SUMMARY OF RESEARCH DURING TENURE Itemize significant findings in concise form, utilizing key concepts/words.

1) Investigated design methodologies for aircraft synchronous generator, including main machine, exciter and pilot exciter;

2) Developed linear and nonlinear electrical models for aircraft sunchronous generator;

3) Developed lumped element thermal and mechanical models for aircraft synchronous generaor;

4) Updated nonlinear electromechanical actuator model;

5) Started to work on generator testing.

(USMA Davies Fellow: please add summary of teaching, including classes taught.)

\section{8) RESEARCH IN PROGRESS Describe in no more than 100 words.}

The design and modeling methodologies for the three-stack aircraft synchronous generator have been developed. The design for the main machine and exciter uses the expansion of the inverse air-gap function to tailor the salient-pole rotor appropriately. Both linear and nonlinear electric modeling techniques have been introduced. The nonlinear modeling incorporates finite-element method and neural networks to provide a more realistic depiction of machine performance. Using these design and modeling methodologies, we have developed a preliminary electrical model for a F-16 generator, which is a three-stack, $40 \mathrm{kVA}, 12 \mathrm{krpm}$ design. Initial etest plans for validation of the models was introduced. Design of experiment and statistical model development as a cross-validation will be incorporated intofuture efforts to develop a functional, accurate electrical, thermal and mechanical models of the F-16 generator.

9) PUBLICATIONS AND PAPERS RESULTING FROM NRC ASSOCIATESHIP RESEARCH

Provide complete citations: author(s), title, full name of journal, volume number, page number(s), and year of publication.

a) Publications in peer-reviewed journals

b) Books, book chapters, other publications

c) Manuscripts in preparation, manuscripts submitted

N. Posey, T. Wu, J. Zumberge, and M. Wolff, "Modeling and Control Scheme Design of a Solenoid-Actuated Fuel Injection System", to be submitted to AIAA Journal of Propulsion and Power.

10) PATENT OR COPYRIGHT APPLICATIONS RESULTING FROM NRC ASSOCIATESHIP RESEARCH

Provide titles, inventors, and dates of applications. 
11) PRESENTATIONS AT SCIENTIFIC MEETINGS OR CONFERENCES

Provide complete references: author(s), title, abstract/proceeding citation, meeting name and location.

International

A. Camarano, T. Wu, J. Zumberge and M. Wolff, "Design and Modeling of a Five Phase Synchronous Generator with High Power Density ", to appear at the IEEE ECCE, Sep. 15-20, Raleigh, NC, 2012.

A. Camarano, T. Wu, J. Zumberge and M. Wolff, "Nonlinear Neural Network Modeling of an Aircraft Synchronous Generator with High Power-Density", to appear at the SAE Power Systems Conference, Oct. 30 - Nov. 1 , Phoenix, AZ, 2012.

Domestic

N. Posey, T. Wu, J. Zumberge and M. Wolff, "Modeling and Control Scheme Design of a Solenoid-Actuated Fuel Injection System", presented at the 2012 IEEE National Aerospace and Electronics Conference (NAECON), Dayton, OH, July 25- 27, 2012.

12) SEMINARS OR LECTURES DELIVERED AT UNIVERSITIES AND/OR INSTITUTES Include dates, names and locations of seminars.

From June 15 to Aug. 14, I was invited to teach a 40 hour summer course on Advanced Electric Machinery at Wright State University arranged by AFRL. The course materials are highly related to my NRC research work.

13) PROFESSIONAL AWARDS RECEIVED DURING TENURE

14) POST-TENURE POSITION / JOB TITLE

Professor

15) NAME AND ADDRESS OF POST-TENURE POSITION / JOB ORGANIZATION

Department of Electrical Engineering and Computer Science, University of Central Florida

16) POST-TENURE POSITION STATUS / CATEGORY Please indicate only one.

Permanent position at the NRC host agency

Contract or temporary position at the NRC host Agency

Abbreviate Host Laboratory/Center

Research/Administrative position with another U.S.government agency

Research/Administrative position with a foreigngovernment agency

$\bigotimes$ Research/teaching position at a U.S. college or university

Research/teaching position at a foreign college or university $\square$ Research/administration position in private industry in the U.S.

$\square$ Research/administration position in private industry outside of the U.S.

$\square$ Research/administration position with a non profit

$\square$ Self-employed/consulting

$\square$ Postdoctoral research

$\square$ Other (Please specify, possible)

$\square$ No information provided

17) APPRAISAL OF RESEARCH ASSOCIATESHIP PROGRAM

On a scale of 1 - 10 (poor - excellent), please rate the following:

SHORT TERM VALUE

9 Development of knowledge, skills, and research productivity Comments

\section{LONG TERM VALUE}

10 How the NRC Associateship award affected your career to date Comments

\section{LAB SUPPORT}

9 Quality of support from the Laboratory--equipment, funding, orientation, safety and health guidelines, etc. Comments

\section{ADVISER/MENTOR SUPPORT}

10 Quality of mentoring from the Laboratory NRC Adviser (USMA Mentor, if applicable) Comments

\section{LPR SUPPORT}

10 Quality of administrative support from the Laboratory (e.g., NIST, NRL, IWR, FHWA) NRC $\underline{\text { Program }} \underline{\text { Representative (LPR) }}$ Comments 


\section{NRC SUPPORT}

10 Quality of administrative support. Please assess respective NRC aspects (e.g., moving company, insurance, Omega, payroll, coordinator, travel, etc.)

\section{Comments}

18) PLEASE PROVIDE ANY SUGGESTIONS FOR PROGRAM IMPROVEMENT.

I am glad to be reviewer for future NRC programs.

Please do NOT scan to PDF. Send the Final Report as MSWord document via e-mail to your NRC Program Coordinator No handwritten signature required;

but you may upload a scanned Asha Davis:

Linda Sligh: adavis@nas.edu

signature file below:

Jason Thornhill: jthornhill@nas.edu

Peggy Wilson: pwilson@nas.edu

Thomas $W u$

Suzanne White: swhite@nas.edu 
Advisers to the Nation on Science, Engineering, and Medicine

National Research Council

\section{Research Associateship Programs}

\section{FINAL REPORT}

1) Associate Last or Family Name

First Name

M.I.

Yang

2) FORWARDING Address (to which your tax statement will be mailed)

Chi

Residence or Institution Residence

Street 6952 Carmelito Loop NE

City, State Zip Albuquerque, NM 87113

3) Today's Date

June 20, 2012

4) Host Agency

AFRL

(e.g., AFRL)

5) Name of Laboratory NRC Adviser (and USMA Mentor, if applicable)

Ron Kaspi

6) TITLE OF RESEARCH PROPOSAL

Improved Hole Confinement in GaSb-Based Type-I Multi Quantum Well (MQW) Diode Lasers for >3 um Emission

7) SUMMARY OF RESEARCH DURING TENURE Itemize significant findings in concise form, utilizing key concepts/words.

1) Developed optically pumped mid-infrared in-plane DBR semiconductor lasers, reached the record power of $3 \mathrm{~W}$ in a $7 \mathrm{~nm}$ spectral range.

2) Realized the first unstable resonator diode laser at $2 \mu \mathrm{m}$ wavelength as precursor to unstable resonator quantum cascade lasers.

3)

4)

5)

(USMA Davies Fellow: please add summary of teaching, including classes taught.)

8) RESEARCH IN PROGRESS Describe in no more than 100 words.

We are developing strategies to extract high brightness from broad-area interband diodes and quantum cascade lasers (QCLs) emitting in the mid-infrared. The method is to use Focused Ion Beam (FIB) milling to generate fabricate cylindrical mirrors to form on-chip unstable resonator cavity geometries.

9) PUBLICATIONS AND PAPERS RESULTING FROM NRC ASSOCIATESHIP RESEARCH

Provide complete citations: author(s), title, full name of journal, volume number, page number(s), and year of publication.

a) Publications in peer-reviewed journals

C. Yang, R. Kaspi, M. L. Tilton, G. C. Dente, J. R. Chavez, A. P. Ongstad. Optically pumped mid-infrared in-plane DBR lasers. Optics Express, 20, 10833-10838, 2012.

R. Kaspi, M. L. Tilton, G. C. Dente, R. Barresi, C. Yang, A. P. Ongstad,. Intersubband photoluminescence in InAs quantum wells, Applied Physics Letters, 97, 201104-201106, 2010.

b) Books, book chapters, other publications

c) Manuscripts in preparation, manuscripts submitted

10) PATENT OR COPYRIGHT APPLICATIONS RESULTING FROM NRC ASSOCIATESHIP RESEARCH

Provide titles, inventors, and dates of applications.

Provide complete references: author(s), title, abstract/proceeding citation, meeting name and location. 
International

Domestic

C. Yang, M. L. Tilton, R. Kapsi, G. C. Dente, A. P. Ongstad. Intersubband photoluminescence in InAs quantum wells. In Photonics West, 2012.

C. Yang, R. Kapsi, M. L. Tilton, G. C. Dente, J. R. Chavez, A. P. Ongstad. Optically pump mid-infrared surface-DBR laser. In Photonics West, 2012.

C. Yang, R. Kaspi, G. C. Dente, M. L. Tilton, J. R. Chavez, A. P. Ongstad. High power mid-infrared in-plane DBR lasers. In Conference on Lasers and Electro-Optics Society, 2011.

12) SEMINARS OR LECTURES DELIVERED AT UNIVERSITIES AND/OR INSTITUTES Include dates, names and locations of seminars.

13) PROFESSIONAL AWARDS RECEIVED DURING TENURE

14) POST-TENURE POSITION / JOB TITLE

Research Assistant Professor

15) NAME AND ADDRESS OF POST-TENURE POSITION / JOB ORGANIZATION

University of New Mexico

16) POST-TENURE POSITION STATUS / CATEGORY Please indicate only one.

Permanent position at the NRC host agency

Contract or temporary position at the NRC host Agency

Abbreviate Host Laboratory/Center AFRL

Research/Administrative position with another U.S.government agency

Research/Administrative position with a foreigngovernment agency

$\bigotimes$ Research/teaching position at a U.S. college or university

Research/teaching position at a foreign college or university $\square$ Research/administration position in private industry in the U.S. Research/administration position in private industry outside of the U.S.

Research/administration position with a non profit

$\square$ Self-employed/consulting

$\square$ Postdoctoral research

$\square$ Other (Please specify, possible)

$\square$ No information provided

17) APPRAISAL OF RESEARCH ASSOCIATESHIP PROGRAM

On a scale of 1 - 10 (poor - excellent), please rate the following:

SHORT TERM VALUE

9 Development of knowledge, skills, and research productivity Comments

LONG TERM VALUE

9 How the NRC Associateship award affected your career to date Comments

\section{LAB SUPPORT}

9 Quality of support from the Laboratory--equipment, funding, orientation, safety and health guidelines, etc. Comments

\section{ADVISER/MENTOR SUPPORT}

10 Quality of mentoring from the Laboratory NRC Adviser (USMA Mentor, if applicable)

Comments

LPR SUPPORT

8 Quality of administrative support from the Laboratory (e.g., NIST, NRL, IWR, FHWA) NRC Program $\underline{\text { Representative (LPR) }}$ Comments

\section{NRC SUPPORT}

9 Quality of administrative support. Please assess respective NRC aspects (e.g., moving company, insurance, Omega, payroll, coordinator, travel, etc.) 


\section{Comments}

18) PLEASE PROVIDE ANY SUGGESTIONS FOR PROGRAM IMPROVEMENT.

Please do NOT scan to PDF. Send the Final Report as MSWord document via e-mail to your NRC Program Coordinator No handwritten signature required; but you may upload a scanned Asha Davis: adavis@nas.edu signature file below:

Linda Sligh: Isligh@nas.edu

Jason Thornhill: jthornhill@nas.edu

Peggy Wilson: pwilson@nas.edu

Suzanne White: swhite@ nas.edu 
Advisers to the Nation on Science, Engineering, and Medicine

National Research Council

FINAL REPORT

1) Associate Last or Family Name

Yen

2) FORWARDING Address (to which your tax statement will be mailed)

Residence or Institution Residence Street

Laboratory or Center Wright Patterson AFB

(e.g., Wright Patterson AFB)

AFRL

(e.g., AFRL)

Name of Laboratory NRC Adviser (and USMA Mentor, if applieable)

Dr. Michael Durstock

TITLE OF RESEARCH PROPOSAL

Plasmonic Enhancement of Organic Photovoltaics
First Name

tyhitatoinCambridge, MA 02138

3) Today's Date

September 11, 2012

4) Host Agency [ Division/Directorate / Department

Materials and Manufacturing

(e.g., High-Speed Propulsion)

SUMMARY OF RESEARCH DURING TENURE Itemize significant findings in concise form, utilizing key concepts/words.

1) Introducing Gold Nanoparticles into PEDOT:PSS Layer

2) Introducing Gold Nanoparticles into Active Layer

3) Modifying the metallic electrode/active layer interface through nano-imprint patterning

4)

5)

JSMA Davies Fellow: please add summary of teaching, including classes taught.)

RESEARCH IN PROGRESS Describe in no more than 100 words.

Polymer-based organic photovoltaic systems hold promise for a low-cost, light-weight alternative renewable energy. To date, organic bulk heterojunction solar cells show power conversion efficiencies up to $8.6 \%$. Recently, the exploitation of surface plasmon resonance effects, based on advantageous optical properties such as light concentration and scattering, has attracted much attention for increasing the photocurrent generation of organic solar cells. Surface plasmon is localized by noble metallic nanoparticles, such as $\mathrm{Au}, \mathrm{Ag}$, and $\mathrm{Cu}$, resulting in highly localized and intense fields. We are seeking methods to incorporate gold nanoparticles into organic solar cells and then improve its light-to-electric conversion efficiency. We have been successfully transferred metllaic nanoparticles into organic device (proven by TEM) and monitored a 30\% efficiency enhancement.

\section{PUBLICATIONS AND PAPERS RESULTING FROM NRC ASSOCIATESHIP RESEARCH}

Provide complete citations: author(s), title, full name of journal, volume number, page number(s), and year of publication.

a) Publications in peer-reviewed journals

b) Books, book chapters, other publications

c) Manuscripts in preparation, manuscripts submitted

0) PATENT OR COPYRIGHT APPLICATIONS RESULTING FROM NRC ASSOCIATESHIP RESEARCH

Provide titles, inventors, and dates of applications.

1) PRESENTATIONS AT SCIENTIFIC MEETINGS OR CONFERENCES

Provide complete references: author(s), title, abstract/proceeding citation, meeting name and location. 
International

Domestic

12) SEMINARS OR LECTURES DELIVERED AT UNIVERSITIES AND/OR INSTITUTES Include dates, names and locations of seminars.

13) PROFESSIONAL AWARDS RECEIVED DURING TENURE

Best Ph.D Thesis Award, Sigma Xi Society

14) POST-TENURE POSITION / JOB TITLE

15) NAME AND ADDRESS OF POST-TENURE POSITION / JOB ORGANIZATION

16) POST-TENURE POSITION STATUS / CATEGORY Please indicate only one.

Permanent position at the NRC host agency

Contract or temporary position at the NRC host Agency

Abbreviate Host Laboratory/Center

Research/Administrative position with another U.S.government agency

Research/Administrative position with a foreigngovernment agency

Research/teaching position at a U.S. college or university

Research/teaching position at a foreign college or university $\square$ Research/administration position in private industry in the U.S.

$\square$ Research/administration position in private industry outside of the U.S.

$\square$ Research/administration position with a non profit

$\square$ Self-employed/consulting

Postdoctoral research

$\square$ Other (Please specify, possible)

$\bigotimes$ No information provided

17) APPRAISAL OF RESEARCH ASSOCIATESHIP PROGRAM

On a scale of 1 - 10 (poor - excellent), please rate the following:

SHORT TERM VALUE

9 Development of knowledge, skills, and research productivity

Comments

LONG TERM VALUE

9 How the NRC Associateship award affected your career to date

Comments

LAB SUPPORT

10 Quality of support from the Laboratory--equipment, funding, orientation, safety and health guidelines, etc.

Comments

ADVISER/MENTOR SUPPORT

10 Quality of mentoring from the Laboratory NRC Adviser (USMA Mentor, if applicable)

Comments

\section{LPR SUPPORT}

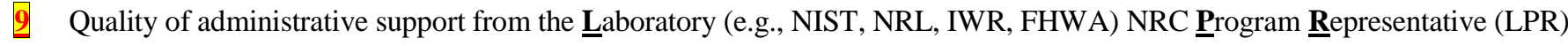
Comments

\section{NRC SUPPORT}

8 Quality of administrative support. Please assess respective NRC aspects (e.g., moving company, insurance, Omega, payroll, coordinator, travel, etc.)

\section{Comments}


Please do NOT scan to PDF. Send the Final Report as MSWord document via e-mail to your NRC Program Coordinator No handwritten signature required; but you may upload a scanned signature file below:

Asha Davis:

Linda Sligh:

Jason Thornhill: jthornhill@nas.edu

Peggy Wilson:

Suzanne White: adavis@nas.edu

Isligh@nas.edu

pwilson@nas.edu

swhite@nas.edu 
Advisers to the Nation on Science, Engineering, and Medicine

Research Associateship Programs

National Research Council

FINAL REPORT

1) Associate Last or Family Name

First Name

M.I.

Zunoubi

2) FORWARDING Address (to which your tax statement will be mailed)

Mohammad

$\mathbf{R}$

Residence or Institution SUNY

FORWARDING Phone(s) and E-Mail (if known)

Home Phone:

Street 1 Hawk Dr.

City, State Zip New Paltz, NY 12561

3) Today's Date

August 28, 2012

Alt. Phone:

Preferred E-mail: zunoubm@engr.newpaltz.edu

Dates of Tenure

from August 1, 2011

4) Host Agency

AFRL

Laboratory or Center

Kirtland AFB

(e.g., AFRL)

(e.g., Wright Patterson AFB)

5) Name of Laboratory NRC Adviser (and USMA Mentor, if applicable)

Dr. William P. Roach

6) TITLE OF RESEARCH PROPOSAL

Massively-Parallel Modeling of High Peak Ultrafast Laser Pulse Propagation and Nonlinear Matter Interaction on MultiGPU Systems

7) SUMMARY OF RESEARCH DURING TENURE Itemize significant findings in concise form, utilizing key concepts/words.

1) Designed a Graphic Precessing Unit (GPU) high-performance computing system with a compute power of 15 Teraflops/s.

2) Implemented the first multiple computational tools for the analysis of coupled propagation equations for the Ultra-Short Laser Pulse (USPL) propagation.

3) Implemented the first multiple computational tools for the propagation of USPL in atmosphere and its interaction with matters.

4) Developed the massively parallel version of the above tool on GPUs to help speeding up the computation times by a factor of 70 over the convetional CPU tools.

5)

(USMA Davies Fellow: please add summary of teaching, including classes taught.)

8) RESEARCH IN PROGRESS Describe in no more than 100 words.

Currently, there exists ongoing research activities to develop the multi-GPU version of the tool described above in item 4 to make the analysis of extremely large compute scenarios and kilometer-long propagation of USPLs possible.

9) PUBLICATIONS AND PAPERS RESULTING FROM NRC ASSOCIATESHIP RESEARCH

Provide complete citations: author(s), title, full name of journal, volume number, page number(s), and year of publication.

a) Publications in peer-reviewed journals

b) Books, book chapters, other publications

c) Manuscripts in preparation, manuscripts submitted

A CUDA-Accelerated nonlinear Schrodinger solver for the propagation of Ultra-Short Laser Pulse and its interaction with matters

10) PATENT OR COPYRIGHT APPLICATIONS RESULTING FROM NRC ASSOCIATESHIP RESEARCH

Provide titles, inventors, and dates of applications.

Provide complete references: author(s), title, abstract/proceeding citation, meeting name and location. 
International

M.R. Zunoubi, J. Payne, and W.P. Roach, " CUDA-MPI-FDTD implementation of Maxwell's equations in general dispersive media," The International Society of Optics and Photonics, San Francisco, CA, 21-26 January 2012.

Domestic

M.R. Zunoubi, W.P. Roach and R.A. Albanese, "Computational Aspects of Competing Nonlinearities," Directed Energy

Professional Society - Advanced High Power Lasers, Broomfield, CO, 11-14 June, 2012.

12) SEMINARS OR LECTURES DELIVERED AT UNIVERSITIES AND/OR INSTITUTES Include dates, names and locations of seminars.

13) PROFESSIONAL AWARDS RECEIVED DURING TENURE

14) POST-TENURE POSITION / JOB TITLE

\section{Associate Professor, ECE Department}

15) NAME AND ADDRESS OF POST-TENURE POSITION / JOB ORGANIZATION

\section{State University of New York}

16) POST-TENURE POSITION STATUS / CATEGORY Please indicate only one.

Permanent position at the NRC host agency

Contract or temporary position at the NRC host Agency

Abbreviate Host Laboratory/Center

Research/Administrative position with another U.S.government agency

Research/Administrative position with a foreigngovernment agency

$\bigotimes$ Research/teaching position at a U.S. college or university

Research/teaching position at a foreign college or university $\square$ Research/administration position in private industry in the U.S.

Research/administration position in private industry outside of the U.S.

$\square$ Research/administration position with a non profit

$\square$ Self-employed/consulting

$\square$ Postdoctoral research

$\square$ Other (Please specify, possible)

$\square$ No information provided

17) APPRAISAL OF RESEARCH ASSOCIATESHIP PROGRAM

On a scale of 1 - 10 (poor - excellent), please rate the following:

SHORT TERM VALUE

10 Development of knowledge, skills, and research productivity

Comments

LONG TERM VALUE

10 How the NRC Associateship award affected your career to date Comments

\section{LAB SUPPORT}

9 Quality of support from the Laboratory--equipment, funding, orientation, safety and health guidelines, etc. Comments

\section{ADVISER/MENTOR SUPPORT}

10 Quality of mentoring from the Laboratory NRC Adviser (USMA Mentor, if applicable)

Comments

\section{LPR SUPPORT}

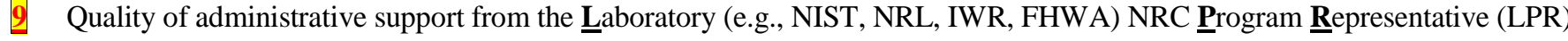
Comments

\section{NRC SUPPORT}

9 Quality of administrative support. Please assess respective NRC aspects (e.g., moving company, insurance, Omega, payroll, coordinator, travel, etc.)

\section{Comments}


Please do NOT scan to PDF. Send the Final Report as MSWord document via e-mail to your NRC Program Coordinator No handwritten signature required;

but you may upload a scanned

Asha Davis: adavis@nas.edu

signature file below:

Linda Sligh:

Isligh@nas.edu

Jason Thornhill: jthornhill@nas.edu

M.R. Zunoubi

Peggy Wilson: pwilson@nas.edu

Suzanne White: swhite@nas.edu

Rev. July 2011

Proj/Act ID\# 